University of Louisville

ThinkIR: The University of Louisville's Institutional Repository

Electronic Theses and Dissertations

$12-2012$

\title{
Self-efficacy in the context of psychological abuse: a model of efficacy erosion.
}

Kristen E. Hosey

University of Louisville

Follow this and additional works at: https://ir.library.louisville.edu/etd

\section{Recommended Citation}

Hosey, Kristen E., "Self-efficacy in the context of psychological abuse: a model of efficacy erosion." (2012). Electronic Theses and Dissertations. Paper 636.

https://doi.org/10.18297/etd/636

This Doctoral Dissertation is brought to you for free and open access by ThinkIR: The University of Louisville's Institutional Repository. It has been accepted for inclusion in Electronic Theses and Dissertations by an authorized administrator of ThinkIR: The University of Louisville's Institutional Repository. This title appears here courtesy of the author, who has retained all other copyrights. For more information, please contact thinkir@louisville.edu. 
SELF-EFFICACY IN THE CONTEXT OF PSYCHOLOGICAL ABUSE: A MODEL OF EFFICACY EROSION

\author{
By \\ Kristen E. Hosey \\ B.S., Centre College, 2004 \\ M.A., University of Dayton, 2007

\begin{abstract}
A Dissertation
Submitted to the Faculty of the

College of Arts and Sciences of the University of Louisville in Partial Fulfillment of the Requirements

for the Degree of
\end{abstract}

\title{
Doctor of Philosophy
}

Department of Psychology

University of Louisville

Louisville, Kentucky

December 2012 
SELF-EFFICACY IN THE CONTEXT OF PSYCHOLOGICAL ABUSE: A MODEL OF EFFICACY EROSION

\author{
By \\ Kristen Elizabeth Hosey \\ B.S. Centre College, 2004 \\ M.A. University of Dayton, 2007 \\ A Dissertation Approved on
}

August 8, 2012

by the following Dissertation Committee:

Tamara Newton

Dissertation Director

Barbara Burns 


\section{DEDICATION}

This dissertation is dedicated to my husband

Ryan P. Hosey, Ph.D.

and my parents

James and Barbara Allison

who have given me limitless love and support. 


\section{ACKNOWLEDGMENTS}

I would like to thank my dissertation chair, Dr. Tamara Newton, for her invaluable feedback and guidance. I would also like to thank my dissertation committee for their thoughtful contributions to my study. I would also like to express my appreciation for and gratitude toward my husband, Dr. Ryan Hosey, for his unwavering support during the trials and tribulations of earning my doctorate. Finally, I would like to thank my parents for instilling in me a strong work ethic and the desire to achieve. 


\title{
ABSTRACT \\ SELF-EFFICACY IN THE CONTEXT OF PSYCHOLOGICAL ABUSE: A MODEL OF EFFICACY EROSION
}

\author{
Kristen E. Hosey
}

August 8, 2012

The current research proposed that psychological abuse within an intimate relationship erodes one's self-efficacy and aimed to demonstrate a negative relationship between past psychological abuse and how one reacts to a challenge. It was hypothesized that when faced with a challenging task past psychological abuse would be related to decreased task persistence, increased negative affect, and choosing low-difficulty future tasks. Each of these relationships would then be simultaneously mediated by general and specific self-efficacy.

The study was conducted in two phases with undergraduate women. During the first phase participants self-reported demographic and relationship history information, level of general self-efficacy, and level of past psychological abuse in a romantic relationship via an online survey. Eligible participants were invited to a participate in the study's second phase, where they were presented with a challenging task - a set of unsolvable anagrams - and their task persistence, change in affect, and chosen difficulty level of a future task were assessed. A total of 300 participants completed the first study phase, with an additional 60 participants completing both the first and second phases. 
A three-path, joint significance test of mediation tested study hypotheses. Past psychological abuse significantly predicted decreases in general self-efficacy, but when controlling for past psychological abuse, general self-efficacy did not significantly predict specific self-efficacy. When controlling for past psychological abuse and general self-efficacy, specific self-efficacy did not significantly predict task persistence or change in negative affect, but did significantly predict the chosen difficulty level of a future task. Support for the proposed models was not found. As predicted, past psychological abuse was negatively and directly related to general self-efficacy, but was not related to specific self-efficacy, task persistence, or change in negative affect. A direct relationship was also found between specific self-efficacy and the chosen difficulty level of a future task; this relationship was not hypothesized but is consistent with the literature. The restricted ranges of past psychological abuse and general self-efficacy found in the sample, as well as internal and external validity limitations, are discussed as possible explanations for the study's results. Future directions are also outlined. 
TABLE OF CONTENTS

PAGE

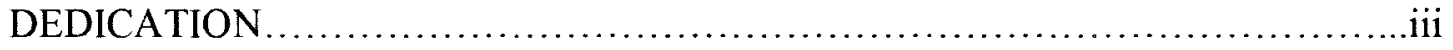

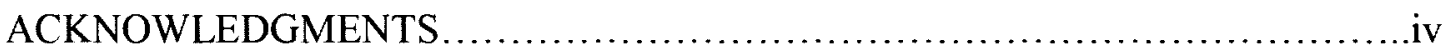

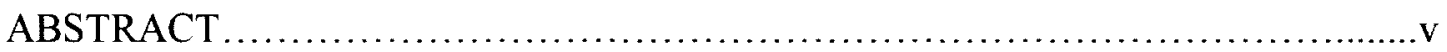

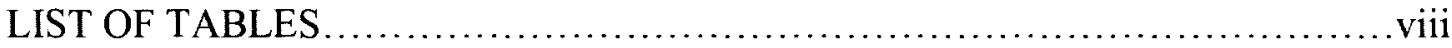

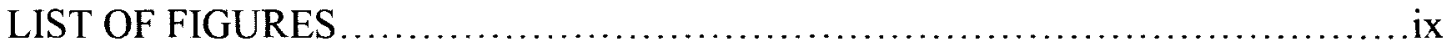

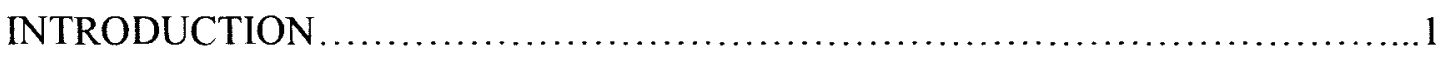

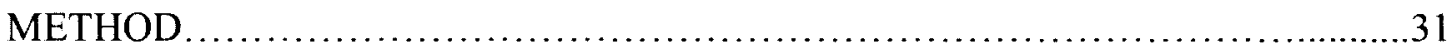

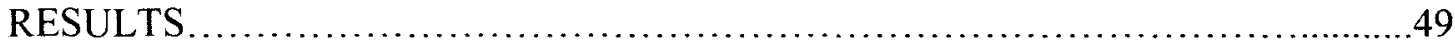

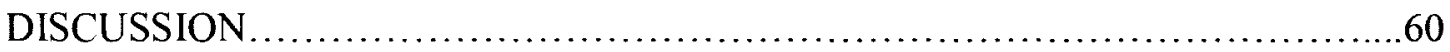

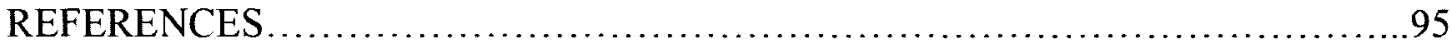

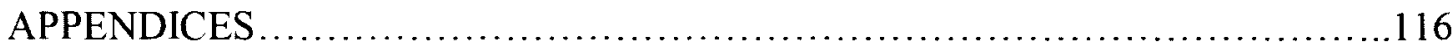

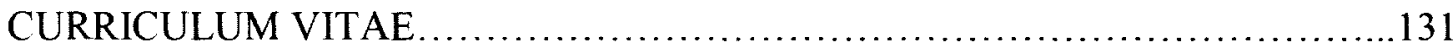




\section{LIST OF TABLES}

TABLE

PAGE

1. Demographics........................................................ 82

2. Relationship history..................................................... 83

3. Group comparisons:

Demographics, relationship history, and eligibility criteria.

4. Descriptive statistics for predictor and outcome variables.

5. Intercorrelations among predictors and outcomes............................ 86

6. Intercorrelations among predictors and external variables.................... 87

7. Means (SD) for predictors and outcomes for

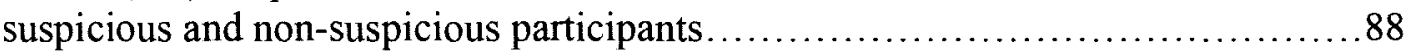

8. Exploratory analysis of trimmed regression models ........................... 89

9. Predictors of specific self-efficacy...................................... 90

10. Intercorrelations among change in positive affect and self-efficacy..............90

11. Intercorrelations among self-efficacy and relationship history $\ldots \ldots \ldots \ldots \ldots \ldots . \ldots 1$ 


\section{LIST OF FIGURES}

FIGURE

PAGE

1. Proposed three-path mediation models ......................................92

2. Estimated effect sizes of the proposed three-path mediation models...............93

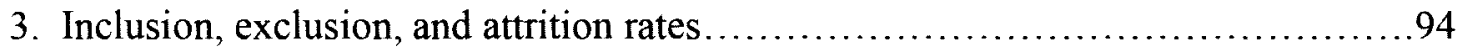




\section{INTRODUCTION}

Self-efficacy is defined as the cognitive appraisal that one can successfully execute a desired behavior (Bandura, 1977, 1997). The construct of self-efficacy was initially conceptualized as situationally specific (Bandura, 1977, 1997). For example, one might have high self-efficacy for performing math tasks, but this belief might be unrelated to efficacy for a separate situation, such as performing athletic tasks. Recent literature has provided an additional, more general conceptualization of self-efficacy. General self-efficacy, in contrast to specific self-efficacy, is the belief in one's ability to perform desired behaviors and cope with adversity in general (Scherbaum, CohenCharash, \& Kern, 2006). Recently, both specific and general self-efficacy have been integrated into the study of protective factors among individuals exposed to potentially traumatic events. Historically, epidemiological studies have assumed a person possesses static protective or risk factors that make mental and physical well-being more or less likely following a potentially traumatic event. Rather than a static protective factor a person simply does or does not possess, self-efficacy considers the interaction between personal attributes and the environment (Bandura, 2008; Benight \& Bandura, 2004). This agentic re-conceptualization of protective factors introduces the possibility that a person may enable his/her own physical and mental well-being following a traumatic event. 
The current study examined self-efficacy within the context of one aspect of intimate partner violence (IPV) - psychological abuse. It was the thesis of the current research that abuse and violence within intimate relationships erode self-efficacy, thereby reducing the reservoir of protective factors available for coping with challenges. In a partial test of this self-efficacy erosion model, the present study investigated associations between exposure to psychological abuse and how one reacts to a challenging task, with a focus on mediation by both general and specific self-efficacy. Specifically, it was hypothesized that when faced with a challenging task, past experiences of psychological abuse would be related to decreased task persistence, an increase in negative affect, and avoidance of difficult, future tasks. Levels of both general and specific self-efficacy were predicted to mediate these associations.

\section{Self-Efficacy and Post-Trauma Outcomes}

Self-efficacy has been studied in survivors of a variety of traumas (e.g., assault, natural disaster, combat) and has been consistently related to mental and physical health functioning following trauma exposure. A body of literature has focused on selfefficacy's relationship with post-traumatic stress disorder (PTSD). PTSD is a mental health disorder experienced by some trauma survivors and characterized by symptoms of hyperarousal, avoidance of trauma reminders, and involuntary re-experiencing of the traumatic event (American Psychiatric Association, 2000). Studies revealed that both general and specific self-efficacy are associated with the presence (Benight \& Bandura, 2004) and severity of PTSD symptoms (Luszczynska, Benight, \& Cieslak, 2009). For example, in a prospective study of male firefighters, low general self-efficacy and high hostility immediately following basic training were strongly associated with the severity 
of PTSD symptoms two years later (Heinrichs et al., 2005). Commensurate results have been seen in a longitudinal study of primarily male survivors of non-domestic assault (Johansen, Wahl, Eilertsen, \& Weisaeth, 2007), as well as in additional cross-sectional (Benight, Freyaldenhoven, Hughes, Ruiz, \& Zoschke, 2000) and longitudinal studies (Benight \& Harper, 2002; Benight et al., 1999) of trauma survivors. Benight and Bandura (2004) also drew consistent conclusions in their review of the literature on the self-efficacy of trauma survivors (Benight \& Bandura, 2004). Low levels of both general and specific self-efficacy prior to and/or immediately following a potentially traumatic event have been consistently related to the presence and severity of PTSD symptoms following exposure.

Self-efficacy has also been linked to physical health functioning following trauma exposure. Luszczynska and colleagues (2009) conducted a review of studies and found that strong self-efficacy beliefs, both general and specific, were related to lower selfreported somatic symptoms, lower self-reported physical health disability, fewer chronic diseases, and better chronic disease care among survivors of war-related traumas. For example, in a cross-sectional study of elderly veterans, low and moderate, but not high, levels of self-efficacy specifically for conducting independent living tasks, were associated with an increased likelihood for experiencing at least one day of pain-related disability (Barry, Guo, Kerns, Duong, \& Reid, 2003).

Trauma survivors both with low specific and general self-efficacy experience more frequent and more severe symptoms of PTSD and poorer self-reported physical health than their high self-efficacy counterparts. Taken together, the literature on selfefficacy and trauma exposure indicates high self-efficacy may play a protective role, 
while low self-efficacy is associated with undesirable mental and physical health outcomes post-trauma. Thus far, however, little empirical attention has been given to the specific potentially traumatic event of IPV. The Centers for Disease Control and Prevention recognizes four primary forms of IPV: physical, sexual, psychological, and threats of physical or sexual violence (Saltzman, Fanslow, McMahon, \& Shelley, 2002). Among U.S women, nearly 5.3 million intimate partner victimizations occur each year and approximately $25 \%$ of women are raped and/or physically assaulted by an intimate partner at some point in their lives (U.S. Department of Justice, 2003). Despite its prevalence in the lives of women, IPV has only a small place in the self-efficacy literature.

\section{Self-Efficacy and IPV-Related Outcomes}

Although self-efficacy's connection to PTSD or physical health functioning has not been examined in the context of IPV, it has been linked to a variety of other, IPVrelated outcomes. It should be noted that the self-efficacy and IPV literature reviewed below does not distinguish among the four types of IPV identified by the CDC. Instead, IPV was generally defined and encompasses any form of abuse or violence. Self-efficacy is related to a woman initially leaving (Burke, Denison, Gielen, McDonnell, \& O'Campo, 2004; Patzel, 2001) and remaining out of an abusive or violent relationship (Lerner \& Kennedy, 2000). Qualitative studies of IPV survivors identified self-efficacy as one of the determining factors in deciding to leave the abusive or violent relationship (Burke et al., 2004; Patzel, 2001). Believing she was capable of leaving, regardless of any other behavioral or cognitive process, was identified as necessary for actually leaving the relationship. Similarly, a cross-sectional study of community women found that as time 
out of the abusive or violent relationship increased, self-efficacy for maintaining independence from the former partner increased as well (Lerner \& Kennedy, 2000). Qualitative and quantitative studies revealed that self-efficacy is related to the initiation and maintenance of independence from the abusive or violent partner.

Concerning mental health outcomes, self-efficacy has been linked to suicidality among IPV survivors. Self-efficacy specifically for coping with the stress of partner abuse and violence (IPV-related self-efficacy) has been negatively associated with the risk of attempted suicide. Two studies, utilizing the same cross-section of low-income African American women, have explored self-efficacy's relationship with attempted suicide in slightly different ways (Meadows, Kaslow, Thompson, \& Jurkovic, 2005; Thompson, Kaslow, Short, \& Wyckoff, 2002). First, IPV-related self-efficacy remained significantly, negatively associated with the likelihood of attempting suicide, even when IPV severity and depression symptoms were controlled (Thompson et al., 2002). Second, Meadows and colleagues (2005) examined the potential protective factors of hope, spirituality, IPV-related self-efficacy, coping, social support from family, social support from friends, and perceived effectiveness of obtaining resources. In a series of independent analyses each protective factor, including IPV-related self-efficacy, was associated with a decreased risk for attempting suicide (Meadows et al., 2005).

Positive results have also been seen among IPV survivors when specific selfefficacy itself is the outcome. Interventions targeted at increasing specific types of selfefficacy have shown initial success. Following a multi-week education and information program, participants in a battered women's support group reported a significant increase in pre- to post-intervention self-efficacy, specifically for taking positive steps to deal with 
an abusive relationship (Varvaro \& Palmer, 1993). Two interventions have focused on increasing career and financial self-efficacy in IPV survivors (Chronister \& McWhirter, 2006; Sanders, Weaver, \& Schnabel, 2007). IPV survivors completing a program focused on job exploration, interviewing, networking, and personal exploration reported an increase in career-search self-efficacy not seen in wait-list controls (Chronister \& McWhirter, 2006). Similarly, IPV survivors completing economic education classes not only reported significantly higher financial self-efficacy than survivors not offered the course, but also displayed a significant increase in financial self-efficacy (Sanders et al., 2007).

High self-efficacy appears to play a protective role for IPV survivors, paralleling the results seen among survivors of various other traumas. In IPV survivors, high selfefficacy is related to initiating and maintaining independence from an abusive or violent partner (Burke et al., 2004; Lerner \& Kennedy, 2000; Patzel, 2001), as well as a reduced risk for attempting suicide (Meadows et al., 2005; Thompson et al., 2002). The IPV literature also underscores the malleability of self-efficacy, as survivors' self-efficacy increased following targeted interventions (Chronister \& McWhirter, 2006; Sanders et al., 2007; Varvaro \& Palmer, 1993). The agentic nature of self-efficacy as a protective factor allows it to be cultivated even following a potentially traumatic event.

\section{Intimate Partner Violence and Self-Efficacy Erosion}

Diverging from the positive relationship between self-efficacy and IPV-related outcomes, a consistently negative relationship has been found between IPV victimization and career-related self-efficacy. In a cross-section of college women, the experience of

sexual coercion by an intimate partner was negatively correlated with multiple aspects of 
career-decision self-efficacy (Albaugh \& Nauta, 2005). Career decision-making selfefficacy was also found to be lower among shelter-based IPV survivors when compared to a sample of college women (Brown, Reedy, Fountain, Johnson, \& Dichiser, 2000). The low self-efficacy reported by survivors suggests that the experience of IPV may, at the very least, erode specific forms of career-related self-efficacy. Identifying selfefficacy as a protective factor among IPV survivors is important, but ultimately insufficient, if aspects of IPV erode that same protective factor.

The limited, largely descriptive approach utilized in the literature thus far does not allow for an investigation of the potentially erosive relationship between IPV victimization and one's self-efficacy - a more mechanistic approach is necessary. Fortunately, the multi-faceted nature of both IPV and self-efficacy allows for this detailed, mechanistic approach to studying the relationship. More than a simple belief in one's ability to perform a task successfully, self-efficacy expectations are an integration of information from four sources: mastery experiences, vicarious experiences/modeling, verbal persuasion, and emotional/physiological arousal (Bandura, 1977, 1997). Mastery experiences are defined as performance successes, and are similar to vicarious learning/modeling, which are learning experiences based on the successful performance of a social model. Verbal persuasion includes messages of efficacy provided by another person and emotional/physiological arousal is the level of arousal associated with performing a specific task. Self-efficacy expectations are determined by the integration of information from all sources.

As aforementioned, the CDC recognizes four primary forms of IPV: physical, sexual, psychological, and threats of violence (Saltzman et al., 2002). The CDC 
definition alone creates four potential dimensions to the experience of IPV. Within each type of IPV, however, lie numerous additional dimensions. Experiences of IPV may include verbal and nonverbal behaviors, threatened acts as well as perpetrated acts, intentional acts of omission, and acts of dominance or control. For example, IPV may include being called names (verbal), threatened with physical harm (threatened acts), and/or having access to family or friends restricted (control).

The multi-faceted nature of both self-efficacy and IPV provide a framework for a mechanistic, rather than descriptive, approach to studying the relationship between the constructs. When the experiences of IPV are filtered through the four sources of selfefficacy, only negative expectations of one's efficacy can be construed. That is, rather than providing efficacy-enhancing information, IPV provides sources of efficacy-eroding information and/or limits access to efficacy-enhancing information. Therefore, the negative relationship between IPV and career and financial self-efficacy described in the literature may be a result of the erosive information collected from each of the four sources. Research has indentified self-efficacy's protective role among trauma survivors, as well as IPV survivors specifically, yet the experience of IPV may make high selfefficacy an unlikely reality.

\section{Psychological Abuse}

Given the multi-faceted nature of IPV, multiple dimensions are present that could erode self-efficacy. The current study focused specifically on the relationship between self-efficacy and the single, potentially erosive dimension of psychological abuse. The solely psychological, rather than physical, consequences of psychological abuse (Baldry, 2003) make it an ideal candidate for eroding the cognitive process of self-efficacy. 
Description. As defined by the CDC, psychological abuse includes behaviors such as deliberately diminishing or embarrassing a partner, controlling what a partner can and cannot do, or isolating a partner from friends and/or family (Saltzman et al., 2002). Psychological abuse is considered a form of partner violence if it occurs in conjunction with at least one additional form of violence (e.g., physical, sexual, threats of physical/sexual violence). If not, the term psychological abuse is retained. The current study focused on psychological abuse, rather than partner violence.

Psychological abuse assumes that the behaviors are intense, occur frequently, (Follingstad, 2007) and target a person's sense of self (Murphy \& Cascardi, 1999) - it is more than a list of specific actions. Unfortunately, a clear threshold that behaviors must cross in order to be considered psychological abuse has yet to be identified in the literature. While not an easily measurable threshold, a distinction has been made between occasional acts of objectionable behavior and psychological abuse (Follingstad, 2007). For example, calling an intimate partner a name during an argument on a single occasion is qualitatively different from degrading a partner daily. The former action is hurtful and undesirable, but the latter action is intense and frequent. Even in the absence of an established consensus in the literature, it is generally agreed that survivors of psychological abuse have experienced frequent and/or severely negative messages about themselves.

Psychological abuse has been linked to a variety of negative mental health outcomes, even after controlling for experiences of physical violence, indicating that it is more than an unpleasant relationship experience. Specifically, psychological abuse victimization is related to symptoms of depression (Baldry, 2003; Follingstad, 2009; 
Gallaty \& Zimmer-Gembeck, 2008; Lawrence, Yoon, Langer, \& Ro, 2009; Mechanic, Weaver, \& Resick, 2008), symptoms of anxiety and PTSD (Baldry, 2003; Lawrence et al., 2009; Mechanic, Weaver, \& Resick, 2008) high levels of negative affect, low levels of positive affect, difficulties in relationships with friends and family, and interpersonal sensitivity (Gallaty \& Zimmer-Gembeck, 2008). Self-esteem has also shown a consistently negative relationship with psychological abuse in multiple studies (Aguilar \& Nightingale, 1994; Baldry, 2003; Sackett \& Saunders, 1999; Stets, 1991). In addition to its psychological content, psychological abuse may be negatively associated with selfefficacy because it shares a negative association with related constructs, notably selfesteem.

Prevalence. Although IPV, including psychological abuse, is often studied among married or cohabiting persons, research documents that these experiences also occur in dating relationships. Among college-aged women, psychological abuse is the most prevalent form of partner abuse or violence. The majority of undergraduate students report experiencing at least one act consistent with psychological abuse by an intimate partner. In a sample of undergraduate women, $80 \%$ reported experiencing at least one act of potentially psychologically abusive behavior by their most recent or current intimate partner (Hines \& Saudino, 2003). More specifically, while in a college dating relationship $71 \%$ of undergraduate women endorsed experiencing at least one act of intentional humiliation or degradation, $57 \%$ endorsed experiencing at least one act of social isolation, and $51 \%$ endorsed experiencing at least one act of intimidating or threatening behavior by a partner (Harned, 2001). 
A smaller portion of the college population experience frequent psychological abuse. In one sample of undergraduate women, participants reported an average of approximately 16 acts of psychological abuse in the past year (Straus, Hamby, McCoy, \& Sugarman, 1996), while $10 \%$ of a separate sample endorsed experiencing six or more acts of verbal abuse in their most recent relationship (Kasian \& Painter, 1992). The frequency of the reported actions indicates that a portion of undergraduate students are frequently exposed to the type of psychologically abusive behavior associated with negative mental health outcomes. More than simple frequency, psychological abuse is highly salient for its victims, with critical or hurtful statements rated as the worst type of abuse among women who had also experienced physical violence (O'Leary \& Jouriles, 1994).

Prevalence studies of psychological abuse in college-aged populations have reported approximately equivalent victimization rates for men and women (Halpern, Oslak, Young, Martin, \& Kupper, 2001; Harned, 2001; Hines \& Saudino, 2003). However, the current study focused exclusively on female, college-aged victims of past psychological abuse. Harned (2001) reported that despite similar prevalence rates, undergraduate women experience more negative outcomes associated with psychological abuse than do men. Specifically, although women and men report comparable levels of depression, anxiety, and posttraumatic stress when rates of psychological abuse are low, as the frequency of abuse increases women report increasingly severe outcomes (Harned, 2001). The experiences of male victims of psychological abuse warrant empirical attention, but were outside the scope of the present study for three primary reasons. First, psychological abuse is potentially more harmful for female than male victims, regardless of the similar prevalence rate (Harned, 2001). Second, the vast majority of IPV research 
is conducted on solely female samples, making it difficult to formulate empirically supported hypotheses for male victims of psychological abuse. Finally, including both male and female victims would increase the heterogeneity of the study sample, and therefore, the focus on females served a practical purpose.

\section{Psychological Abuse and Self-Efficacy Erosion}

The current study posits that psychological abuse shares a potentially erosive relationship with three of the four sources of self-efficacy - verbal persuasion, mastery experiences, and vicarious learning - creating the mechanism by which psychological abuse survivors report lower self-efficacy than their non-abused counterparts. Given that the fourth source of self-efficacy, emotional/physiological arousal, is tied to the level of arousal associated with performing a specific task a relationship between it and psychological abuse is not posited in the current study. Psychological abuse targets one's general sense of self and one's ability to perform a wide variety of tasks (Murphy \& Cascardi, 1999), rather than one's performance of a specific task.

Psychological abuse as verbal persuasion. Psychological abuse may erode selfefficacy by acting as a source of negative verbal persuasion, communicating inefficacy rather than efficacy to an abuse survivor. Verbal persuasion is defined as the verbal suggestion that one can successfully cope with tasks or stressors that may have been overwhelming in the past (Bandura, 1977, 1982, 1997) and is more effective when delivered by a significant other or credible source (Bandura, 1997). While positive messages have been shown to increase self-efficacy (Schunk, 1983; Wise \& Trunnell, 2001), the experimental literature has also shown that verbal persuasion can effectively undermine self-efficacy (Bandura, 1997; Lane, Daugherty, \& Nyman, 1998; Newman \& 
Goldfried, 1987). For example, students receiving negative messages about a role-play performance reported lower self-efficacy and predicted greater difficulty on future performances than students receiving positive messages (Newman \& Goldfried, 1987).

Survivors of psychological abuse receive frequent negative verbal messages. All definitions of psychological abuse incorporate at least one form of negative verbal messaging directed at a partner. Victims of psychological abuse are commonly criticized (Marshall, 2001; O’Leary \& Jouriles, 1994), called names, intentionally made to feel inadequate (Marshall, 2001; Outlaw, 2009), have their abilities undermined (Marshall, 2001), and are deliberately humiliated or diminished (O'Leary \& Jouriles, 1994; Saltzman et al., 2002) by an intimate partner. Bandura (1997) also includes indirect or subtle messages of efficacy in his definition of verbal persuasion, as they are often equally clear forms of communication. In addition to the specifically verbal messages, survivors of psychological abuse experience indirect, nonverbal messages of inefficacy, such as being treated as an inferior (Tolman, 1998), given the silent treatment (Tolman, 1998; Straus et al., 2003), having personal possessions destroyed, or being threatened with violence (Straus, et al., 2003). These nonverbal acts must be included as a primary component when considering the consistent, negative messages conveyed to survivors of psychological abuse. The negative messages of psychological abuse, both verbal and nonverbal, communicate that an abuse survivor is useless and inefficacious. Just as positive messages may foster self-efficacy, the current study speculated that negative messages such as these may erode self-efficacy.

Psychological abuse as an obstacle to mastery experiences. Mastery experiences are described as the most influential source of self-efficacy and are simply 
defined as performance successes (Bandura, 1977, 1997). Initial mastery experiences not only support the development of specific forms of self-efficacy, but may also generalize and foster self-efficacy for separate, related behaviors (Bandura, 1997). Successes increase self-efficacy, while failures, particularly during early attempts of a new behavior, decrease self-efficacy. Experimental literature supports the causal role of mastery experiences in self-efficacy development. After obtaining mastery experiences in a self-defense class, women reported significant pre- to post-intervention increases in multiple defense-specific forms of self-efficacy (e.g., defending oneself, controlling interpersonal threats) and had maintained these gains six months later (Ozer \& Bandura, 1990). Elevations in self-efficacy were not seen in the control condition (Ozer \& Bandura, 1990). Additional studies have reported similar results (Bandura et al., 1982; Gist, Schwoerer, \& Rosen, 1989; Williams, 1982)

Social isolation, as an aspect of psychological abuse, limits one's personal territory or freedom by restricting access to friends or family and/or preventing a person from working, going to school, or doing things independently (Maiuro, 2001). Social isolation is included as a core component in multiple conceptual frameworks of psychological abuse (Maiuro, 2001; Marshall, 2001; NiCarthy, 1986; Hoffman, 1984; Russell, 1982; Sonkin, Martin, \& Walker, 1985), is assessed by validated measures of IPV (Hegarty, Sheehan, \& Schonfeld, 1999; Hudson \& McIntosh, 1981; Tolman, 1989, 1998), and occurs cross-culturally (Garcia-Moreno, Jansen, Ellsberg, Heise, \& Watts, 2006)

In a shelter-based sample of survivors of psychological abuse and other forms of IPV, over half reported they had not experienced a single supportive or group social 
interaction in the previous month (Forte, Franks, Forte, \& Rigsby, 1996). Commensurate results were seen among mothers recruited from community parent groups; mothers with a severe IPV history reported fewer friends, contacts with friends, long-term friendships, and fewer friends who "really listened" than mothers with a less severe IPV history (Coohey, 2007, p. 508).

Unfortunately, studies of undergraduate students assess social isolation less frequently than studies of other populations of IPV survivors. However, it would be incorrect to assume that the infrequent assessment of social isolation among college-aged survivors of psychological abuse is a statement about the frequency with which it occurs. Harned (2001) reported that $57 \%$ of undergraduate participants endorsed at least one incident of social isolation during a college dating relationship, while Pipes and LeBovKeeler (1997) found that $21 \%$ of college participants self-identifying as "psychologically abused" (p. 591) endorsed experiencing at least six incidents of social isolation in the previous two months. The current study posited that, regardless of age-group, social isolation prevents survivors of psychological abuse from obtaining the mastery experiences necessary for developing social self-efficacy. As a result, the self-efficacy to build a social network independent of the abusive or violent partner may be lacking, ultimately increasing interpersonal dependence. If a survivor of psychological abuse does successfully leave a partner, the lack of social self-efficacy may make forming new relationships seem an insurmountable task.

Economic abuse and work/school control is an additional component of psychological abuse that may limit access to mastery experiences. Survivors of all forms of IPV have limited access to economic or employment/educational successes due to a 
lack of economic resources, higher rates of unemployment, low educational status (Hien \& Ruglass, 2009; Lindhorst, Oxford, \& Gilmore, 2007), and/or partners controlling access to employment and education. Among survivors of IPV, between 16- $46 \%$ were forbidden to seek employment and between $18-31 \%$ were forbidden to attend school by their partners (Brush, 2002; Riger, Ahrens, \& Blickenstaff, 2001; Swanberg, Macke, \& Logan, 2006).

The work or educational restraint and interference associated with psychological abuse may also lead to failure experiences (Brush, 2002; Raphael, 1996; Riger et al., 2001; Riger, Raja, \& Camacho, 2005; Swanberg et al., 2006). Being prevented from attending work/school, threatened with physical harm if work/school is attended, or regularly harassed while at work/school were some of the most common tactics of restraint and interference reported by IPV survivors (Brush, 2002; Raphael, 1996; Riger et al, 2001; Riger et al., 2005; Swanberg et al., 2006). At least $20 \%$ of IPV survivors reported unwanted termination of employment or education due to experiences of abuse or violence (Riger et al., 2001; Swanberg et al., 2006).

Although some studies of economic abuse and work/school interference have included college-aged participants (Brush, 2002; Riger, Raja, \& Camacho, 2002; Swanberg et al., 2006), it is rarely assessed in the college population specifically, with some researchers assuming its complete irrelevance. When it is assessed, the prevalence of economic dependence among college participants is lower than other forms of psychological abuse, with $7 \%$ of one sample endorsing at least one incident of economic abuse during a college dating relationship (Harned, 2001). However, the failure to 
regularly assess economic abuse or work/school interference in undergraduate samples makes an accurate prevalence rate difficult to determine.

Even if a rare occurrence, economic abuse or work/school interference prevents psychological abuse survivors from mastering the financial skills necessary for economic independence, such as money management or financial decision making. Similar to social isolation, the current study suggests that if access to finances, employment, or education is prevented, mastery experiences are also prevented, leading to the erosion of economic self-efficacy. In relation, the inability to successfully maintain employment or education due to interference or control by a partner also introduces failure experiences. Just as performance successes foster self-efficacy, the current study also suggests that the educational and/or employment failure experiences of psychological abuse survivors erode self-efficacy. Studies of career development in IPV survivors highlight the importance of career and financial self-efficacy (Albaugh \& Nauta, 2005; Brown et al., 2000; Chronister \& McWhirter, 2003, 2006; Sanders et al., 2007), yet the absence of mastery experiences and the presence of failure experiences make its development unlikely.

Psychological abuse as an obstacle to vicarious learning. Vicarious learning, also referred to as social modeling, is a third source of self-efficacy (Bandura, 1977, 1982, 1997). Social models provide vicarious learning experiences, upon which an observer may base his/her efficacy expectations (Bandura, 1977, 1997). Vicarious learning as a causal mechanism of self-efficacy development is supported by the experimental literature (Bandura, Reese, \& Adams, 1982; Zimmerman \& Ringle, 1981). Following exposure to a social model successfully performing threatening interactions 
with a snake, self-efficacy among adults with a snake phobia increased significantly (Bandura et al., 1982). Similar results have been seen in additional experimental studies (e.g., Zimmerman \& Ringle, 1981).

In order for vicarious learning to be effective, the observer must feel similar to, and equally as capable as, the social model (Bandura, 1997), making social support networks a valuable source of effective models (Benight \& Bandura, 2004). Social support increases access to positive social models and opportunities for vicarious learning, ultimately increasing self-efficacy (Benight $\&$ Bandura, 2004). Self-efficacy has consistently been found to mediate the relationship between social support and a variety of desirable outcomes among survivors of potentially traumatic events (Benight, et al., 1999a; Benight, Swift, Sanger, Smith, \& Zeppelin, 1999; Cheung \& Sun, 2000; Major et al., 1990), supporting the theoretical assumption that a strong social network is a source of vicarious learning and self-efficacy.

Two studies proposed that self-efficacy leads to social support, rather than the inverse (Johansen, et al., 2007; Thompson et al., 2002). While self-efficacy may aid in the development of a social support network, social mastery experiences and vicarious learning are likely first necessary for developing the self-efficacy to form social relationships. Therefore, social support and self-efficacy may share a bidirectional relationship, but the empirical evidence indicates social support is an effective source of self-efficacy.

Qualitative research has shown that access to positive social models is advantageous for survivors of IPV. Discussions with women who had successfully left an abusive or violent relationship were identified as helpful to IPV victims attempting to 
leave their own relationship (Burke et al., 2004; Patzel, 2001). Positive, successful social models essentially provided vicarious learning experiences to IPV victims, which in turn increased self-efficacy for leaving the relationship. Unfortunately, as previously described, social isolation and low social support are common components of psychological abuse (Coohey, 2007; Forte et al., 1996; Panchanadeswaran, El-Bassel, Gilbert, Wu, \& Chang, 2008). Therefore, access to models of adaptive behavior, such as career development or leaving the abusive or violent relationship, is likely restricted. Vicarious learning cannot foster self-efficacy if adaptive social models are not accessible. As a result, the current study suggests that the absence of social models, due to psychological abuse, ultimately erodes self-efficacy. In the absence of self-efficacy, victims of psychological abuse might not attempt to end the relationship or increase social integration, perpetuating a cycle of isolation, lack of vicarious experiences, and self-efficacy erosion. Psychological abuse in the form of social isolation may erode selfefficacy by simultaneously restricting access to mastery experiences and vicarious learning - two vital sources of self-efficacy (Bandura, 1977, 1999).

\section{General and Specific Self-Efficacy}

Psychological abuse, encompassing all previously detailed components, is hypothesized to share a direct and negative relationship with general self-efficacy, rather than specific self-efficacy. General self-efficacy is defined as the overall belief in one's ability to successfully cope with a wide variety of stressful or challenging tasks (Luszczynska, Scholz, \& Schwarzer, 2005; Scherbaum, Cohen-Charash, \& Kern, 2006). In contrast to specific self-efficacy, general self-efficacy is conceptualized as a more stable, trait-like sense of general competence (Chen, Gully, \& Eden, 2004). General self- 
efficacy can be reliably assessed (Chen, Gulley, \& Eden, 2001; Chen et al., 2004; Tipton \& Worthington, 1984), has demonstrated strong construct validity (Tipton \& Worthington, 1984), and has been identified in cross-cultural samples (Luszczynska et al., 2005). Due to its potentially erosive relationship with three separate sources of selfefficacy and wide variety of criticized behaviors and abilities, psychological abuse is hypothesized to foster a sense of general inefficacy. Regardless of the situation, survivors of psychological abuse may enter with an efficacy vulnerability, believing that they are generally incapable of coping with challenges and successfully performing desired behaviors.

Bandura (1997) states that specific, rather than general, self-efficacy is the strongest predictor of behavior. Studies investigating the relationship between general and specific self-efficacy consider how Bandura's (1997) assertion might be integrated with general self-efficacy. While it cannot be assumed that high general self-efficacy would be equivalent to high self-efficacy for all tasks, the constructs are also not thought to be mutually exclusive. One brings general expectations of competence into more specific situations.

Research thus far has reported an inconsistent relationship between general and specific self-efficacy, with some studies reporting a strong, positive relationship between the constructs (Betz \& Klein, 1996; Chen, Gully, Whiteman, \& Kilcullen, 2000; Tzeng, 2009; Yeo \& Neal, 2006) while others fail to find a relationship (Earley \& Lituchy, 1991; Eden \& Zuk, 1995). In a model including specific self-efficacy, Earley and Lituchy (1991) found general self-efficacy to be the poorest predictor of performance and found it to make only a minimal contribution to the predictive ability of the model. Specific self- 
efficacy, however, was a meaningful predictor of task performance (Earley \& Lituchy, 1991). Similarly, Eden and Zuk (1995) found that while general and specific selfefficacy were each independently related to task performance, general self-efficacy was not related to specific self-efficacy. Chen and colleagues (2001) explain that the failure to find a relationship between general and specific self-efficacy may be due to measurement, rather than theoretical, error.

General self-efficacy is presented as an unidimensional construct, yet the most widely used measure, the general subscale of the Self-Efficacy Scale (SGSE; Sherer \& Adams, 1983) has consistently demonstrated a three-factor structure (Chen et al., 2001). Two independent studies (Bosscher \& Smit, 1998; Woodruff \& Cashman, 1993) have shown that the SGSE (Sherer \& Adams, 1983) possesses three distinct factors: selfperception of behavior initiation, effort, and persistence. Rather than measuring general self-efficacy, the SGSE measures its behavioral implications. Both studies failing to find a relationship between general and specific self-efficacy utilized the SGSE (Earley \& Lituchy, 1991; Eden \& Zuk, 1995).

Three additional studies have found a strong, positive relationship between general self-efficacy and various types of specific self-efficacy, such as efficacy for career decision making, mathematics, occupational performance (Betz \& Klein, 1996), and college exam performance (Chen et al., 2000), among others (Tzeng, 2009; Yeo \& Neal, 2006). Of the studies demonstrating a strong positive relationship between general and specific self-efficacy only one utilized the potentially flawed SGSE measure (Betz \& Klein, 1996). In addition, when an appropriately unidimensional measure of general selfefficacy is utilized an indirect relationship between general self-efficacy and task 
performance is also found. Yeo and Neal (2006), for example, found that specific selfefficacy for an experimental task completely mediated the relationship between general self-efficacy and task performance in a sample of college students. The same pattern was seen in a study of exam scores; specific exam self-efficacy mediated the relationship between general self-efficacy and actual exam performance (Chen et al., 2000). These results suggest that general self-efficacy is indirectly related to task performance as a result of its direct relationship with specific self-efficacy.

The co-occurrence of null findings and the use of the SGSE lends some support to Chen and colleagues (2001) argument that measurement error plays a role in the inconsistent relationship between general and specific self-efficacy reported in the literature. When an appropriately unidimensional measure is used, both a positive relationship between general and specific self-efficacy is seen, as well as an indirect relationship between general self-efficacy and task performance, mediated by specific self-efficacy. Therefore, if appropriate measures of general self-efficacy are utilized, psychological abuse may be indirectly related to specific self-efficacy via its proposed direct relationship with general self-efficacy. The hypothesized link between a vulnerability in general self-efficacy and psychological abuse may be expressed in specific situations due to the relationship between general and specific self-efficacy. It was an additional thesis of the current study that psychological abuse would share an indirect, negative relationship with specific self-efficacy via its proposed direct relationship with general self-efficacy. 


\section{Specific Self-Efficacy and Reactions to Challenging Tasks}

The utility of specific self-efficacy is at least partially a result of its relationship with how one reacts to challenging tasks. The relationship between specific self-efficacy and task-related reactions is the clearest when tasks are challenging. If a task is simple, the majority of people report high self-efficacy and react well. When faced with a challenge, however, heterogeneity in efficacy expectations is present and the reactions of high self-efficacy individuals are generally superior to those reporting low self-efficacy (Bandura, 1977, 1982, 1997). Therefore, abuse survivors may react undesirably to challenging tasks as a result of the proposed indirect relationship between psychological abuse and specific self-efficacy. It was the final thesis of the current study that psychological abuse would share an indirect relationship with reactions to challenging tasks, via its direct relationship with general self-efficacy and indirect relationship with specific self-efficacy.

How one reacts to a challenging task is meaningful for psychological abuse survivors in a number of ways. Survivors may be facing the challenge of choosing to end the abusive relationship, or may be adjusting to newfound independence. Survivors who had cohabited with the abusive partner may be confronting the challenge of the financial and caretaking responsibilities of maintaining an independent household. Psychological abuse survivors must also likely maintain employment and cope with employment-related stress. Undergraduate psychological abuse survivors, in particular, face the additional daily challenges of coursework and beginning career development. Therefore, understanding how psychological abuse relates to one's reaction to challenging tasks could provide valuable information about how survivors respond to important, daily 
struggles. The current study focused on three aspects of how one reacts to challenging tasks: persistence, affect, and chosen difficulty level for a future task.

Persistence. Bandura $(1977,1997)$ reported that high self-efficacy is related to greater persistence on a challenging task, where the opposite is expected in the case of low self-efficacy. A meta-analysis of 18 studies of self-efficacy and persistence revealed that across various operational definitions of persistence - time spent on a specific task, number of items attempted or completed, or number of completed academic terms - it shared a strong, positive relationship with self-efficacy (Multon, Brown, \& Lent, 1991). Among college students, specific self-efficacy has shown a consistently positive relationship with academic persistence (Lent, Brown, \& Larkin, 1984; Lent, Brown, \& Larkin, 1986; Multon et al., 1991) as well as persistence in lab tasks (Brown \& Inouye, 1978; Cervone \& Peak, 1986; Jacobs, Prentice-Dunn, \& Rogers, 1984). For example, when faced with difficult or unsolvable anagram tasks those undergraduates reporting high specific self-efficacy spent more time working on the tasks than those reporting low self-efficacy (Cervone \& Peak, 1986; Jacobs et al., 1984). Similarly, undergraduates who judged themselves as more efficacious than an ineffective model were more persistent on an anagram task than undergraduates who judged themselves as equally or less efficacious than the model (Brown \& Inouye, 1978).

Overall, the positive relationship between specific self-efficacy and task persistence is both theoretically and empirically supported. Therefore, if survivors of psychological abuse possess low specific self-efficacy, as the current study posited, decreased task persistence may be observed. When confronted with challenges in academic coursework, employment, or relationships, psychological abuse survivors may 
abandon the task more quickly than their non-abused counterparts. While attempting a challenging task, it was hypothesized that past experiences of psychological abuse would be indirectly and negatively related to task persistence.

Affective response. Self-efficacy has also been related to one's affective response to a challenging task (Bandura, 1977, 1982, 1997). Bandura (1982) stated that negative affect is not related to the demands of a challenging or aversive task, but is ultimately related to the perceived inefficacy to successfully complete the task. A negative association between specific self-efficacy and measures of general negative affect has been reported in a variety of populations. Among undergraduates courserelated self-efficacy was negatively correlated with course-related anxiety and the typical level of negative affect felt in the classroom (Shell \& Husman, 2008). Similarly, cancerrelated self-efficacy was negatively associated with the frequency of five negative emotions in a sample of male veterans with cancer, even after considering the influence of age, education, time since diagnosis, and current treatment status (Beckham et al., 1997).

More than general affect, some studies have considered how specific self-efficacy might be related to task-specific affective responses. In a series of studies with snake phobic participants, greater anticipatory fear was reported prior to performing a snake interaction task for which participants reported low self-efficacy, than when approaching a high self-efficacy task (Bandura, 1982; Bandura \& Adams, 1977; Bandura, Adams, \& Beyer, 1977). In addition to anticipatory fear, snake phobic participants reported significantly more fear during the performance of low self-efficacy tasks than high selfefficacy tasks (Bandura, 1982; Bandura \& Adams, 1977; Bandura et al., 1977). 
Inversely, exercise self-efficacy was positively associated with the level of positive affect endorsed immediately following the performance of a challenging exercise task in a sample of sedentary middle-aged adults (McAuley \& Courneya, 1992). Higher exercise self-efficacy was related to the endorsement of a higher level of positive affect following the exercise task (McAuley \& Courneya, 1992). When exercise self-efficacy was induced in a lab setting, participants in the high self-efficacy condition reported higher positive well-being during and immediately following an exercise task than participants in the low self-efficacy condition (McAuley, Talbot, \& Martinez, 1999). Participants in the low self-efficacy condition also reported greater psychological distress during and immediately following the exercise task than did their high self-efficacy counterparts (McAuley et al., 1999). Commensurate results were reported in a sample of undergraduate women; participants reported lower levels of cognitive worry and somatic anxiety when completing a simple task for which they reported high specific selfefficacy, compared to a difficult task for which they reported low specific self-efficacy (Lan \& Gill, 1984).

Overall, specific self-efficacy has displayed a relationship both with general affect as well as affective responses to specific tasks. When performing a challenging task, low specific self-efficacy has been related to high negative affect, while high specific selfefficacy has been related to high positive affect. Therefore, people reporting low specific self-efficacy would be expected to respond to a challenging task with a greater level of negative affect than those with high self-efficacy. Due to their proposed low specific self-efficacy, psychological abuse survivors might respond to a challenging task with negative affect, causing daily challenges to be perceived as distressing rather than 
stimulating. Specifically, it was hypothesized that past psychological abuse would be positively related to increased negative affect following a challenging task. In addition to reduced persistence, past psychological abuse may also be indirectly associated with significant spikes in negative affect when a woman is faced with daily challenges.

Chosen difficulty level of future task. The level of difficulty one is willing to attempt on a future task is a third reaction to an initial challenging task that may be influenced by self-efficacy. People with high self-efficacy are more likely to attempt difficult tasks because they believe they can be successful (Bandura, 1977, 1997). Supporting this claim, Jerusalem and Schwarzer (1992) found that among community adults, those with high self-efficacy interpreted difficult anagrams and intelligence test items as challenges, while those with low self-efficacy interpreted the same items as threatening or potentially damaging to their self-esteem. Across multiple trials, the interpretation of the difficult items as threatening showed a stronger increase among low self-efficacy participants than high self-efficacy participants (Jerusalem $\&$ Schwarzer, 1992).

Not only do persons with high self-efficacy perceive difficult tasks as a challenge rather than a threat, but they also voluntarily set higher, more difficult-to-attain personal goals. Even when considering ability level and previous training on a lab task, high selfefficacy was strongly related to setting a high task goal among college undergraduates (Lock, Frederick, Lee, \& Bobko, 1984). Similar results have been seen in separate college samples, with self-efficacy sharing a strong, positive relationship with the level of personal goals set (Cheng \& Chiou, 2010; Gibbons \& Weingart, 2001). People with high self-efficacy also voluntarily choose challenging rather than simple tasks. In an 
undergraduate population self-efficacy was associated with choosing a complex task that maximized learning (Tabernero \& Wood, 2009), choosing a leadership over a follower task (Dickerson \& Taylor, 2000), and choosing to attempt a physical task of high difficulty (Escarti \& Guzman, 1999). As Bandura $(1977,1997)$ initially posited, selfefficacy is associated with interpreting a difficult task as a challenge, attempting those challenging tasks, and setting higher personal goals. Inversely, low self-efficacy is associated with the avoidance of challenging tasks (Bandura, 1977, 1997).

Understanding whether or not undergraduate psychological abuse survivors choose to attempt difficult tasks might provide information about the kind of choices they would make in their daily lives - Would they register for challenging courses? Choose a challenging major? Apply for a promotion at work? If psychological abuse survivors possess low specific self-efficacy, as is suggested in the current study, they may choose low-difficulty tasks. Specifically, it was hypothesized that past psychological abuse would be indirectly and negatively related to the level of difficulty a woman chose to attempt on a future task.

\section{The Current Study}

The self-efficacy literature demonstrates that people with high self-efficacy choose to undertake challenging tasks and react to these challenges with greater persistence and less negative affect than their low self-efficacy counterparts. However, given the proposed indirect, negative relationship between psychological abuse and specific self-efficacy, psychological abuse may also share an indirect, negative relationship with the aforementioned reactions to challenging tasks. Therefore the proposed, direct relationship between psychological abuse and general self-efficacy may 
manifest in specific situations when survivors encounter a challenge. The efficacy vulnerability created in the context of psychological abuse could negatively impact a survivor's response to challenges in daily life.

The current study examined the hypothesized relationships between psychological abuse, general self-efficacy, specific self-efficacy, and reactions to challenging tasks in the undergraduate dating population. Psychological abuse is the most common form of IPV reported in the college population and undergraduates are at a developmental period marked by daily challenges, be it in academic work, employment, or career development. The hypotheses were also tested in the context of past rather than ongoing psychological abuse. Focusing on past rather than current psychological abuse allowed the study to examine if the harmful, yet distal, occurrence of psychological abuse shared a negative relationship with proximal, task-related reactions. If efficacy expectations are eroded over time via the integration of damaging, psychologically abusive messages, how does that process continue to affect the victim even after those messages have stopped? The erosive influence of psychological abuse on self-efficacy may continue to negatively impact one's performance even after the abusive relationship has ended; ending the relationship may not ameliorate all of its harmful effects. In addition, a focus on past psychological abuse is consistent with previous studies of the construct (Aosved \& Long, 2005; Baldry, 2003; Follingstad, et al., 1990; Harned, 2001; Marshall, 1996; Neufeld, McNamara, \& Ertl, 1999; Stets, 1991). Three separate, three-path models of mediation were proposed (See Figure 1). The relationships between past psychological abuse and task persistence, affective response, and chosen difficulty of a future task were all predicted to be mediated by both general and specific self-efficacy. 
The following hypotheses were tested:

Hypothesis 1: Past psychological abuse will share a direct, negative relationship with general self-efficacy.

Hypothesis 2: The negative, indirect relationship between past psychological abuse and specific self-efficacy will be mediated by general self-efficacy.

Hypothesis 3: The negative, indirect relationship between past psychological abuse and task persistence will be simultaneously mediated by both general and specific self-efficacy.

Hypothesis 4: The positive, indirect relationship between past psychological abuse and change in negative affect will be simultaneously mediated by both general and specific self-efficacy.

Hypothesis 5: The negative, indirect relationship between past psychological abuse and the chosen difficulty level of a future task will be simultaneously mediated by both general and specific self-efficacy. 


\section{METHOD}

\section{Participant Recruitment and Sample Selection}

Participants were recruited from the undergraduate psychology subject pool for the "Relationship Experiences in Women Study" via a computer-based research participation system. The undergraduate psychology subject pool includes students enrolled in both introductory and advanced psychology courses that offer course credit for participation in research studies.

Inclusion criteria. The current study employed three inclusion criteria. One, to ensure that study participants were in the same developmental period only women reporting an age between 18 and 30 years old were eligible for study participation. Two, women must have reported having at least one former romantic partner with whom they were no longer involved. Due to recruiting from the college population, the majority of participants were expected to reference psychological abuse that occurred in a dating relationship. Dating relationships may include a wider range of emotional significance than would marital or cohabiting relationships, introducing a potential source of heterogeneity into the sample. Therefore, the third inclusion criterion required that a woman's former partner be someone she dated often, at a minimum, which was operationalized as a score of two or higher on the measure of emotional attachment (Billingham, 1987). 
Exclusion criteria. The current study employed three exclusion criteria. One, as previously discussed the study excluded all men. Two, the study excluded women endorsing any incident of physical or sexual IPV in the former romantic relationship, operationalized as a score of two or greater on the STaT (Paranjape \& Liebschutz, 2003). Given that the study focused exclusively on psychological abuse, other types of IPV may have introduced additional sources of self-efficacy erosion and confounded study results. Three, women reporting psychological abuse in a current romantic relationship, operationalized as a score of six or more on the Psychological Aggression subscale of the Conflict Tactics Scale - Revised (Straus, Hamby, \& Warren, 2003), were excluded. Allowing experiences of both past and current psychological abuse into the study sample would have confounded study results. Would significant results - if found - be related to past or current psychological abuse? Given that the study focused on past psychological abuse, women endorsing more than a minimal level of infrequent psychological maltreatment within a current romantic relationship were excluded. This exclusion criterion acknowledged the reality that some objectionable behavior occasionally occurs in the majority of romantic relationships while still effectively excluding current psychological abuse. Given the high correlation between psychological abuse and physical and sexual IPV, excluding current psychological abuse indirectly excluded participants experiencing current physical or sexual IPV (Aosved \& Long, 2005; Hamby \& Sugarman, 1999; Harned, 2001; Hines \& Saudino, 2003). Therefore, physical and sexual IPV within a current relationship were not directly assessed. 


\section{Measures}

\section{Demographics, relationship history, and screening measures.}

Demographics and relationship history. Participants reported age, ethnicity, academic class (e.g., freshman, sophomore), and number of children. Participants reported the gender of the former partner, level of commitment in the former relationship (e.g., monogamously dating, cohabiting), how long ago the former relationship ended, and who ended the former relationship. Participants also reported if they were in a current relationship, and if so, the gender of the current partner (see Appendix A). Case deletion was utilized for missing data.

Emotional attachment. Participants rated on a seven-point scale the level of emotional attachment to their former partner (Billingham, 1987; see Appendix B). The scale ranges from minimal emotional attachment to extremely high emotional attachment, with higher scores indicating greater emotional attachment. The single-item measure has displayed construct validity by correlating in expected directions with related measures (e.g., positive correlation with measure of global relationship commitment; Katz et al., 2006). Case deletion was utilized for missing data.

Conflict Tactics Scale - Revised. The Conflict Tactics Scale - Revised (CTS2;

Straus, Hamby, \& Warren, 2003) assesses experiences of minor and severe partner abuse or violence and is a revision of the widely used Conflict Tactics Scale. Two subscales, Psychological Aggression and Negotiation, were used in the current study (see Appendix C). The eight-item Psychological Aggression subscale screened for psychological abuse in a current relationship. Participants reported the frequency of each psychologically abusive act on a six-point scale and frequency scores were calculated. Acts endorsed as 
having a high frequency were assigned higher scores and the scores for all acts were then summed; higher total scores indicate more frequent psychological abuse. The subscale has demonstrated high internal consitency both in a previous study of the undergraduate population, Cronbach's $\alpha=.79$ (Straus et al., 2003), and in the current study, Cronbach's $\alpha=.74$. The CTS2 subscale has also correlated in expected directions with related measures (Straus, 2004; Straus et al., 2003). Participant-specific mean imputation for was utilized for missing data.

The six-item Negotiation subscale assessed postive conflict resolution tactics in the former relationship. Participants reported the frequency of each positive resoluton tactic on a six-point scale, with higher scores indicating higher frequency of positive resolution tactics. The Negotiation subscale was administered so participants would not end their study participation focused on the negative or potentially distressing aspects of the former relationship.

STaT. The STaT (slapped, threatened, and throw [things] ) is a three-item, IPV screening tool (Paranjape \& Liebschutz, 2003) and was used to screen for exclusionary physical and sexual violence in study participants' former relationships (see Appendix D). Participants responded either "yes" (one point) or "no" (zero points) to each item, creating a possible range of zero to three points. When predicting intimate partner violence, a score of two or higher has demonstrated good sensitivity $(84.8 \%)$, acceptable specificity (54\%), and good negative predictive power (87.9\%) (Paranjape, Rask, \& Liebschutz, 2006). The measure also demonstrated acceptable internal consistency in the current study, Cronbach's $\alpha=.69$. Case deletion was utilized when data were missing. 
Two-Item Screener for History of Abuse in Childhood. The Two-Item Screener for History of Abuse in Childhood (Child Abuse Screener; Thombs, Bernstein, Ziegelstein, Bennett, \& Walker, 2007), taken from the Childhood Trauma Questionnaire - Short Form (Bernstein \& Fink, 1998), screens for a history of physical or sexual abuse in childhood (Thombs et al., 2007; see Appendix E). The Child Abuse Screener has demonstrated good sensitivity $(84.8 \%)$ and specificity $(88.1 \%)$ for identifying adults with a history of childhood physical or sexual abuse (Thombs et al., 2007). Case deletion was utilized for missing data.

\section{Predictor variable measures.}

Psychological Maltreatment Inventory. The Psychological Maltreatment Inventory (PMI) is a 40-item measure of psychological abuse (Kasian \& Painter, 1992; see Appendix F). The PMI was modified from the Psychological Maltreatment for Women Inventory (PMWI; Tolman, 1989), a longer measure of non-physical abuse by a romantic partner. The PMI was designed to be more appropriate for use with undergraduate populations that are more likely to reference dating than marital relationships. Items referencing shared finances, housework, childcare, and restricted use of shared property (e.g., telephone, car) were eliminated from the original measure, with Kasian and Painter (1992) proposing that these items would not be applicable to the college population.

Participants report the frequency of psychologically abusive acts on a six-point scale, with higher scores indicating higher levels of psychological abuse. The PMI has demonstrated high internal consistency in previous studies, Cronbach's $\alpha=.72-.82$ (Kasian \& Painter, 1992), as well as in the current study, Cronbach's $\alpha=.97$. In addition, 
the PMI has related in expected directions with theoretically relevant constructs, such as sexual assault victimization (Aosved \& Long, 2005), symptoms of depression, low positive affect, and interpersonal difficulties (Gallaty \& Zimmer-Gembeck, 2008). The PMI is a valid measure of psychological abuse among college-aged women. Participantspecific mean imputation was utilized for missing data.

New General Self-Efficacy Scale. The eight-item New General Self-Efficacy Scale (NGSE; Chen et al., 2001) assessed participants' current level of general selfefficacy (see Appendix G). Items are rated on a five-point scale, with higher scores reflecting higher general self-efficacy. The items of the NGSE represent a unidimensional factor with high internal consistency, both in previous studies, Cronbach's $\alpha=.85-.90$ (Chen et al., 2001; Scherbaum, Cohen-Charash, \& Kern, 2006) and in the current study, Cronbach's $\alpha=.97$. The NGSE has also displayed high testretest reliability, $r=.62-.86$ (Chen et al., 2001; Scherbaum et al., 2006).

Among groups of graduate and undergraduate students, the NGSE was rated as significantly more content valid than another, common measure of general self-efficacy (Chen et al., 2001). When compared with two other measures of general self-efficacy, the NGSE was found to be better at discriminating between people with similar, but slightly different, levels of general self-efficacy and provided the same amount of information as longer measures (Scherbaum et al., 2006). Although highly correlated, a confirmatory factor analysis found that the NGSE represented a construct distinct from self-esteem (Chen et al., 2001). The high content validity, strong test-retest reliability, positive results of item response theory analyses, and positive correlation with the related 
construct of self-esteem all indicate that the NGSE is a valid measure of general selfefficacy. Participant-specific mean imputation was utilized for missing data.

Specific Self-Efficacy. The 11-item Specific Self-Efficacy Scale (SSES) assessed participants' self-efficacy specifically for the study's challenging task - a set of anagrams (see Appendix H). The SSES adheres to Bandura's (2006) guidelines for constructing specific self-efficacy scales. More specifically, the scale was constructed in terms of what a participant believes she currently "can do" rather than that what she "will do" or might be capable of doing in the future (Bandura, 2006, p. 308). In addition, the SSES assessed self-efficacy for performing anagram tasks of varying difficulty levels and for successfully performing anagram tasks on a regular basis, rather than occasionally solving an anagram correctly.

An average specific self-efficacy rating was calculated from the 0 to 100 efficacy ratings provided by participants, with higher scores corresponding to higher specific selfefficacy. Participant-specific mean imputation was utilized for missing data. Specific self-efficacy scales developed based on Bandura's (2006) guidelines have reported high internal consistency, Cronbach's $\alpha=.85-.98$ (Holden, Anastas, Meenaghan, \& Metrey, 2002; Marsden, Carroll, \& Neill, 2005; Salbach, Jaglal, Korner-Bitensky, Rappolt, \& Davis, 2007). The scale constructed for the current study also possessed high internal consistency, Cronbach's $\alpha=.95$.

\section{Outcome variable measures.}

Task Persistence. Task persistence was measured by the amount of time, in minutes and seconds, a participant worked on the laboratory task. A researcher timed a participant's performance with a stopwatch. Time has been used as a measure of task 
persistence in multiple self-efficacy studies (Brown \& Inouye, 1978; Cervone \& Peak, 1986; Jacobs et al., 1984; Multon, Brown, \& Lent, 1991).

Positive Affect/ Negative Affect Scale. The Positive Affect / Negative Affect Scale (PANAS; Watson, Clark, \& Tellegan, 1988) assessed participants' state affect (See Appendix I). The PANAS includes two, ten-item scales assessing either positive or negative affect. Using a five-point scale, participants are asked to rate each item according to "how you feel right now." When these instructions are utilized the PANAS provides a brief and easily administered measure of state affect. The ratings of the ten negative emotions are summed to create a negative affect score and the ratings of the ten positive emotions are summed to create a positive affect score, with higher scores representing higher state affect. Change-scores were calculated for both the negative and positive affect scales by subtracting scores prior to the challenging laboratory task from those following the task. Participant-specific mean imputation was utilized for missing data.

The PANAS demonstrated high internal consistency both in previous studies, for the positive affect scale, Cronbach's $\alpha=.86-.90$, and for the negative affect scale, Cronbach's $\alpha=.84-.87$ (Crawford \& Henry, 2004; Watson et al., 1988), and in the current study, Cronbach's $\alpha=.92$, Cronbach's $\alpha=.79$, respectively. Factor analyses have confirmed that the scale measures two primarily independent constructs (Tuccitto, Giacobbi, \& Leite, 2009). For state affect ratings, the positive affect scale possesses a test-retest reliability of $r=.54$, while the negative affect scale possesses a test-retest reliability of $r=.45$ (Watson et al., 1988). The low reliability coefficients are desirable for a state affect scale. The PANAS has also correlated with related measures in 
predicted directions (i.e., strong positive correlations between the negative affect scale and depression inventories) (Crawford \& Henry, 2004; Watson \& Clark, 1997; Watson et al., 1988) and is a valid measure of state affect.

Difficulty level rating scale. The Difficulty Level Rating Scale assessed a participant's chosen difficulty level for a future task (see Appendix J). The participant was asked to indicate on a ten-point scale the difficulty level she would like to attempt on a future task by circling the corresponding number. Case deletion was utilized for missing data.

\section{Procedure}

Screening phase. Participants first completed a Screening Phase, the purpose of which was two-fold. One, information necessary for adequately describing the study sample and assessing inclusion and exclusion criteria was collected. Two, information for which recall or report might contaminate the Laboratory Phase (e.g., past psychological abuse) was collected. The Screening Phase was conducted via an online survey hosted by the service Survey Monkey and the information was associated with a confidential identification number. Upon beginning the Screening Phase participants were presented with a study preamble, which served as informed consent for the online survey. Participants were required to indicate that they understood the information that was to be requested of them and that they voluntarily chose to complete the survey.

Participants then provided demographic information, completed the measure of general self-efficacy and completed the child abuse screener. Next, participants were asked if they were currently in a romantic relationship. If participants reported a current relationship, the Psychological Aggression subscale of the CTS2 was administered to 
screen for psychological abuse in the current relationship. From that point forward, all questions in the on-line survey referenced the participant's former romantic partner. Participants provided relationship history information about the former relationship and then completed the emotional attachment measure and IPV screener. If a participant endorsed having experienced physical or sexual violence in the former relationship, she was presented with information about local resources for partner violence survivors. Next, participants completed the PMI to measure psychological abuse in the former relationship. Finally, the Negotiation subscale of the CTS2 was completed, allowing the participant to focus on the potentially positive aspects of the former relationship before ending study participation.

When the survey was completed the participants chose between two forms of compensation for their Screening Phase participation -1.0 research credit or a $10 \%$ coupon for local retail store - and provided their email address for future communication. Participants were informed that the study included a second phase and that, if eligible, they would be contacted via email about further study participation and compensation.

Laboratory phase. Participants meeting study inclusion criteria were contacted via email and invited to participate in the Laboratory Phase, consisting of a single individual session. Upon arrival, participants were provided the opportunity to ask questions and completed informed consent.

Baseline. Following informed consent, participants completed a "vanilla baseline" task (Jennings, Kamarck, Stewart, Eddy, \& Johnson, 1992, p. 743) designed to maintain alertness, but to be simple and unexciting. Participants viewed a ten-minute, computer-based slideshow where the color of a single rectangle randomly alternated 
every ten seconds (i.e., red, green, yellow, blue, purple, white). Participants were asked to count the number of times the rectangle appeared yellow. The task allowed for the collection of a stable baseline measure in the laboratory setting and provided a comparison condition for future assessments (Jennings et al., 1992). Although initially designed for use in physiological research, the vanilla baseline task has been used to provide a baseline of state affect (Jacob et al., 2009; Kuo \& Linehan, 2009). Immediately following the vanilla baseline task participants' pre-task state affect was assessed.

Anagrams. Next, the researcher explained that the first laboratory task consisted of multiple anagrams and participants were informed they would be asked to form a single word by rearranging each set of letters. Following the introduction of the anagram task, the specific self-efficacy scale was administered. A list of six unsolvable anagrams (see Appendix K; Calef, Choban, Calef, Brand, \& Rogers, 1992) was then presented to participants. Participants were told they were permitted as much time as they would like to work on the anagrams but they may also stop at any point and continue to the next task. Participants were then left alone to work on the unsolvable anagrams. In a separate room, the researcher timed how long participants worked on the anagram task before asking to continue. Immediately following participants' request to move on to the next task, participants' post-task affect was assessed. Participants were then told they would complete a second set of anagrams and could choose their difficulty level. The Difficulty Level Rating Scale was then administered. At this time participants were informed that study participation was complete.

During data collection one anagram listed as unsolvable in the literature was found to have a solution; this anagram was immediately replaced. Also during data 
collection, a study participant spontaneously disclosed that she suspected the anagrams were unsolvable. Following this disclosure a validity check was implemented.

Validity check and debriefing. Once informed their study participation was complete, participants were asked the open-ended question of why they stopped working on the unsolvable anagrams. After providing an answer, participants were informed that the anagrams were unsolvable and were asked - yes or no - if they suspected at any time that the anagrams were unsolvable. Finally, participants were fully debriefed, including an explanation of the specific purpose of the study and that they would not be performing any additional laboratory tasks. Following debriefing participants chose between two forms of compensation for their Laboratory Phase participation - 1.0 research credit or $\$ 20.00$ - and were compensated.

\section{Data Analysis Plan}

Three-path mediation. A three-path, joint significance test of mediation was utilized to test the study hypotheses. The joint significance test is a regression-based variant of the causal steps approach to testing mediation (Fritz \& MacKinnon, 2007; MacKinnon, Lockwood, Hoffman, West, \& Sheets, 2002). Unlike the traditional approach, the joint significance test does not require a significant relationship between the predictor and outcome variable to justify testing for mediation (Fritz \& MacKinnon, 2007; MacKinnon et al., 2002). The joint significance test considers each mediated path separately, and if all mediated paths are significantly different from zero the meditational model is supported (Fritz \& MacKinnon, 2007; MacKinnon et al., 2002). The joint significance test was utilized because it could effectively test the hypothesized models 
while also minimizing Type I error, possessing statistical sensitivity, and being simple to conduct and interpret (MacKinnon et al., 2002; Taylor, MacKinnon, \& Tein, 2008).

Initially proposed for a single mediator, two-path mediation model, the joint significance test has been generalized to the two-mediator, three-path mediation model (Taylor et al., 2008). Three regression equations are required to test a three-path mediation model. The regression equations for the current study are below (see Figure 1). In each regression equation psychological abuse refers to the total score on the measure of past psychological abuse, while GSE refers to the total score on the measure of general self-efficacy and SSE refers to the total score on the measure of specific selfefficacy.

$$
\begin{aligned}
& \text { General Self-Efficacy }=b^{*}{ }_{\text {intercept }}+b^{*}(\text { Psychological Abuse })+\varepsilon \\
& \text { Specific Self-Efficacy }=b^{*}{ }_{\text {intercept }}+b^{*}(G S E)+b^{*}(\text { Psychological Abuse })+\varepsilon \\
& \text { Specific Task Reaction }=b^{*}{ }_{\text {intercept }}+b^{*}(S S E)+b^{*}(G S E)+b^{*}(\text { Psychological } \\
& \text { Abuse })+\varepsilon
\end{aligned}
$$

Three iterations of the final regression equation were calculated, with task persistence, change in negative affect, and chosen difficulty level of a future task each serving as a separate, specific task reaction. Equation 1 tested the first path of the models and the hypothesized direct, negative relationship between past psychological abuse and general self-efficacy. Equation 2 tested the second path of the models and the hypothesized indirect, negative relationship between past psychological abuse and specific self-efficacy. Finally, Equation 3 tested the third path of each model and the separate hypothesized indirect relationships between past psychological abuse and task persistence, change in negative affect, and chosen difficulty level of a future task. 
A $t$-statistic was then calculated for each mediated path and compared to a table of critical $t$-values. If the path's $t$-value exceeds the critical value it is considered significant; all paths must be significant for mediation to be supported. The formulas below were utilized to calculate $t$-statistics for the paths of the study's models.

Psychological abuse refers to the total score on the measure of past psychological abuse, while GSE refers to the measure of general self-efficacy and SSE refers to the measure of specific self-efficacy.

$$
\begin{aligned}
t_{(\mathrm{n}-2)} & =b^{*}{ }_{\text {Psychological Abuse }} / s_{\text {Psychological Abuse }} \\
t_{(\mathrm{n}-3)} & =b^{*} *_{\mathrm{GSE}} / s_{\mathrm{GSE}} \\
t_{(\mathrm{n}-4)} & =b^{*}{ }_{\mathrm{SSE}} / s_{\mathrm{SSE}}
\end{aligned}
$$

Equation 4 tested the significance of the first path, Equation 5 tested the significance of the second path, and Equation 6 tested the significance of the third paths of each model (see Figure 1).

Taylor and colleagues (2008) conducted a series of data simulations to assess the Type I error rate and power of the joint significance test for a three-path mediation model. Sample sizes of $N=50,100,200,500$, and 1,000 were included in the data simulations, as were continuous and dichotomous definitions of the independent variable. In addition, the three paths of the mediation model were set to represent all possible combinations of small, medium, or large effect sizes. Based on the results of Taylor and colleagues' (2008) data simulations, one can multiply the expected effect sizes of the model's three paths and use the product to estimate Type I error rate and the statistical power for a specific sample size. Therefore, to determine the Type I error rate and power 
for the current study, the effect sizes for each path of the proposed models had to be estimated.

Estimated effect sizes. Effect sizes were estimated for each path of the three hypothesized mediation models (see Figure 2). No studies to date have linked psychological abuse and general self-efficacy; therefore effect size estimates for the first path of the models were drawn from related literature. Studies of psychological abuse and self-esteem report a consistently negative relationship with a medium effect size (Baldry, 2003; Gross \& Keller, 1992; Jezl, Molidor, \& Wright, 1996; Matud, 2005; Soffer, Gilboa-Schectman, \& Shahar, 2008). As a result, the relationship between past psychological abuse and general self-efficacy was estimated to possess a medium effect size. The second path of the current study's model, from general to specific self-efficacy, was estimated based on results reported in the literature. The presence of a relationship between general and specific self-efficacy has been inconsistent in the literature. When a relationship between the constructs is found, it has possessed a large, positive effect size (Chen et al., 2000; Tzeng, 2009; Yeo \& Neal, 2006), therefore the second path of the current study's model was estimated to also possess a large effect size.

Finally, effect sizes between specific self-efficacy and each task reaction were separately estimated. Across a variety of settings, the relationship between specific selfefficacy and task persistence has been consistently positive and displayed a large effect size (Brown \& Inouye, 1978; Cervone \& Peake, 1985; Gao \& Newton, 2009; Lent, Brown, \& Larkin, 1984). Therefore, the third path from specific self-efficacy to task persistence was estimated to possess a large effect size. 
The strength of specific self-efficacy's relationship with negative affect is less consistent than with task persistence. Studies have reported small (Shell \& Husman, 2008) medium (McAuley \& Courneya, 1992; McAuley et al., 1999; Shell \& Husman, 2008), and large effect sizes (Bandura \& Adams, 1977; Bandura et al., 1977; Beckham et al., 1997; McAuley et al., 1999). The effect sizes appear to vary with the operational definition of negative affect (e.g., anxiety vs. depression vs. general negative affect), as well as if general or task-specific affect was assessed. Studies assessing negative affect during or immediately following a challenging task - the experimental procedure most similar to that of the current study - reported both medium and large effect sizes (Bandura \& Adams, 1977; Bandura et al., 1977; McAuley \& Courneya, 1992; McAuley et al., 1999). Therefore, the path from specific self-efficacy to change in negative affect was estimated to possess at least a medium effect size.

The third and final relationship between specific self-efficacy and chosen difficulty level of a future task has been reported to possess both a medium (Dickerson \& Taylor, 2000; Gibbons \& Weingart, 2001) and large effect size (Locke et al., 1984).

Because no one study's operationalization of this variable was more similar to the current study's than another, the path from specific self-efficacy to the chosen difficulty level was estimated to possess at least a medium effect size.

Type I Error and power. The products of the estimated effect sizes, detailed above, were utilized to determine the current study's power and Type I error rate. Taylor and colleagues (2008) utilized Cohen's (1988) definition of small, medium, and large effect sizes to calculate the product of estimated effect sizes, upon which Type I error rates and power are estimated. Of the three hypothesized models, the model of task 
persistence possessed the most consistently reported effect sizes in the literature, making it the most reliable model upon which to base the study's power and error rate estimates (see Figure 2 for estimated effect sizes). Following Taylor and colleagues' (2008) procedure, the estimated effect sizes of the three paths in the model of task persistence were multiplied and the product was utilized to estimate the power and Type I error rate given the sample size $(n=60)$ with which the mediation models were tested. Based on Taylor and colleagues' (2008) estimates, a sample size of 50 is estimated to achieve statistical power of at least .76 and a Type I error rate of .03 . Given the sample size of participants completing the Laboratory Phase $(n=60)$ the current study's statistical power is estimated to exceed .76 and the Type I error rate is estimated to not exceed 03 .

\section{Data Management}

Prior to conducting study analyses, the data was examined for missing data and outliers. Missing data points were found to be missing at random; no discernible pattern was present in the missing data (Tabachnick \& Fidell, 2001). No specific study item or measure was more likely to possess missing data than any other. In addition, less than $5 \%$ of the total data points consisted of missing values (Tabachnick \& Fidell, 2001). Given that the data was missing at random and represented only a small percentage of the overall data set, missing data does not pose a serious threat to the validity of study results (Tabachnick \& Fidell, 2001).

The presence of outliers within study variables was also investigated, with an outlier defined as a $z$-score $>3.59$ (Field, 2005; Tabachnick \& Fidell, 2001). Two participants who reported an age of 32 in the Screening Phase were found to be outliers in the distribution. Given that the intended scope of the study was to include only 
participants between the ages of 18 and 30, the two outliers were beyond the intended scope and removed from the sample (Tabachnick \& Fidell, 2001). The measure of past psychological abuse was found to possess high scores meeting criteria to be classified as outliers; however these scores were not beyond the scope of the intended study sample and were therefore retained. 


\section{RESULTS}

A total of 389 participants accessed the online survey of the Screening Phase and consented to study participation; five participants chose not to complete the survey. Twenty-one participants consented to participation and began, but did not complete, the online survey, preventing study eligibility from being assessed. Therefore, these participants were excluded from further study participation and study analyses.

\section{Study Eligibility and Attrition}

Of the 363 participants completing the Screening Phase, 100 participants did not meet study eligibility criteria and were therefore not invited to participate in the Laboratory Phase. Two hundred sixty-three participants met study eligibility criteria and were invited to participate in the Laboratory Phase. Of the eligible participants, 63 enrolled in and completed the Laboratory Phase. During the Laboratory Phase three participants provided a correct solution to an anagram originally believed to be unsolvable, creating a qualitatively different experience of the experiment than had by other participants. Therefore, these three participants were excluded from study analyses (see Figure 3 for detailed study eligibility information).

Across the final full sample ( $N=360 ; 300$ completing only the Screening Phase and 60 completing both the Screening and Laboratory Phases) study participants were primarily White, college freshmen who had not experienced child abuse, with a mean age 
of 20.53 years (see Table 1). The majority of participants reported being "in love" with their former partner, and had been involved in a monogamous, dating relationship (see Table 2). Participants had been out of the former relationship for an average of 6.44 months and approximately half of the sample reported they ended the former relationship and were now re-partnered. Ineligible participants $(n=100$; those completing the Screening Phase and ineligible for the Laboratory Phase), Eligible participants ( $n=200$; those completing the Screening Phase and eligible for, but not completing the Laboratory Phase), and Laboratory participants ( $n=60$; those completing both the Screening and Laboratory Phases) were compared on demographics and relationship history to determine how eligibility criteria and attrition may have affected the composition of the final laboratory sample (see Table 3).

Variables were assessed for the presence of a normal distribution using the full study sample. The following variables possessed a non-normal distribution, as determined by the Shapiro-Wilke test for normality: participant age, time out of the former relationship, general self-efficacy, and past psychological abuse. Data transformations were unsuccessful in achieving normal distributions for these variables, therefore non-parametric rather than parametric analyses were performed with the aforementioned variables. In addition, both mean and median are included when measures of central tendency are reported.

Demographics. Chi-square tests compared the three participant groups on ethnicity, academic class, and history of child abuse. For age, the Kruskal-Wallis nonparametric analysis of variance was conducted. The groups were not significantly 
different on any demographic variable; therefore demographic characteristics do not appear to confound study results.

Relationship history. Chi-square tests compared the three participant groups on level of commitment to the former partner, who ended the former relationship, and if the participant is re-partnered. Significant group differences were found on all variables. To interpret the significant results, the overall Chi-square contingency tables were partitioned into independent Chi-squares. Given the multiple, post-hoc comparisons the Bonferroni correction was implemented to control the Type I error rate.

Despite a significant overall Chi-square, when the Bonferroni correction was applied, no significant differences were found between Ineligible, Eligible, or Laboratory participants on the level of commitment to the former partner. Ineligible participants were significantly more likely to be re-partnered than either Eligible, $\chi^{2}(1, n=297)=$ $33.35, p<.001$, or Laboratory participants, $\chi^{2}(1, n=157)=36.36, p<.001$; no difference was found between Eligible and Laboratory participants. Finally, a significant difference was found between Ineligible and Eligible participants on who ended the former relationship, $\chi^{2}(2, n=297)=11.43, p=.003$; Laboratory participants did not differ from either Ineligible or Eligible participants. Compared to Eligible participants, Ineligible participants were more likely to report that they, rather than the former partner, ended the relationship, $\chi^{2}(1, n=220)=7.03, p=.008$, or that ending the relationship was a mutual decision, $\chi^{2}(1, n=213)=7.96, p=.005$.

The three participant groups were also compared on time out of the former relationship using the Kruskal-Wallis non-parametric analyses of variance and a significant group difference was found. To interpret the significant result a pair-wise, 
Wilcoxon rank-sum test was conducted and the Bonferroni correction was applied. Ineligible participants had been out of the former relationship $(M=8.18, M d n=6.00, S D$ $=7.10)$ for significantly longer than Eligible $(M=6.06, M d n=5.00, S D=5.22), z=2.86$, $p=.004$, or Laboratory participants $(M=4.90, M d n=4.00, S D=3.49), z=-3.47, p=$ .0005. Laboratory and Eligible participants did not differ on amount of time out of the former relationship, $z=-1.54, p=.12$.

Eligibility criteria. Kruskal-Wallis non-parametric analyses of variance evaluated group differences on the IPV screener, psychological aggression in a current relationship, and level of emotional attachment to former partner. Significant group differences were found on the IPV screener and Psychological Aggression subscale, but not on emotional attachment.

To interpret the significant results pair-wise, Wilcoxon rank-sum tests were conducted and the Bonferroni correction was applied. Ineligible participants reported significantly higher scores on the IPV screener $(M=1.20, M d n=1.00, S D=1.14)$ than did Eligible participants $(M=0.23, M d n=0.00, S D=0.41), z=8.02, p<.001$, or Laboratory participants $(M=0.13, M d n=0.00, S D=0.39), z=-6.41, p<.001$. Ineligible participants also reported significantly higher levels of current psychological aggression $(M=20.46, M d n=12.00, S D=21.85)$ than did Eligible participants $(M=$ $1.67, M d n=1.00, S D=1.89), z=7.39, p<.001$, or Laboratory participants $(M=2.83$, $M d n=1.00, S D=2.81), z=-3.81, p<.001$. No differences were found between Eligible and Laboratory participants on either the IPV screener, $z=-1.77, p=.08$, or current psychological aggression, $z=0.72, p=.47$. 
Predictor variables. Finally, to assess for predictor variable bias, a KruskalWallis non-parametric analysis of variance compared the three participant groups on general self-efficacy and past psychological abuse. A significant difference was found on past psychological abuse, but not on general self-efficacy, Kruskal-Wallis $=2.48, p=.29$. To interpret the significant group difference on past psychological abuse, a pair-wise, Wilcoxon rank-sum test was conducted and the Bonferroni correction was applied. Ineligible participants reported significantly higher levels of past psychological abuse ( $M$ $=102.48, M d n=88.00, S D=51.36)$ than Eligible $(M=71.51, M d n=63.00, S D=28.40)$, $z=5.07, p<.001$, or Laboratory participants $(M=72.76, M d n=62.50, S D=34.37), z=-$ $3.95, p<.001$. No difference was found between Laboratory and Eligible participants, $z$ $=-0.46, p=.64$. Group comparisons could not be conducted for the predictor variable specific self-efficacy as this data was not collected until the study's Laboratory Phase.

Overall, then, the Laboratory participants were demographically similar and reported comparable levels of general self-efficacy to the larger pool of participants. Laboratory participants and Eligible participants also reported similar relationship histories. Laboratory participants differed from Ineligible participants by being less likely to be re-partnered, out of the former relationship for a shorter period of time, and having lower levels of past psychological abuse, psychological aggression in a current relationship, and lower scores on the IPV screener.

\section{Laboratory Sample}

Data collected from Laboratory participants was utilized to test the study hypotheses. Prior to hypothesis testing, the distributions of the predictor and outcome variables were examined in this participant group alone (see Table 4). 
Predictor variables. Among Laboratory participants, the distributions of both past psychological abuse and general self-efficacy were significantly non-normal, while specific self-efficacy was normally distributed. Participants reported a generally low level of past psychological abuse. On a measure with a possible range of $40-240,75 \%$ of the sample earned a score of 89.00 or below. In contrast, participants reported generally high levels of general self-efficacy. On a measure with a possible range of 8 40 , only $25 \%$ of the sample earned a score of 28.00 or less. Participants reported a moderate level of specific self-efficacy. With a possible range of $0-100,50 \%$ of the sample earned a score of 61.05 or higher.

Outcome variables. The distributions of task persistence and change in negative affect were significantly non-normal, while chosen difficulty level was normally distributed. Square root transformations were performed on task persistence and change in negative affect to obtain a normal distribution. Participants experienced a significant increase in negative affect from pre-task $(M=13.07, S D=3.59)$ to post-task $(M=17.11$, $S D=5.91), t(118)=4.53, p<.0001$. Overall, participants worked on the anagram task for an average of 14.08 minutes and chose a low level of difficulty for future anagrams tasks, with no participant choosing a difficulty level higher than 6 on a $1-10$ scale.

Statistical assumptions. Prior to testing the proposed models, the assumptions of multiple regression were assessed. The following assumptions were met: non-zero variance, homoscedasticity, independence of errors, normally distributed residuals, independence of outcome variables, and linear predicted relationships between independent and dependent variables (Field, 2005). The assumption of lack of multicollinearity was also met (see Table 5). To assess the assumption that predictors are 
uncorrelated with external variables (Field, 2005) and that the model is self-contained (Taylor, MacKinnon, \& Tein 2008), a series of Spearman correlations were conducted between the predictor variables and demographic and relationship history variables (see Table 6). Two of the model's predictors were found to correlate significantly with external variables. A negative correlation was found between general self-efficacy and the level of emotional attachment to the former partner. A positive correlation was also found between past psychological abuse and the IPV screener. Although significant relationships with external variables were identified, the variables were not included as covariates in the model because they were not identified a priori (Babyak, 2004).

Analysis of study hypotheses. A three-path, joint significance test of mediation was utilized to test the study hypotheses. General self-efficacy was regressed on past psychological abuse; past psychological abuse predicted general self-efficacy, accounting for $15 \%$ of the variance, $b^{*}=-.09, p<.05$, and the regression coefficient was significantly different from zero, $t(59)=-3.15, p<.01 ; F(1,58)=9.95, p<.05$. Second, specific self-efficacy was regressed on general self-efficacy and past psychological abuse. When controlling for past psychological abuse, general selfefficacy did not significantly predict specific self-efficacy, with the model accounting for $3 \%$ of the variance, $b^{*}=.42, p=.26$, and the regression coefficient was not significantly different from zero, $t(58)=1.15, p>.05 ; F(2,57)=1.02, p=.37$.

Third and finally, three separate multiple regression analyses were conducted with each specific task reaction. The transformed value of task persistence was regressed on specific self-efficacy, general self-efficacy, and past psychological abuse. When controlling for past psychological abuse and general self-efficacy, specific self-efficacy 
did not significantly predict task persistence, with the model accounting for $4 \%$ of the variance, $b^{*}=-.02, p=.77$, and the regression coefficient was not significantly different from zero, $t(57)=-.29, p>.05 ; F(3,56)=0.85, p=.47$. The hypothesized model of task persistence was not supported.

The transformed value of change in negative affect was regressed on specific selfefficacy, general self-efficacy, and past psychological abuse. When controlling for past psychological abuse and general self-efficacy, specific self-efficacy did not significantly predict change in negative affect, with the model accounting for $6 \%$ of the variance, $b^{*}=$ $-.01, p=.09$, and the regression coefficient was not significantly different from zero, $t$ $(57)=-1.76, p>.05 ; F(3,56)=1.06, p=.37$. The hypothesized model of change in negative affect was not supported.

Chosen difficulty level of a future task was regressed on specific self-efficacy, general self-efficacy, and past psychological abuse. When controlling for past psychological abuse and general self-efficacy, specific self-efficacy significantly predicted the chosen difficulty level of a future task, with the model accounting for $17 \%$ of the variance, $b^{*}=.02, p=.01$, and the regression coefficient was significantly different from zero, $t(57)=3.07, p<.01 ; F(3,56)=3.90, p=.01$. Despite the significant relationship between specific self-efficacy and chosen difficulty level, the hypothesized model was not supported as a whole because, as discussed above, the model's second regression coefficient from general to specific self-efficacy was not significant. In fact, the percentage of variance accounted for when specific self-efficacy was the sole predictor did not significantly increase with the addition of either general self-efficacy, $R^{2}$ 
$=.14, \Delta R^{2}=.00, F(3,56)=.00, p=.96$, or past psychological abuse, $R^{2}=.17, \Delta R^{2}=.03$, $F(3,56)=2.44, p=.12$, to the model.

Validity check. As previously outlined, a validity check of the unsolvable anagrams was implemented during data collection. Of the 32 participants on whom the validity check was performed, 15 expressed suspicion that the anagrams were unsolvable. To determine if reported suspicion influenced how participants reacted to the laboratory task, the suspicious and non-suspicious groups were compared on task persistence, change in negative affect and chosen difficulty level of a future task (see Table 7). Suspicious participants worked on the anagrams significantly longer than did their nonsuspicious counterparts; no significant differences were found for change in negative affect or chosen difficulty level. Given that suspicious participants did not prematurely abandon the anagram task and did not differ on other reactions to the laboratory task, the integrity of the stimulus appears to have been maintained.

The presence of suspicious participants created an unintentional subsample within the study, which may act as a confounding variable. To determine if the subsample was likely to confound study results, the groups were also compared on the predictor variables past psychological abuse, general self-efficacy, and specific self-efficacy (see Table 7). The groups did not significantly differ on any variable. Given that the integrity of the stimulus was maintained and that the presence of suspicious participants appears unlikely to confound study results, all participants were included in all study analyses.

\section{Exploratory Analyses}

Given that the hypothesized models were not supported, non-significant relationships were systematically trimmed from the models, with past psychological 
abuse, general self-efficacy, and specific self-efficacy alternately removed from each model. The trimmed models were not supported and no new significant associations were observed (see Table 8). Similarly, given that the hypothesized mediated relationship between past psychological abuse and specific self-efficacy was not supported, a moderated relationship was explored. Specific self-efficacy was regressed on the interaction of past psychological abuse and general self-efficacy, as well as each construct separately; the interaction did not significantly predict specific self-efficacy. In contrast to the hypothesized mediation model, in the moderation model general selfefficacy did significantly predict specific self-efficacy; however this relationship did not remain significant once the Bonferroni correction was applied. (see Table 9).

Previous studies have found relationships between self-efficacy and positive affect, as well as negative affect. Positive affect significantly decreased from pre-task ( $M$ $=26.38, S D=9.22)$ to post-task $(M=22.39, S D=8.65), t(118)=-2.44, p=.02$. To determine if past psychological abuse, general self-efficacy, or specific self-efficacy were related to change in positive affect, a series of Spearman correlations were conducted. No significant associations were observed (see Table 10).

Finally, additional analyses were conducted on the entire study sample $(N=360$; see Table 11). The Bonferroni correction was applied to all analyses. Several specific questions were addressed. First, the relationship between psychological abuse and selfefficacy may have weakened as the abuse experiences became more distal. Therefore relationships between time out of the former relationship and general and specific selfefficacy were investigated via a series of Spearman correlations; no significant associations were observed. Second, it is possible that simply being out of the abusive 
relationship, no matter the length of time, is enough to weaken the relationship between efficacy and psychological abuse. Therefore relationships between current psychological abuse and general and specific self-efficacy were investigated via a series of Spearman correlations; no significant associations were observed. Third, messages of efficacy - or in the case of psychological abuse - messages of inefficacy are more powerful when communicated by a trusted person. Therefore possible relationships between emotional attachment to the former partner and both general and specific self-efficacy were investigated; no significant associations were observed. Fourth and finally, messages of inefficacy and experiences of abuse as a child might establish a pattern of low selfefficacy that continues into adulthood. Wilcoxon rank-sum tests were conducted to explore relationships between reporting childhood abuse and general self-efficacy, $z=$ $0.52, p=.06$, as well as specific self-efficacy, $z=1.15, p=.25$; no significant associations were observed. 


\section{DISCUSSION}

The current study proposed that abuse and violence within intimate relationships erode self-efficacy, ultimately reducing the reservoir of protective factors available for coping with challenges. As a partial test of this self-efficacy erosion model, the present study focused on one aspect of IPV - past psychological abuse. The current study aimed to demonstrate a negative relationship between past psychological abuse and how one copes with a challenging task. More specifically, it was hypothesized that when faced with a challenging task past experiences of psychological abuse would be related to decreased task persistence, increased negative affect, and avoidance of difficult, future tasks. These hypotheses were tested via the analysis of three, three-path mediation models. General self-efficacy was hypothesized to mediate the indirect relationship between past psychological abuse and specific self-efficacy. Both general and specific self-efficacy were then hypothesized to mediate each of the indirect relationships between past psychological abuse and task persistence, change in negative affect, and the chosen difficulty level of a future task.

Support for the proposed models was not found. Consistent with study hypotheses, past psychological abuse was negatively and directly related to general selfefficacy. This finding provides minimal support for the model of efficacy erosion via psychological abuse. However, within the present sample of undergraduate women, general self-efficacy did not mediate an indirect relationship between past psychological 
abuse and specific self-efficacy, nor was a direct relationship between general and specific self-efficacy found. In addition, neither general nor specific self-efficacy predicted a participant's persistence on or change in negative affect following a challenging task.

In slight contrast with the models of task persistence and change in negative affect, a direct relationship was found between specific self-efficacy and the chosen difficulty level of a future task. When controlling for past psychological abuse and general self-efficacy, specific self-efficacy predicted the level of difficulty one chose for a future, hypothetical task. However, the proposed, three-path model of mediation was not supported given that a relationship between general and specific self-efficacy was not present. In fact, general self-efficacy and past psychological abuse were not meaningful additions to the model of chosen difficulty level, as their presence did not significantly increase the amount of accounted for variance. The findings are indicative of a direct relationship between specific self-efficacy and chosen difficulty level, rather than the meditated relationships proposed.

Kazdin (2002) suggests two categories of explanation for null findings. First, a lack of significant findings may reflect the actual state of nature and the null hypothesis could be accepted, although never actually proven. While this is a possible explanation of study results, the validity of the null hypothesis becomes increasingly less likely when a complex set of variables is under study, when a large sample size is not acquired, and when methodological limitations are present (Frick, 1995). Given that the current study meets all of the aforementioned criteria, the null hypothesis is a possible, but improbable, explanation for the study results. 
Second, null findings could be explained by methodological issues, such as suboptimal measurement of the independent or dependent variables, insufficient power, uncontrolled error variability, failure of protocol, and confounders accounting for too much variance in the outcome variables (Kazdin, 2002). Multiple potential methodological explanations exist for the study's null results. The study design may have unintentionally restricted the ranges of predictor variables, potential limitations to external and internal validity are present, and the study may have been underpowered. All of these factors could have prevented significant relationships from being detected and are discussed below.

\section{Restriction of Range}

\section{General self-efficacy.}

Mediator vs. moderator. As previously stated participants in the current study reported high levels of general self-efficacy, ultimately restricting the variable's available range. Applying to, being accepted to, and successfully attending a university likely requires a high level of general self-efficacy. Undergraduates are also exposed to a variety of potential mastery experiences in their course work, positive verbal messages from peers and professors, and positive vicarious learning from social models, which may only increase their levels of general self-efficacy. Therefore, by focusing exclusively on undergraduates the current study may have unintentionally selected a highly efficacious population.

It should also be noted that the level of general self-efficacy found in the current study was particularly high, exceeding the level reported by undergraduate samples in the existing literature (Chen, Gully, \& Eden, 2001; Chen, Gully, \& Eden, 2004; Eschleman 
\& Bowling, 2011; Scherbaum, Cohen-Charash, \& Kern, 2007). Participants' average level of general self-efficacy was also either comparable to (Chen, Gully, \& Eden, 2004; Little, Nelson, Wallace, \& Johnson, 2011; Park, Beehr, Han, \& Grebner, 2012) or exceeded that found in samples of adult full-time employees (Chen, Gully, \& Eden, 2001; Unsworth \& Mason, 2012). The atypically high general self-efficacy may be an artifact of the online assessment method; previous studies have assessed the construct in classroom, work, or laboratory settings. Perhaps at the privacy of their own computers participants were more comfortable reporting higher estimates of their general selfefficacy then they would be in public settings. It is also possible that the level of general self-efficacy was due to the solely female sample, as previous studies have included both sexes. A gender difference in general self-efficacy may exist, but has not yet been investigated. A wider range of general self-efficacy may have been found if women not pursuing or prematurely terminating a college education had been sampled, if a larger, more diverse sample of undergraduate students had been obtained, or if a different data collection method had been used.

Regardless of its cause, the globally high level of general self-efficacy found within the study sample may have served a protective rather than meditational role. While a negative relationship between general self-efficacy and past psychological abuse was found, general self-efficacy still remained high. The high level of general selfefficacy may have served as a protective buffer between past psychological abuse and specific self-efficacy. Past studies of survivors of diverse traumas have reported that both general and specific self-efficacy can be protective against the development and severity of PTSD symptoms (Benight \& Bandura, 2004; Heinrichs et al., 2005; Luszczynska, 
Benight, \& Cieslak, 2009), self-reported somatic symptoms, self-reported physical health disability, number of chronic diseases, and quality of chronic disease self-care (Barry et al., 2003; Luszczynska, Benight, \& Cieslak, 2009). In IPV survivors specifically, high specific self-efficacy is protective via its relationship with initiating and maintaining independence from an abusive or violent partner (Burke et al., 2004; Lerner \& Kennedy, 2000; Patzel, 2001), as well as a reduced risk for attempting suicide (Meadows et al., 2005; Thompson et al., 2002). Rather than protecting against negative outcomes, perhaps general self-efficacy is protective of specific self-efficacy in the current sample.

As a result of the protective barrier formed by general self-efficacy, the negative effects of past psychological abuse may have been prevented from impacting specific self-efficacy and the proposed indirect relationship could not be detected. Moderate or low levels of general self-efficacy may serve as less effective barriers against the impact of past psychological abuse, allowing specific self-efficacy to be negatively impacted. In this vein, general self-efficacy's role may be closer to that of a moderator than a mediator; at high levels general self-efficacy is protective of specific self-efficacy while at moderate or low levels it may not be. Although a moderated relationship between general self-efficacy and past psychological abuse was not seen in the current study, the sample is inappropriate for testing such a relationship. Due to the sample's restricted range, moderate to low levels of general self-efficacy were essentially absent and a moderated relationship cannot be adequately explored. A full range of general selfefficacy must first be obtained before the possibility of a moderated relationship can be accepted or rejected. 
Inconsistent relationship with specific self-efficacy. Thus far an inconsistent relationship between general and specific self-efficacy has been reported in the literature, with some studies reporting a strong relationship between the two constructs (Betz \& Klein, 1996; Chen, Gully, Whiteman, \& Kilcullen, 2000; Tzeng, 2009; Yeo \& Neal, 2006) and some studies failing to find a relationship (Earley \& Lituchy, 1991; Eden \& Zuk, 1995). Chen and colleagues (2001) have questioned the validity of one of the most widely used measures of general self-efficacy and posited that measurement error may be a factor in inconsistent study results. While Chen and colleagues present a strong argument for the role of measurement error, the current study addressed this measurement limitation by using the New General Self-Efficacy Scale (Chen et al., 2001) rather than the flawed measure. Therefore, measurement error may play a role in the inconsistencies in the literature but it may not be the sole explanation for failing to find a relationship between general and specific self-efficacy.

General self-efficacy's possible role as a moderator rather than mediator may provide an explanation for the lack of relationship between general and specific selfefficacy in the current study, as well as the inconsistencies seen in the existing literature. If general self-efficacy functioned as a moderator and at high levels truly protected specific self-efficacy from the negative impact of past psychological abuse, then a direct relationship between the two types of efficacy would not be expected and one was not found in the current study. Similarly, if specific self-efficacy was truly protected by general self-efficacy no relationships between it and aspects of the former romantic relationship (e.g., amount of time since the former relationship ended, emotional attachment to the former partner) would be expected and none were found in the current 
study. More broadly, investigations of the relationship between general and specific selfefficacy have focused exclusively on a direct relationship between the constructs in highly efficacious populations. If the relationship between general and specific selfefficacy is more accurately characterized as indirect or moderated, then studies focusing solely on direct or meditated relationships are unlikely to produce consistent findings. Studies should begin to consider that the relationship between general and specific selfefficacy may be subtle and indirect, as suggested by Early and Lituchey (1991).

\section{Psychological abuse.}

Undergraduate population. The level of psychological abuse found in the current population is of low frequency and intensity. Past psychological abuse was assessed using a measure consisting of 40 undesirable behaviors in which one's romantic partner might engage. The median score on this measure indicated that study participants experienced only approximately half of these behaviors one to two times over the course of the relationship or may have experienced only a few of these behaviors more frequently. Not only was the level of past psychological abuse low in the overall study sample, but those participants eligible for the Laboratory Phase reported even lower levels than did their ineligible counterparts. Therefore, the study hypotheses were tested with a subsample of participants reporting lower past psychological abuse than the full sample.

According to some definitions of the construct, the level of psychological abuse found in the current study and other comparable samples may not qualify as "abuse." When defining psychological abuse, previous researchers have suggested that behaviors must be intense, occur frequently (Follingstad, 2007), and target a person's sense of self 
(Murphy \& Cascardi, 1999) in order for the label "abuse" to be applied. The average level of past psychological abuse found in the current undergraduate sample might not exceed the necessary threshold of intensity and frequency to truly be considered abusive.

Despite being low, the rate of psychological abuse found in the current sample is comparable to levels found in other studies of undergraduates (Gallaty \& ZimmerGemback, 2008; Kasian \& Painter, 1992; Straight, Harper, \& Arias, 2003) and was negatively related to general self-efficacy. However, this negative relationship did not translate to decrements in specific self-efficacy. As discussed above, participants' high levels of general self-efficacy may have played a protective role. Perhaps the average level of psychological abuse found in an undergraduate population is not intense or frequent enough to penetrate the protective barrier of the high general self-efficacy also seen in this population. While psychologically abusive acts are very common in romantic relationships, a pattern of frequent and intense psychological abuse may be much rarer both in undergraduate and community samples. As a result a larger, more diverse sample may have been necessary in order for true psychological abuse to be captured and the proposed relationships to be detected. The small, exclusively undergraduate sample may have restricted the range of psychological abuse available for study.

Single-factor assessment. The current study conceptualized psychological abuse as a single factor and utilized an assessment measure possessing only a single factor (Kasian \& Painter, 1992). Kasian and Painter's (1992) Psychological Maltreatment Inventory (PMI) was modified from Tolman's (1989) Psychological Maltreatment of Women Inventory (PMWI) to be more appropriate for use with the undergraduate population. However, while the PMI possesses a single factor the PMWI possesses two 
factors: dominance-isolation and emotional-verbal (Tolman, 1989, 1999). Although the current sample possessed a restricted range on the single-factor measure of psychological abuse, normal distributions of either the dominance-isolation or emotional-verbal factors may have been present. The use of the modified PMI prevented these factors of psychological abuse from being identified or investigated.

Rather than a relationship with the single factor of psychological abuse selfefficacy may relate to a specific factor of psychological abuse. For example, the emotional-verbal factor of psychological abuse may more strongly relate to self-efficacy than the dominance-isolation factor as it directly overlaps with verbal persuasion as a source of efficacy expectations. Support for differential effects due to different types of psychological abuse is present in the literature. Katz and Arias (1999) found that among dating, undergraduate women the dominance-isolation factor of psychological abuse predicted change in depressive symptoms over time, but the emotional-verbal factor did not. Beck and colleagues (2011) found a significant relationship between feelings of shame and the emotional-verbal factor, but not the dominance-isolation factor in a sample of women seeking assessment and/or treatment for IPV at an outpatient research clinic. Similar, differential results may be present in the relationship between self-efficacy and psychological abuse but, given the current study's measure and design, could not be explored in the present sample. It is possible that by investigating the relationship between self-efficacy and the single factor of psychological abuse, relationships between self-efficacy and more specific factors, such as emotional-verbal or dominance-isolation, were unable to be detected. 
Exclusion of IPV. The exclusion of IPV may have further restricted the range of psychological abuse. Given that the current study focused on the relationship between past psychological abuse and self-efficacy, participants reporting past physical or sexual IPV were excluded to ensure that study results were not confounded; however, this exclusion criteria may have unintentionally lowered the level of psychological abuse within the study sample. This idea is supported by the significant, positive correlation between past IPV and psychological abuse found in both the current and previous studies (Aosved \& Long, 2005; Hamby \& Sugarman, 1999; Harned, 2001; Hines \& Saudino, 2003) as well as the fact that the excluded subsample of participants reported the highest level of past psychological abuse. Women experiencing physical or sexual IPV report more severe and frequent levels of psychological abuse than do women experiencing psychological abuse alone (Aosved \& Long, 2005; Hamby \& Sugarman, 1999; Harned, 2001; Hines \& Saudino, 2003). By excluding survivors of physical or sexual IPV, participants who experienced the most severe and frequent psychological abuse may have also been excluded. As a result, the range of psychological abuse available for inclusion in the study sample may have been truncated and, again, not severe enough to penetrate the protective barrier of high general self-efficacy. Therefore, the proposed indirect relationships with specific self-efficacy and specific task reactions could not be seen. In relation, previous studies reporting relationships between IPV and selfefficacy, or efficacy-related constructs, considered the full range of IPV rather than psychological abuse alone (Albaugh \& Nauta, 2005; Brown, et al., 2000; Burke et al., 2004; Chronister \& McWhirter, 2006; Lerner \& Kennedy, 2000; Meadows et al., 2005; Patzel, 2001; Sanders et al., 2007; Thompson et al., 2002; Varvaro \& Palmer, 1993). 
Perhaps the protective barrier of high general self-efficacy is more effectively breached when psychological abuse is combined with physical or sexual violence. In the absence of physical or sexual IPV, psychological abuse may need to be particularly intense and severe for general self-efficacy's protective presence to be overcome.

Each restriction of range issue may have impacted the study results separately but the interaction of restricted ranges likely was also important. For example, it is possible that the efficacy of women experiencing severe psychological abuse is so eroded that they no longer possess the high level of general self-efficacy necessary for college attendance. Due to this interaction the women available for study in the undergraduate population report both low levels of psychological abuse and high levels of general selfefficacy. The study's restricted ranges may have interacted in a variety of ways to lead to null results.

\section{Additional Limitations}

External validity. One possible external validity limitation is present. In order to examine persistence while controlling for individual strengths and weaknesses a novel laboratory task was chosen. Persistence could have been operationalized as progress toward participants' academic or employment goals, but would have introduced multiple confounds into the study. For example, a grade in a challenging course could have represented persistence but would have introduced confounds such as individual differences in intelligence or the course's relevance to one's major. While the use of a laboratory task addressed these concerns it may not have accurately captured how specific self-efficacy relates to performance on personally relevant or real-world tasks. 
Anagrams may not have been an ecologically valid task, ultimately reducing the external validity of the study's results.

As previously discussed, specific self-efficacy expectations are based on the integration of information from past mastery experiences, vicarious learning, verbal messages from others, and related levels of physiological or emotional arousal (Bandura, 1977 ; 1997). Given the novelty of the laboratory task, participants may not have had sufficient exposure to or previous experience with anagrams to form robust self-efficacy expectations. Although past studies have found relationships between anagram-specific self-efficacy and task reactions (Brown \& Inouye, 1978; Cervone \& Peak, 1986; Jacobs et al., 1984; Jerusalem \& Schwarzer, 1992), namely task persistence, these studies were conducted with a very different participant cohort. It is possible that within the current cohort of technologically dependent and savvy study participants performing paper-andpencil anagrams is a particularly novel or foreign task.

Without a history of mastery or vicarious learning experiences to draw from, participants' sense of self-efficacy for solving anagrams may not be as well developed or reliable as their specific self-efficacy for more familiar tasks, such as succeeding in a math course or playing a computer game. If specific self-efficacy is not well developed or reliable it may not influence behavior or relate to task performance - providing a possible explanation for the lack of relationship between specific self-efficacy, task persistence, and change in negative affect. Participants' specific self-efficacy may have been too loosely formed prior to the task to relate to how long they worked or how aversive the task felt. Previous studies have reported relationships between specific selfefficacy for novel tasks and task reactions, but these participants first gained experience 
with the novel task before rating specific self-efficacy (Chen et al., 2000; Eden \& Zuk, 1995; Yeo \& Neal, 2006). Additional studies reporting relationships between specific self-efficacy and task reactions utilized personally relevant or familiar tasks, such as interacting with a feared object (e.g., snake) or academic performance (Beckham et al., 1997; Bandura, 1982; Bandura \& Adams, 1977; Bandura, Adams, \& Beyer, 1977; Cheng \& Chio, 2010; Gibbons \& Weingart, 2001; Lent, Brown, \& Larkin, 1984; MacAuley \& Courneya, 1992; Multon, Brown, \& Lent, 1991; Shell \& Husman, 2008; Trice, Elliott, Pope, \& Tryall, 1991). Overall, those studies relating specific self-efficacy to task reactions either chose familiar, ecologically valid tasks or reduced the novelty of a laboratory task via direct exposure prior to assessing specific self-efficacy. The current study utilized a novel laboratory task and provided only a verbal description of, rather than direct exposure to, the task before requesting that participants rate their specific selfefficacy. As a result, participants' specific self-efficacy may not have been robust enough to predict how long they persisted on the task or how aversive it felt.

The novelty of the laboratory task may have also limited the likelihood of finding a relationship between general and specific self-efficacy. The measure of specific selfefficacy was intentionally tailored to the laboratory task, assessing self-efficacy only for successfully solving anagrams. However, general self-efficacy's relationship with specific self-efficacy for a new or novel task may be weaker than its relationship with a specific yet familiar task. Tzeng (2009) suggested that one's past performances or general success rate may not be the best predictor of how one evaluates her chances of performing a new or challenging task. Similarly, Eden and Zuk (1995) posited that one's experienced-based general self-efficacy may be an ineffective predictor of specific self- 
efficacy for a new or novel task with which one has no experience. If the past experiences on which one's general self-efficacy is based appear to be unreliable or unrelated estimates of one's performance on a novel task then a relationship between the two types of efficacy may not be found. In addition to the possibility of a moderated rather than meditated relationship between general and specific self-efficacy, the laboratory task's limited ecological validity may have also played a role in the study's null results.

In sum, the hypothesized relationships between specific self-efficacy and other constructs in the proposed models may have been found if a more familiar or ecologically valid task had been chosen. For example, participants could have been asked to perform a challenging computer game or to complete vocational assessment questions.

Participants may have had a history of experiences with these more familiar tasks and, therefore, possessed better developed and more reliable specific self-efficacy expectations. Robust self-efficacy expectations may have been more strongly related to how participants reacted to the task and the hypothesized relationships may have been found. In addition, the use of a familiar or more ecologically valid task may have strengthened the relationship between general and specific self-efficacy. If the past performances or general success rates on which one's general self-efficacy is based appear related to the specific and familiar task at hand, then a relationship between general and specific self-efficacy may be more likely.

Internal validity. Three potential internal validity limitations were present in the current study. First, the order of the laboratory procedure may have influenced specific self-efficacy's relationship with the three outcome variables. In contrast with persistence 
and change in negative affect, specific self-efficacy was directly related to the chosen difficulty level of a future task, defined as a hypothetical second set of anagrams. Chosen difficulty level was not measured until participants had a failure experience with the initial set of unsolvable anagrams and rated their state affect both pre- and post-task. Therefore, when participants chose the difficulty level of the second set they had collected more information about their efficacy for performing anagrams then at any other point in the study. Bandura (1997) identified mastery experiences or experiences with similar tasks as the most influential source of self-efficacy. While study participants experienced failure rather than mastery, direct exposure to the task may have confirmed participants' reported level of specific self-efficacy and, as a result, strengthened its relationship with chosen difficulty level. In addition, chosen difficulty level was assessed after participants reflected on and rated their post-task state affect - a second source of efficacy information. By completing a measure of state affect participants were required to incorporate their current emotional and physiological arousal into their understanding of their ability to perform the laboratory task. Reflecting on their affect may have further solidified their specific self-efficacy and, as a result, its relationship with chosen difficulty level.

The relationship between specific self-efficacy and chosen difficulty level - but no other task reaction - may have been found because of the direct exposure to two sources of self-efficacy immediately preceding its assessment. As seen in previous studies once thorough exposure to a novel laboratory task was provided, specific selfefficacy and task reactions were related (Chen et al., 2000; Eden \& Zuk, 1995; Yeo \& Neal, 2006). If introductory experience to the laboratory task had been provided in the 
current study the task may have appeared less novel and participants more robust specific self-efficacy expectations may have been provided. As a result, the predictive power of specific self-efficacy may have been increased and the hypothesized relationships with all three task reactions may have been found.

Second, although it did not appear to impact task persistence or the validity of the study design, some participants reported suspicion that the anagrams were unsolvable. Given that the participants reporting suspicion persisted longer on the anagrams without producing solutions, the task may have been perceived as a more salient failure experience than for participants not reporting suspicion and working for a shorter period of time. Following individual failure experiences, adults have been found more likely to make external attributions in order to protect their positive self-view; if one fails it is due to external rather than internal causes. This attribution has been labeled the self-serving bias and has been supported in a variety of experimental paradigms (Campbell \& Sedikides, 1999; Coleman, 2011; Krusemark, Campbell, \& Clementz, 2008; Sedikides \& Strube, 1995; Taylor \& Doria, 1981). It is possible that participants were genuinely suspicious of the solvability of the anagrams but it is also possible that these participants engaged in the self-serving bias and attributed their personal failure to external forces (e.g., "If I can't succeed at these anagrams, there must be something wrong with the anagrams"). Regardless of motivation for the reported suspicion, future studies should take steps to increase the effectiveness of the study deception or could choose a different stimulus entirely. For example, solvable anagrams could be intermixed among the unsolvable anagrams to increase believability or an unsolvable maze could be used in place of anagrams. 
Third, the range of the measure of chosen difficulty level of a future task appears to have been truncated. Chosen difficulty level was assessed by asking participants to indicate the level of difficulty they would like to attempt on a second set of anagrams after they had abandoned the initial, unsolvable set. The available difficulty levels ranged from one to ten, with the unsolvable anagrams labeled as "moderately difficult" and a "five" on the scale. Given that no participant could successfully complete the unsolvable anagrams, a difficulty level higher than six for the future task was never chosen. As a result, the true range of difficulty for a future task was restricted to a one to six scale rather than a one to ten scale.

Exclusion of current psychological abuse. Similar to the exclusion of physical and sexual IPV, the exclusion of participants experiencing current psychological abuse served to reduce potential confounds. If both participants experiencing current and/or past psychological abuse had been included it would have been unclear what form of psychological abuse - past or current - was related to self-efficacy. This exclusion criteria also effectively excluded participants who may have been experiencing current physical or sexual IPV, given the high correlation between the constructs (Albaugh \& Nauta, 2005; Brown, et al., 2000; Burke et al., 2004; Chronister \& McWhirter, 2006; Lerner \& Kennedy, 2000; Patzel, 2001; Sanders et al., 2007; Thompson et al., 2002). As a result, study participants were no longer exposed to the potentially efficacy-eroding effects of psychological abuse at the time of their participation. The relationship between the variables may have therefore been diluted, decreasing the likelihood that the negative effects of psychological abuse could overcome the protective barrier of high general selfefficacy and be transmitted to specific self-efficacy or task reactions. 
Lerner and Kennedy (2000) reported that a specific form of self-efficacy, efficacy for maintaining independence from an abusive partner, increased significantly approximately six months after leaving the relationship. Although in the current study participants had been out of the former relationship for an average of less than six months, a natural efficacy recovery process may have already begun and the protective barrier of general self-efficacy strengthened. As aforementioned, undergraduates encounter a variety of experiences that could bolster general self-efficacy. The multiple, wide-ranging opportunities for efficacy enhancement afforded this population may have begun to counteract the erosive messages provided by former partners and weakened the constructs' relationship. Although a relationship between current psychological abuse and self-efficacy was not found in the current study, all recruitment materials specifically appealed to women who were no longer in a romantic relationship. A large percentage of women currently experiencing psychological abuse likely never enrolled in the study, making it an inappropriate sample for effectively addressing this research question.

Power. Based on a priori estimates of effect size, the current study was likely sufficiently powered. However, the target sample size and associated power level was based on the assumption that the proposed models would include medium or large effect sizes, as seen in previous studies with the same or highly related constructs (Bandura \& Adams, 1977; Bandura et al., 1977; Baldry, 2003; Brown \& Inouye, 1978; Cervone \& Peake, 1985; Chen et al., 2000; Dickerson \& Taylor, 2000; Gao \& Newton, 2009; Gibbons \& Weingart, 2001; Gross \& Keller, 1992; Jezl, Molidor, \& Wright, 1996; Lent, Brown, \& Larkin, 1984; Locke et al., 1984; Matud, 2005; McAuley \& Courneya, 1992; McAuley et al., 1999; Soffer, Gilboa-Schectman, \& Shahar, 2008; Tzeng, 2009; Yeo \& 
Neal, 2006). The restriction of range limitations detailed earlier may have reduced the size of the effects available for detection. For example, if a relationship between specific and general self-efficacy was present, it would have been of much smaller magnitude because general self-efficacy was only truly free to vary a few points. While the current study was sufficiently powered to detect medium or large effect sizes, it was insufficiently powered for the detection of small effect sizes. According to Taylor and colleagues (2008) if even one of the three paths in the hypothesized models possessed a small effect size, a sample of at least 100 participants would have been necessary to achieve sufficient power. As a result, the study may have been under-powered.

Study attrition and design. The current study also experienced a high attrition rate (see Figure 3 ). Only $24 \%$ of the eligible participants completed the Laboratory Phase. Steps were taken during data collection to reduce attrition, such as increasing advertisements and compensation for participation in the Laboratory Phase. While these changes were somewhat successful, a large attrition rate remained. Although minimal differences were found between Eligible and Laboratory participants, meaningful differences may have been present on unmeasured constructs, such as personality. Future studies should take steps to reduce study attrition, such as gathering all data in a single session or providing a variety of motivating compensation choices.

Finally, the study's cross-sectional design prevents causal relationships from being identified. The hypothesized models are predicated on a theory of efficacy erosion, which cannot be fully validated via a cross-sectional design without a control group who had not experienced psychological abuse. The models may have received more support if changes in efficacy over time could have been captured or a control group recruited, 
rather than a single-moment snap shot of the relationship between efficacy and psychological abuse.

\section{Future Directions}

Future studies of the model of efficacy erosion should begin by addressing the restriction of range limitations present in the current sample. First, a larger, more generalizable, community sample should be recruited. By expanding to a larger and more diverse population a greater range of both general self-efficacy and psychological abuse may be acquired. When a full range of general self-efficacy is acquired, both moderated and mediated relationships between it and specific self-efficacy should be explored. In addition, those women who chose not to or whose experiences of IPV prevent them from pursuing a college education could be represented. Similarly, the full range of IPV experiences should be included in the sample. Detailed information should be collected about each type of IPV - psychological, physical, and sexual - and the relationships with self-efficacy explored. In addition, the factor structure of psychological abuse should be explored so that a precise understanding of the relationship between self-efficacy and psychological abuse can be developed and potentially meaningful relationships are not overlooked. The inclusion of the factors of psychological abuse and the full range of IPV would capture the variety of ways partner abuse might impact self-efficacy and would allow for an investigation into which specific IPV type is most strongly related to self-efficacy. Also, including both participants experiencing current IPV and those with only a history of IPV might allow researchers to compare how the relationship between self-efficacy and IPV differs when one is and is not exposed to ongoing messages of inefficacy. 
Secondly, a combination of observational-longitudinal and experimental study designs would be a more robust test of the model of efficacy erosion. For example, changes in self-efficacy over the course of an abusive relationship could be observed longitudinally by assessing efficacy prior to, during, and following the relationship. Selfefficacy could also be assessed in a control group of participants experiencing changes in a non-abusive romantic relationship. At pre-determined time points during longitudinal data collection, all participants could return to the lab and complete challenging - yet ecologically valid - tasks such as vocational placement exams or Law School Admissions Test practice exams. Participants could be randomly assigned to perform tasks of varying difficulty levels. Such a study design would allow for the natural, changing relationship between self-efficacy and IPV to be observed, while also capturing how these changing levels relate to performance of controlled tasks of varying difficulty.

Finally, future studies could consider related and potentially meaningful constructs, such as PTSD or depression. Both PTSD and depression are extremely common sequelae of IPV (Baldry, 2003; Follingstad, 2009; Gallaty \& Zimmer-Gembeck, 2008; Lawrence, et al., 2009; Meadows 2005; Mechanic, Weaver, \& Resick, 2008) and have also been linked to self-efficacy (Benight \& Bandura, 2004; Heinrichs et al., 2005; Johansen et al., 2007; Thompson, 2002). Perhaps IPV, combined with symptoms of PTSD or depression, would more effectively overpower the protective barrier of high general self-efficacy and result in decrements in specific self-efficacy. IPV is a multilayered construct that exists within a larger network of related constructs. Considering IPV and self-efficacy in isolation could ignore other potentially powerful relationships. 
In conclusion, a negative relationship was found between past psychological abuse and general self-efficacy. A direct relationship between specific self-efficacy and chosen difficulty level of a future task was also found. However, study results did not support the roles of general and specific self-efficacy as mediators of an indirect relationship between past psychological abuse and reactions to a challenging task. The high level of general self-efficacy found within the current study sample may have served as a buffer, protecting specific self-efficacy from the negative impact of past psychological abuse. The low level of past psychological abuse present in the sample may also not have been strong enough to penetrate the protection of general self-efficacy, leaving specific self-efficacy unaffected. The exclusion of current psychological abuse and past IPV likely further reduced the range of psychological abuse available for study, decreasing the likelihood that the proposed indirect relationships could be detected. Future studies should address the current study's limitations by recruiting a large and representative, community sample of women who report a variety of IPV experiences, both past and present. By doing so, potential relationships between the various types of IPV and self-efficacy can be explored. 


\section{TABLES}

Table 1

Demographics

\begin{tabular}{lll}
\hline \multicolumn{1}{c}{ Variable } & $\underline{\text { Mean (SD) }}$ & Median \\
Age $^{\mathrm{a}}$ & $20.53(2.50)$ & 20.00 \\
& $\underline{\text { \%of Sample }}$ \\
Ethnicity & \\
Non-Hispanic White & 70.59 \\
African American & 2.80 \\
Asian American & 15.97 \\
Hispanic American / Latina & 0.56 \\
Native American & 3.36 \\
Biracial / Multiracial & 5.32 \\
Other Race & 1.40 \\
Academic Class & \\
Freshman & 31.74 \\
Sophomore & 19.38 \\
Junior & 17.70 \\
Senior & 27.53 \\
Childhood Abuse & \\
Physical & & \\
Sexual & & \\
\hline
\end{tabular}

Note. Demographics for full study sample $(N=360)$.

${ }^{\mathrm{a}} n=321 ;{ }^{\mathrm{b}} n=357 ;{ }^{\mathrm{c}} n=356 ;{ }^{\mathrm{d}} n=357$ 
Table 2

Relationship History

\begin{tabular}{|c|c|c|}
\hline Variable & Mean (SD) & Median \\
\hline Months out of Relationship ${ }^{a}$ & $6.44(5.67)$ & 5.00 \\
\hline $\mathrm{STaT}^{\mathrm{b}}$ & $\begin{array}{l}0.48(0.82) \\
\% \text { of Sample }\end{array}$ & 0.00 \\
\hline \multicolumn{3}{|l|}{ Emotional Attachment ${ }^{\mathrm{c}}$ : } \\
\hline "In love" with former partner & 63.58 & \\
\hline \multicolumn{3}{|l|}{ Commitment to Former Partner ${ }^{d}$ : } \\
\hline Dating, Not Monogamous & 10.64 & \\
\hline Monogamously Dating & 75.63 & \\
\hline Engaged & 2.80 & \\
\hline Cohabiting & 9.24 & \\
\hline Married & 1.68 & \\
\hline \multicolumn{3}{|l|}{ Ended Former Relationship ${ }^{\mathrm{e}}$ : } \\
\hline Participant & 46.22 & \\
\hline Participant's Former Partner & 28.01 & \\
\hline Mutual & 25.77 & \\
\hline Participant Re-partnered ${ }^{\mathrm{f}}$ & 45.94 & \\
\hline
\end{tabular}

Note. Relationship History for full study sample $(N=360)$. STaT $=$ total score on three-item screening instrument for past physical and sexual partner violence

${ }^{\mathrm{a}} n=356 ;{ }^{\mathrm{b}} n=357 ;{ }^{\mathrm{c}} n=357 ;{ }^{\mathrm{d}} n=357 ;{ }^{\mathrm{e}} n=357 ;{ }^{\mathrm{f}} n=357$ 
Table 3

Group Comparisons: Demographics, Relationship History, and Eligibility Criteria

\begin{tabular}{lcc}
\hline \multicolumn{1}{c}{ Variable } & $\chi^{2}(d f)$ & $\underline{p}$ \\
Ethnicity & $16.58(12)$ & 0.17 \\
Academic Class & $9.19(10)$ & 0.51 \\
Childhood Abuse & $2.55(2)$ & 0.27 \\
Commitment to Former Partner & $16.51(8)$ & 0.04 \\
Who Ended Former Relationship & $11.54(4)$ & 0.02 \\
Re-partnered & $46.30(2)$ & $<.0001$ \\
& Kruskal-Wallis (df) & $\underline{0.02}$ \\
Age & $0.97(2)$ & 0.62 \\
Time out of Former Relationship & $13.85(2)$ & $<.001$ \\
Past Psychological Abuse & $28.41(2)$ & $<.0001$ \\
STaT & $80.98(2)$ & 0.97 \\
Current Psychological Aggression & $57.87(2)$ & $0.05(2)$ \\
Emotional Attachment to Former Partner & & $<01$ \\
\hline
\end{tabular}

Note. Comparing Ineligible participants $(n=100)$ vs. Eligible participants $(n=200)$ vs. Laboratory participants $(n=60)$. Time out Former Relationship $=$ months since former relationship ended; Current Psychological Aggression = total score on Psychological Aggression subscale of the Conflict Tactics Scale - Revised referencing a current partner 
Table 4

Descriptive Statistics for Predictor and Outcome Variables $(n=60)$

\begin{tabular}{|c|c|c|c|c|c|c|c|c|}
\hline & $M(S D)$ & $M d n$ & $\begin{array}{c}\text { Possible } \\
\text { Range }\end{array}$ & $\begin{array}{l}\text { Min. } \\
\text { Score }\end{array}$ & $\begin{array}{c}1^{\text {st }} \\
\text { Quartile }\end{array}$ & $\begin{array}{c}2^{\text {nd }} \\
\text { Quartile }\end{array}$ & $\begin{array}{c}3^{\text {rd }} \\
\text { Quartile }\end{array}$ & $\begin{array}{l}\text { Max. } \\
\text { Score }\end{array}$ \\
\hline Past Psychological Abuse & $72.78(34.37)$ & 62.50 & $40-240$ & 40.00 & 48.00 & 62.50 & 89.00 & 213.00 \\
\hline General Self-Efficacy & $31.40(8.35)$ & 34.00 & $8-40$ & 8.00 & 28.00 & 34.00 & 38.00 & 40.00 \\
\hline Specific Self-Efficacy & $61.05(21.98)$ & 62.50 & $0-100$ & 5.00 & 47.25 & 62.50 & 76.10 & 100.00 \\
\hline Task Persistence & $14.08(9.70)$ & 11.85 & ---- & 1.73 & 7.08 & 11.85 & 18.03 & 51.20 \\
\hline Change in Negative Affect & $4.04(1.04)$ & 3.00 & $0-40$ & -3.00 & 0.50 & 3.00 & 6.40 & 18.00 \\
\hline Chosen Difficulty Level & $3.23(1.03)$ & 3.00 & $1-10$ & 1.00 & 3.00 & 3.00 & 4.00 & 6.00 \\
\hline
\end{tabular}

Note. Task Persistence $=$ minutes participants worked on anagram; Change in Negative Affect $=$ change in negative affect from pre- to post-task; Chosen Difficulty Level = chosen difficulty of future anagrams 
Table 5

Intercorrelations Among Predictors and Outcomes $(n=60)$

\begin{tabular}{lcccccc}
\hline Variable & 1 & 2 & 3 & 4 & 5 & 6 \\
\hline 1. Past Psychological Abuse & ---- & & & & & \\
2. General Self-Efficacy & $-.40^{*}$ & ---- & & & & \\
3. Specific Self-Efficacy & -.25 & .21 & $-\cdots$ & & & \\
4. Task Persistence & -.09 & -.06 & .00 & ---- & & \\
5. Change in Negative Affect & .08 & -.17 & -.10 & .03 & ---- & \\
6. Chosen Difficulty Level & .05 & .03 & $.37^{*}$ & .13 & $-.34^{*}$ & ---- \\
\hline
\end{tabular}

Note. Spearman correlations calculated using raw values.

$* p<.05$ 
Table 6

Intercorrelations Among Predictors and External Variables $(n=60)$

\begin{tabular}{|c|c|c|c|c|c|c|c|c|c|}
\hline Variable & 1 & 2 & 3 & 4 & 5 & 6 & 7 & 8 & 9 \\
\hline 1. Past Psychological Abuse & --- & & & & & & & & \\
\hline 2. General Self-Efficacy & $-.40 *$ & $-\cdots$ & & & & & & & \\
\hline 3. Specific Self-Efficacy & -.25 & .22 & $-\cdots$ & & & & & & \\
\hline 4. Age & .05 & .03 & -.11 & --- & & & & & \\
\hline $\begin{array}{l}\text { 5. Current Psychological } \\
\text { Aggression }\end{array}$ & .07 & .19 & -.35 & .38 & $\cdots$ & & & & \\
\hline 6. Time out of Former Relationship & .11 & -.11 & .04 & $.34^{*}$ & .35 & --- & & & \\
\hline $\begin{array}{l}\text { 7. Emotional Attachment to } \\
\text { Former Partner }\end{array}$ & .28 & $-.35 *$ & -.22 & .02 & -.03 & -.07 & --- & & \\
\hline 8. STaT & $.44^{* *}$ & -.23 & .05 & -.11 & -.06 & .12 & .06 & --- & \\
\hline 9. Negotiation & -.34 & .04 & .17 & .04 & -.21 & -.22 & -.00 & -.07 & --- \\
\hline
\end{tabular}

Note. Spearman correlations calculated using raw values. Negotiation $=$ total score on Negotiation Subscale of Conflict Tactics Scale - Revised referencing former partner

$* p<.05$

$* * p<.001$ 
Table 7

Means (SD) for Predictors and Outcomes for Suspicious and Non-Suspicious Participants $(n=32)$

\begin{tabular}{lllll}
\hline Variable & Suspicious & Non-Suspicious & $t(31)$ & $p$ \\
\hline Past Psychological Abuse & $74.34(31.99)$ & $76.50(34.27)$ & 0.19 & .85 \\
General Self-Efficacy & $31.53(8.55)$ & $31.52(8.38)$ & -0.01 & .99 \\
Specific Self-Efficacy & $62.79(22.10)$ & $62.94(13.07)$ & 0.03 & .98 \\
Task Persistence & $13.86(7.25)$ & $8.63(6.71)$ & -2.12 & $.04 *$ \\
Change in Negative Affect & $-2.71(3.39)$ & $-3.54(4.91)$ & -0.56 & .58 \\
Chosen Difficulty Level & $3.27(0.82)$ & $3.08(1.06)$ & -0.55 & .59 \\
\hline
\end{tabular}

$* p<.05$ 
Table 8

Exploratory Analysis of Trimmed Regression Models $(n=60)$

\begin{tabular}{lccc}
\hline & \multicolumn{3}{c}{ Specific task reaction } \\
\cline { 2 - 4 } & $\begin{array}{c}\text { Task } \\
\text { persistence }\end{array}$ & $\begin{array}{c}\text { Change in } \\
\text { negative affect }\end{array}$ & $\begin{array}{c}\text { Chosen } \\
\text { difficulty level }\end{array}$ \\
Model 1 $\left(b^{*}\right)$ & & & 0.00 \\
General Self-Efficacy & 0.00 & 0.02 & $0.02^{*}$ \\
Specific Self-Efficacy & 0.06 & -0.01 & $4.51^{*}$ \\
$F(2,57)$ & 0.02 & 1.60 & 0.14 \\
$R^{2}$ & 0.00 & 0.06 & \\
Model 2 $\left(b^{*}\right)$ & & & 0.01 \\
Past Psychological Abuse & -0.05 & 0.00 & $0.02^{*}$ \\
Specific Self-Efficacy & -0.02 & -0.01 & $5.78^{*}$ \\
$F(2,57)$ & 1.12 & 1.54 & 0.14 \\
$R^{2}$ & 0.04 & 0.06 & \\
Model 3 $\left(b^{*}\right)$ & & & 0.01 \\
Past Psychological Abuse & -0.06 & 0.00 & 0.02 \\
General Self-Efficacy & -0.10 & 0.00 & 0.99 \\
$F(2,57)$ & 1.25 & 0.05 & 0.03 \\
$R^{2}$ & 0.04 & 0.00 & \\
\hline
\end{tabular}

$* p<.05$ 
Table 9

Predictors of Specific Self-Efficacy $(n=60)$

\begin{tabular}{lc}
\hline Variable & $b^{*}$ \\
\hline Past Psychological Abuse & 0.51 \\
General Self-Efficacy & $1.96^{*}$ \\
General Self-Efficacy x Past Psychological Abuse & -0.02 \\
$R^{2}$ & 0.09 \\
$F$ & 1.74 \\
\hline$* p<.05$ &
\end{tabular}

Table 10

Intercorrelations Among Change in Positive Affect and Self-Efficacy $(n=60)$

\begin{tabular}{lccc}
\hline Variable & 1 & 2 & 3 \\
\hline 1. Change in Positive Affect & --- & & \\
2. General Self-Efficacy & .08 & --- & \\
3. Specific Self-Efficacy & .21 & .21 & $-\cdots$ \\
\hline
\end{tabular}

Note. Spearman correlations calculated using raw values. Change in Positive Affect $=$ change in positive affect from pre-to post-task 
Table 11

Intercorrelations Among Self-efficacy and Relationship History

\begin{tabular}{lccccc}
\hline \multicolumn{1}{c}{ Variable } & 1 & 2 & 3 & 4 & 5 \\
\hline 1. General Self-Efficacy & --- & & & & \\
2. Specific Self-Efficacy & $.22^{\mathrm{a}}$ & $-\cdots$ & & & \\
3. Time out of Former Relationship & $.07^{\mathrm{b}}$ & $.04^{\mathrm{a}}$ & $-\ldots$ & & \\
4. Emotional Attachment to Former Relationship & $.03^{\mathrm{b}}$ & $-.22^{\mathrm{a}}$ & $.02^{\mathrm{b}}$ & & \\
5.-- & & \\
\hline
\end{tabular}

Note. Spearman correlations calculated using raw values.

${ }^{\mathrm{a}} n=60 ;{ }^{\mathrm{b}} n=357 ;{ }^{\mathrm{c}} n=164$ 


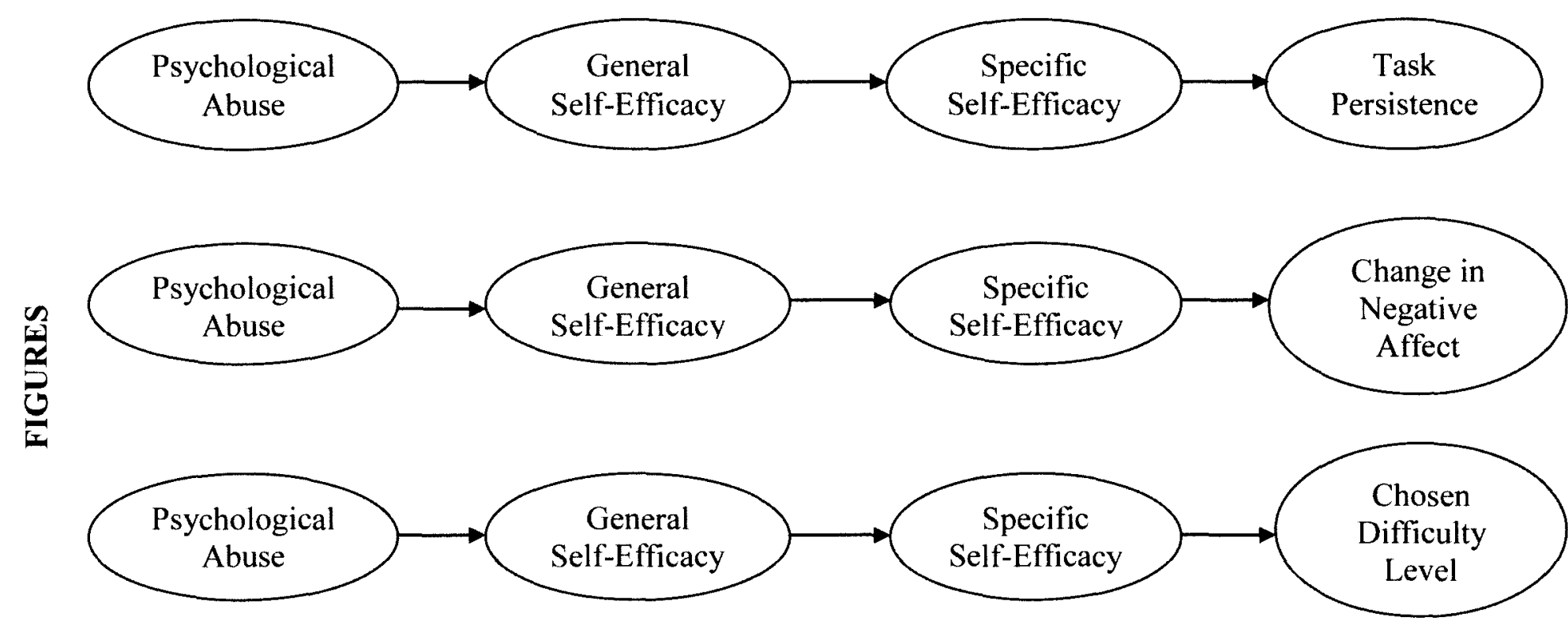

Figure 1. Proposed three-path mediation models between past psychological abuse, general self-efficacy, specific self-efficacy, and reactions to challenging tasks. 


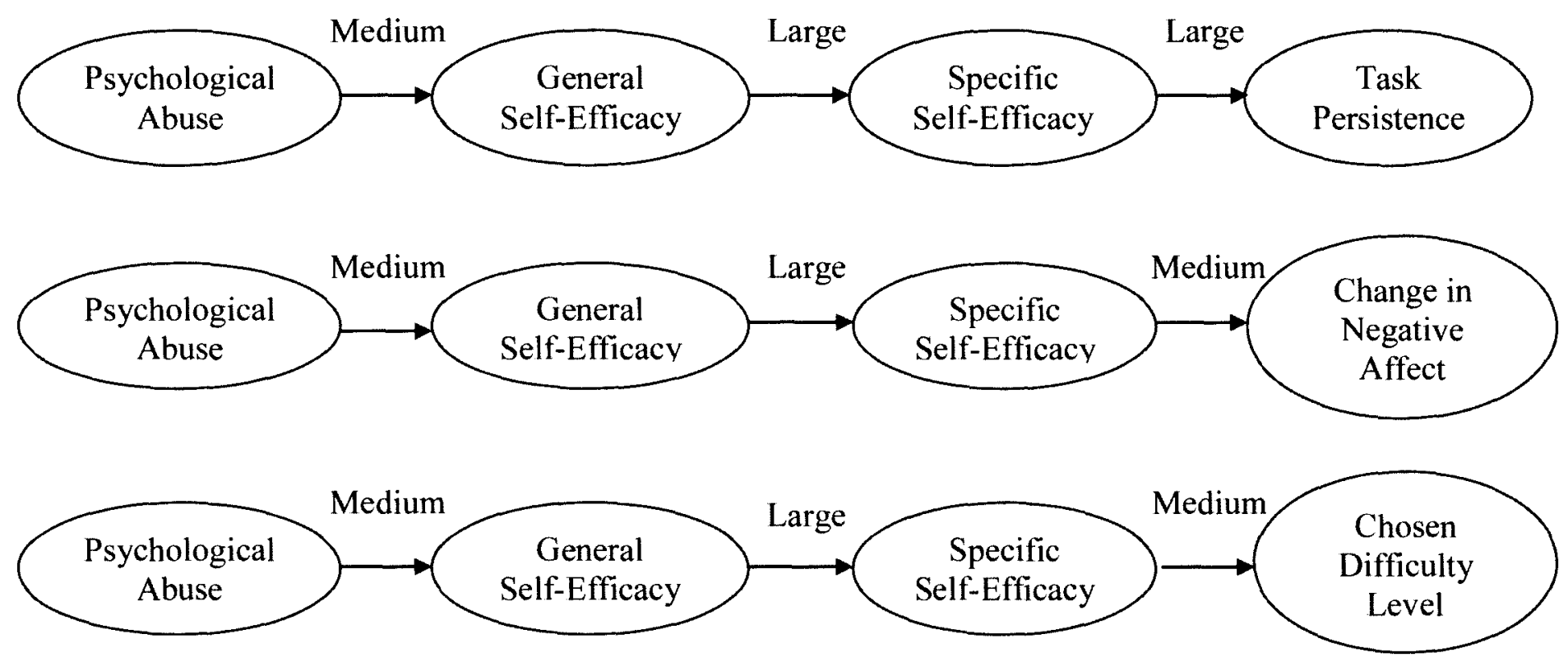

Figure 2. Estimated effect sizes of the proposed three-path mediation models between past psychological abuse, general self-efficacy, specific self-efficacy, and reactions to challenging tasks 


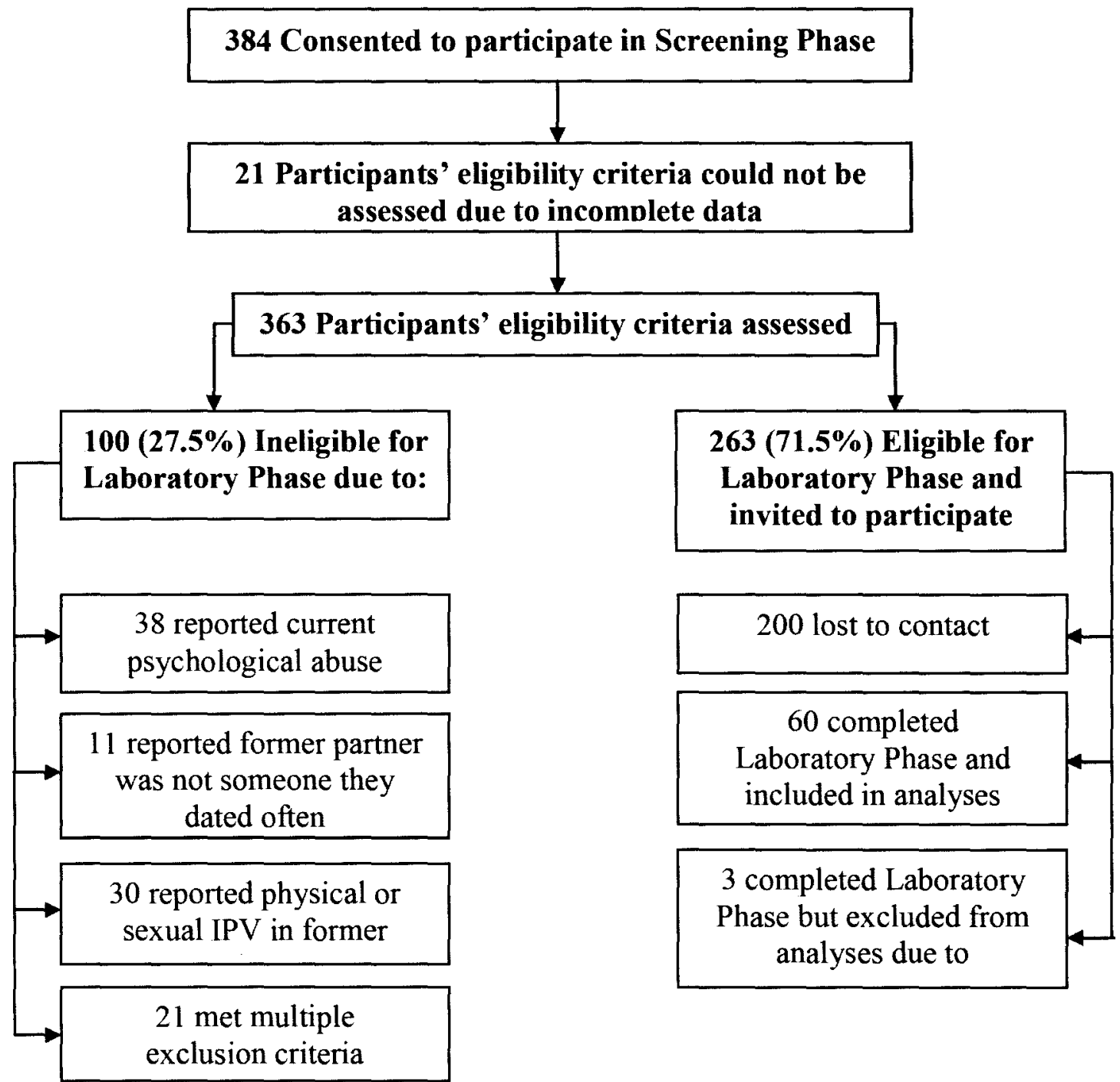

Figure 3. Inclusion, exclusion, and attrition rates of participants throughout Screening and Laboratory Phases. 


\section{REFERENCES}

Aguilar, R.J. \& Nightingale, N.N. (1994). The impact of specific battering experiences on the self-esteem of abused women. Journal of Family Violence, 9, 35-45.

Albaugh, L.M., \& Nauta, M.M. (2005). Career decision self-efficacy, career barriers, and college women's experiences of Intimate Partner Violence. Journal of Career Assessment, 13, 288-306.

American Psychiatric Association. (2000). Diagnostic and statistical manual of mental disorders: DSM-IV-TR. Washington, DC: Author.

Aosved, A.C. \& Long, P.J. (2005). College women's experiences of psychological maltreatment and sexual assault. Violence and Victims, 20, 577-587.

Arias , I. \& Pape, K.T. (1999). Psychological abuse: Implications for adjustment and commitment to leave violent partners. Violence and Victims, 14, 55-67.

Babyak, M.A. (2004). What you see may not be what you get: A brief, nontechnical introduction to overfitting in regression-type models. Psychosomatic Medicine, $66,411-421$.

Baldry, A.C. (2003). "Stick and stones hurt my bones but his glance and words hurt more": The impact of psychological abuse and physical violence by current and former partners on battered women in Italy. International Journal of Forensic Mental Health, 2, 47-57. 
Bandura, A. (1977). Self-efficacy: Toward a unifying theory of behavioral change. Psychological Review, 84, 191-215.

Bandura, A. (1982). Self-efficacy mechanism in human agency. American Psychologist, $37,122-147$.

Bandura, A. (1997). Self-efficacy: The exercise of control. New York: Freeman \& Co. Bandura, A. (2006). Guide for constructing self-efficacy scales. In T. Urdan \& F. Pajares (Eds.), Self-Efficacy Beliefs of Adolescents (pp. 307-337).

Bandura, A. (2008). An agentic perspective on positive psychology. In S.J. Lopez (Ed.), Positive psychology: Exploring the best in people, Vol. 1: Discovering human strength (pp. 167-196). Westport, CT: Praeger Publishers/Greenwood Publishing Group.

Bandura, A. \& Adams, N.E. (1977). Analysis of self-efficacy theory of behavioral change. Cognitive Therapy and Research, 1, 287-310.

Bandura, A., Adams, N.E., \& Beyer, J. (1977). Cognitive processes mediating behavioral change. Journal of Personality and Social Psychology, 35, 125-139.

Bandura, A., Reese, L., \& Adams, N.E. (1982). Microanalysis of action and fear arousal as a function of differential levels of perceived self-efficacy. Journal of Personality and Social Psychology, 43, 5-21.

Barry, L.C., Guo, Z., Kerns, R.D., Duong, B.D., \& Reid, M.C. (2003). Functional selfefficacy and pain-related disability among older veteran with chronic pain in a primary care setting. Pain, 104, 131-137.

Beck, C.T. (1994). Achieving statistical power through research design sensitivity. Journal of Advanced Nursing, 20, 912-916. 
Beck, J.G., McNiff, J., Olsen, S.A., Avery, M.L., \& Hagewood, J.H. (2011). Exploring negative emotion in women experiencing intimate partner violence: Shame, guilt, and PTSD. Behavior Therapy, 42, 740-750.

Beckham, J.C., Burker, E.J., Lytle, B.L., Feldman, M.E., \& Costakis, M.J. (1997). Selfefficacy and adjustment in cancer patients: A preliminary report. Behavioral Medicine, 23, 138-142.

Benight, C.C. \& Bandura, A. (2004). Social cognitive theory of posttraumatic recovery: The role of perceived self-efficacy. Behaviour Research and Therapy, 42, 1129 1148.

Benight, C.C., Freyaldenhoven, R.W., Hughes, J., Ruiz, J.M., \& Zoschke, T.A. (2000). Coping self-efficacy and psychological distress following the Oklahoma City bombing. Journal of Applied Social Psychology, 30, 1331-1344.

Benight, C.C., Harding-Taylor, A.S., Midboe, A.M., \& Durham, R.L. (2004).

Development and psychometric validation of the Domestic Violence Coping SelfEfficacy Measure (DV-CSE). Journal of Traumatic Stress, 17, 505-508.

Benight, C.C. \& Harper, M.L. (2002). Coping self-efficacy perceptions as a mediator between acute stress response and long-term distress following natural disasters. Journal of Traumatic Stress, 15, 177-186.

Benight, C.C., Ironson, G., Klebe, K., Carver, C.S., Wynings, C., Burnett, K., Greenwood, D., Baum, A., \& Schneiderman, N. (1999). Conservation of resources and coping self-efficacy predicting distress following a natural disaster: A causal model and analysis where the environment meets the mind. Anxiety, Stress, and Coping, 12, 107-126. 
Benight, C.C., Swift, E., Sanger, J., Smith, A., \& Zeppelin, D. (1999). Coping selfefficacy as a mediator of distress following a natural disaster. Journal of Applied Social Psychology, 29, 2443-2464.

Bernstein, D.P. \& Fink, L. (1998). Childhood Trauma Questionnaire: A retrospective self-report. Manual. The Psychological Corporation: San Antonio, TX.

Betz, N.E. \& Klein, K.L. (1996). Relationships among measures of career self-efficacy, generalized self-efficacy, and global self-esteem. Journal of Career Assessment, $4,285-298$.

Billingham, R.E. (1987). Courtship violence: The patterns of conflict resolution strategies across seven levels of emotional commitment. Family Relations, 36, 283-289.

Borich, G.D. \& Godbout, R.C. (1974). Extreme groups designs and the calculation of statistical power. Educational and Psychological Measurement, 34, 663-675.

Bosscher, R.J. \& Smit, J.H. (1998). Confirmatory factor analysis of the General SelfEfficacy Scale. Behaviour Research and Therapy, 36, 339-343.

Brown Jr., I. \& Inouye, D.K. (1978). Leamed helplessness through modeling: The role of perceived similarity in competence. Journal of Personality and Social Psychology, 36, 900-908.

Brown, C., Reedy, D., Fountain, J., Johnson, A., \& Dichiser, T. (2000). Battered women's career decision-making self-efficacy: Further insights and contributing factors. Journal of Career Assessment, 8, 251-265.

Brush, L.D. (2002). Work-related abuse: A replication, new items, and persistent questions. Violence and Victims, 17, 743-757. 
Burke, J.G., Denison, J.A., Gielen, A.C., McDonnell, K.A., \& O’Campo, P. (2004). Ending intimate partner violence: An application of the transtheoretical model. American Journal of Health Behavior, 28, 122-133.

Calef, R., Choban, M.C., Calef, R.A., Brand, R.L., \& Rogers, M.J. (1992). Effects of unsolvable anagrams on retention. Bulletin of the Psychodynamic Society, 30, 164-166.

Campbell, W.K. \& Sedikides, C. (1999). Self-threat magnifies the self-serving bias: A meta-analytic integration. Review of General Psychology, 3, 23-43.

Cervone, D. \& Peak, P.K. (1986). Anchoring, efficacy, and action: The influence of judgmental heuristics on self-efficacy judgments and behavior. Journal of Personality and Social Psychology, 50, 492-501.

Chen, G., Gully, S.M., Whiteman, J.A., \& Kilcullen, R.N. (2000). Examination of relationships among trait-like individual differences, state-like individual differences, and learning performance. Journal of Applied Psychology, 85, 835847.

Chen, G., Gully, S.M., \& Eden, D. (2001). Validation of a New General Self-Efficacy Scale. Organizational Research Methods, 4, 62-83.

Chen, G., Gully, S.M., \& Eden, D. (2004). General self-efficacy and self-esteem: Toward theoretical and empirical distinction between correlated self-evaluations. Journal of Organizational Behavior, 25, 375-395.

Cheng, P. \& Chiou, W. (2010). Achievement, attributions, self-efficacy, and goal setting by accounting undergraduates. Psychological Reports, 106, 54-64. 
Cheung, S. \& Sun, S.Y.K. (2000). Effects of self-efficacy and social support on the mental health conditions of mutual-aid organization members. Social Behavior and Personality, 28, 413-422.

Chronister, K.M., \& McWhirter, E.H. (2003). Applying Social Cognitive Career Theory to the empowerment of battered women. Journal of Counseling \& Development, $81,418-425$.

Chronister, K.M., \& McWhirter, E.H. (2006). An experimental examination of two career interventions for battered women. Journal of Counseling Psychology, 53, 151164.

Cohen, J. (1988). Multiple regression and correlation analysis. In J. Cohen Statistical Power Analysis for the Behavioral Sciences (pp. 407-466). Hillsdale, NJ: Lawrence Erlbaum Associates, Publishers.

Coleman, M.D. (2011). Emotion and the self-serving bias. Current Psychology, 30, 345354.

Coohey, C. (2007). The relationship between mothers' social networks and severe domestic violence: A test of the social isolation hypothesis. Violence and Victims, $22,503-512$.

Cortina, J.M. \& DeShon, R.P. (1998). Determining relative importance of predictors with the observational design. Journal of Applied Psychology,83, 798-804.

Crawford, J.R. \& Henry, J.D. (2004). The Positive and Negative Affect Schedule (PANAS): Construct validity, measurement properties and normative data in a large non-clinical sample. British Journal of Clinical Psychology, 43, 245-265. 
Dickerson, A. \& Taylor, M.A. (2000). Self-limiting behavior in women: Self-esteem and self-efficacy as predictors. Group \& Organization Management, 25, 191-210.

Dutton, D.G. \& Hemphill, K.J. (1992). Patterns of socially desirable responding among perpetrators and victims of wife assault. Violence and Victims, 7, 29-39.

Earley, P.C. \& Lituchy, T.R. (1991). Delineating goal and efficacy effects: A test of three models. Journal of Applied Psychology, 76, 81-98.

Eden, D. \& Zuk, Y. (1995). Seasickness as a self-fulfilling prophecy: Raising selfefficacy to boost performance at sea. Journal of Applied Psychology, 80, 628635 .

Escarti, A. \& Guzman, J.F. (1999). Effects of feedback on self-efficacy, performance, and choice in an athletic task. Journal of Applied Sport Psychology, 11, 83-96.

Eschleman, K.J. \& Bowling, N.A. (2011). A construct validation of the Neutral Objects Satisfaction Questionnaire (NOSQ). Journal of Business Psychology, 26, 501515.

Fairchild, A.J. \& MacKinnon, D.P. (2009). A general model for testing mediation and moderation effects. Prevention Science, 10, 87-99.

Field, A. (2001). Discovering Statistics Using SPSS: Second Edition. London: Sage Publications.

Follingstad, D.R. (2007). Rethinking current approaches to psychological abuse: Conceptual and methodological issues. Aggression and Violent Behavior, 12, 439458. 
Follingstad, D.R. (2009). The impact of psychological aggression on women's mental health and behavior: The status of the field. Trauma, Violence, \& Abuse, 10, 271289.

Forte, J.A., Franks, D.D., Forte, J.A., \& Rigsby, D. (1996). Asymmetrical role-taking: Comparing battered and nonbattered women. Social Work, 41, 59-73.

Frick, R.W. (1995). Accepting the null hypothesis. Memory \& Cognition, 23, 132-138.

Fritz, M.S. \& MacKinnon, D.P. (2007). Required sample size to detect the mediated effect. Psychological Science, 18, 233-239.

Gallaty, K. \& Zimmer-Gembeck, M.J. (2008). The daily social and emotional worlds of adolescents who are psychologically maltreated by their romantic partner. Journal of Youth and Adolescence, 37, 310-323.

Gao, Z. \& Newton, M. (2009). Examining the mediating role of strategy use on students' motivation and persistence/effort in physical education. Journal of Sport Behavior, 32, 278-297.

Garcia-Moreno, C., Jansen, H., Ellsberg, M., Heise, L., \& Watts, C.H. (2006). Prevalence of intimate partner violence: Findings from the WHO multi-country study on women's health and domestic violence. Lancet, 368, 1260-1269.

Gibbons, D.E. \& Weingart, L.R. (2001). Can I do it? Will I try? Personal efficacy, assigned goals, and performance norms as motivators of individual performance. Journal of Applied Social Psychology, 31, 624-648.

Gist, M.E., Schwoerer, C., \& Rosen, B. (1989). Effects of alternative training methods on self-efficacy and performance in computer software training. Journal of Applied Psychology, 74, 884-891. 
Gross, A.B. \& Keller, H.R. (1992). Long-term consequences of childhood physical and psychological maltreatment. Aggressive Behavior, 18, 171-185.

Halpern, C.T., Oslak, S.G., Young, M.L., Martin, S.L., \& Kupper, L.L. (2001). Partner violence among adolescents in opposite-sex romantic relationships: Findings from the National Longitudinal Study of Adolescent Health. American Journal of Public Health, 91, 1680-1685.

Hamby, S.L. \& Sugarman, D.B. (1999). Acts of psychological aggression against a partner and their relation to physical assault and gender. Journal of Marriage and the Family, 61, 959-970.

Harned, M.S. (2001). Abused women or abuse men? An examination of the context and outcomes of dating violence. Violence and Victims, 16, 269-285.

Hegarty, K., Sheehan, M., \& Schonfeld, C. (1999). A multidimensional definition of partner abuse: Development and preliminary validation of the composite abuse scale. Journal of Family Violence, 14, 399-415.

Heinrichs, M., Wagner, D., Schoch, W., Soravia, L.M., Hellhammer, D.H., \& Ehlert, U. (2005).

Predicting posttraumatic stress symptoms from pretraumatic risk factors: A 2-year prospective follow-up study in firefighters. American Journal of Psychiatry, 162, 2276-2286.

Hien, D. \& Ruglass, L. (2009). Interpersonal partner violence and women in the United States: An overview of prevalence rates, psychiatric correlates, and consequences and barriers to help seeking. International Journal of Law and Psychiatry, 32, 4855. 
Hines, D.A. \& Saudino, K.J. (2003). Gender differences in psychological, physical, and sexual aggression among college students using the Revised Conflict Tactics Scales. Violence and Victims, 18, 197-217.

Hoffman, P. (1984). Psychological abuse of women by spouses and live-in lovers. Women \& Therapy, 3, 37-47.

Holden, G., Anastas, J., Meenaghan, T., \& Metrey, G. (2002). Outcomes of social work education: The case for social work self-efficacy. Journal of Social Work Education, 38, 115-133.

Hudson, W.W. \& McIntosh, S.R. (1981). The assessment of spouse abuse: Two quantifiable dimensions. Journal of Marriage and Family, 43, 873-885.

Jacob, G.A., Hellstern, K., Ower, N., Pillman, M., Scheel, C.N., Rusch, N., \& Lieb, K. (2009).

Emotional reactions to standardized stimuli in women with Borderline Personality Disorder. The Journal of Nervous and Mental Disease, 197, 808-815.

Jacobs, B., Prentice-Dunn, S., \& Rogers, R.W. (1984). Understanding persistence: An interface of control theory and self-efficacy theory. Basic and Applied Social Psychology, 5, 333-347.

Jennings, J.R., Kamarck, T., Stewart, C., Eddy, M., \& Johnson, P. (1992). Alternate cardiovascular baseline assessment techniques: Vanilla or resting baseline. Psychophysiology, 29, 742-750.

Jerusalem, M. \& Schwarzer, R. (1992). Self-efficacy as a resources factor in stress appraisal processes. In R. Schwarzer (Ed.) Self-efficacy: Thought control of action (pp. 195-213). Washington, DC: Hemisphere Publishing Corp. 
Jezl, D.R., Molidor, C.E., \& Wright, T.L. (1996). Physical, sexual, and psychological abuse in high school dating relationships: Prevalence rates and self-esteem issues. Child and Adolescent Social Work Journal, 13, 69-87.

Johansen, V.A., Wahl, A.K., Eilertsen, D.E., \& Weisaeth, L. (2007). Prevalence and predictors of post-traumatic stress disorder (PTSD) in physically injured victims on non-domestic violence: A longitudinal study. Social Psychiatry and Psychiatric Epidemiology, 42, 583-593.

Kasian, M. \& Painter, S.L. (1992). Frequency and severity of psychological abuse in dating population. Journal of Interpersonal Violence, 7, 350-364.

Katz, J. \& Arias, I. (1999). Psychological abuse and depressive symptoms in dating women: Do different types of abuse have differential effects? Journal of Family Violence, 14, 281-295.

Katz, J., Kuffel, S.W., \& Brown, F.A. (2006). Leaving a sexually coercive dating partner: A prospective application of the investment model. Psychology of Women Quarterly, 30, 267-275.

Kazdin, A. E. (2003) Research Design in Clinical Psychology. Needham Heights, MA: Allyn and Bacon Publishing.

Krusemark, E.A., Campbell, W.K., \& Clementz, B.A. (2008). Attributions, deception, and event related potentials: An investigation of the self-serving bias. Psychophysiology, 45, 511-515. 
Kuo, J.R. \& Linehan, M.M. (2009). Disentangling emotion processes in Borderline Personality Disorder: Physiological and self-reported assessment of biological vulnerability, baseline intensity, and reactivity to emotionally evocative stimuli. Journal of Abnormal Psychology, 118, 531-544.

Lan, L.Y. \& Gill, D.L. (1984). The relationship among self-efficacy, stress responses, and a cognitive feedback manipulation. Journal of Sport Psychology, 6, 227-238.

Lane, E.J., Daugherty, T.K., \& Nyman, S.J. (1998). Feedback on ability in counseling, self-efficacy, and persistence on task. Psychological Reports, 83, 1113-1114.

Lawrence, E., Yoon, J., Langer, A., \& Ro, E., (2009). Is psychological aggression as detrimental as physical aggression? The independent effects of psychological aggression on depression and anxiety symptoms. Violence and Victims, 24, 20-35.

Lent, R.W., Brown, S.D., \& Larkin, K.C. (1984). Relation of self-efficacy expectations to academic achievement and persistence. Journal of Counseling Psychology, 31, 356-362.

Lent, R.W., Brown, S.D., \& Larkin, K.C. (1986). Self-efficacy in the prediction of academic performance and perceived career options. Journal of Counseling Psychology, 33, 265-269.

Lerner, C.F. \& Kennedy, L.T. (2000). Stay-leave decision making in battered women: Trauma, coping and self-efficacy. Cognitive Therapy and Research, 24, 215-232.

Lindhorst, T., Oxford, M. \& Gilmore, M.R. (2007). Longitudinal effects of domestic violence on employment and welfare outcomes. Journal of Interpersonal Violence, 22, 812-828. 
Little, L.M., Nelson, D.L., Wallace, J.C., \& Johnson, P.D. (2011). Integrating attachment style, vigor at work, and extra-role performance. Journal of Organizational Behavior, 32, 464-484.

Locke, E.A., Frederick, E., Lee, C., \& Bobko, P. (1984). Effect of self-efficacy, goals, and task strategies on task performance. Journal of Applied Psychology, 69, 241 251.

Luszczynska, A., Benight, C.C., \& Cieslak, R. (2009). Self-efficacy and health-related outcomes of collective trauma. European Psychologist, 14, 51-62.

Luszczynska, A., Scholz, U., \& Schwarzer, R. (2005). The General Self-Efficacy Scale: Multicultural validation studies. The Journal of Psychology, 139, 439-457.

MacKinnon, D.P., Lockwood, C.M., Hoffman, J.M., West, S.G., \& Sheets, V. (2002). A comparison of methods to test mediation and other intervening variable effects. Psychological Methods, 7, 83-104.

Maiuro, R.D. (2001). Sticks and stones may break my bones, but names will also hurt me: Psychological abuse in domestically violent relationships. In K.D. O'Leary \& R.D. Maiuro (Eds.), Psychological Abuse in Violent Domestic Relations (pp. ixxx). New York, NY: Springer Publishing

Major, B., Cozzarelli, C., Sciacchitano, A.M., Cooper, M.L., Testa, M., \& Mueller, P.M. (1990). Perceived social support, self-efficacy, and adjustment to abortion. Journal of Personality and Social Psychology, 59, 452-463.

Marsden, H., Carroll, M., \& Neill, J.T. (2005). Who cheats at university? A self-report study of dishonest academic behaviours in a sample of Australian university students. Australian Journal of Psychology, 57, 1-10. 
Marshall, L.L. (2001). Effects of men's subtle and overt psychological abuse on lowincome women. In K.D. O'Leary \& R.D. Maiuro (Eds.), Psychological Abuse in Violent Domestic Relations (pp. 153-176). New York, NY: Springer Publishing Company, Inc.

Matud, M.P. (2005). The psychological impact of domestic violence on Spanish women. Journal of Applied Social Psychology, 35, 2310-2322.

McAuley, E. \& Courneya, K.S. (1992). Self-efficacy relationships with affective and exertion responses to exercise. Journal of Applied Social Psychology, 22, 312326.

McAuley, E., Talbot, H., \& Martinez, S. (1999). Manipulating self-efficacy in the exercise environment in women: Influences on affective responses. Health Psychology, 18, 288-294.

McClelland, G.H. (1997). Optimal design in psychological research. Psychological Methods, 2, 3-19.

Meadows, L.A., Kaslow, N.J., Thompson, M.P., \& Jurkovic, G.J. (2005). Protective factors against suicide attempt risk among African American women experiencing intimate partner. American Journal of Community Psychology, 36, 109-121.

Mechanic, M.B., Weaver, T.L., \& Resick, P.A. (2008). Mental health consequences of intimate partner abuse. Violence Against Women, 14, 634-654.

Multon, K.D., Brown, S.D., \& Lent, R.W. (1991). Relation of self-efficacy beliefs to academic outcomes: A meta-analytic investigation. Journal of Counseling Psychology, 38, 30-38. 
Murphy, C.M. \& Cascardi, M. (1999). Psychological abuse in marriage and dating relationships. In R.L. Hampton (Ed.), Family Violence, $2^{\text {nd }}$ Edition: Prevention and Treatment (pp. 198-226). Thousand Oaks, CA: SAGE Publications, Inc.

Neufeld, J., McNamara, J.R., \& Ertl, M. (1999). Incidence and prevalence of dating partner abuse and its relationship to dating practices. Journal of Interpersonal Violence, 14, 125-137.

Newman, C., \& Goldfried, M.R. (1987). Disabusing negative self-efficacy expectations via experience, feedback, and discrediting. Cognitive Therapy Research, 11,401 417.

NiCarthy, G. (1986). Getting free: A handbook for women in abusive relationships. Seattle, WA: Seal Press.

O’Leary, K.D. \& Jouriles, E.N. (1994). Psychological abuse between adult partners. In L. L'Abate (Ed.), Handbook of Developmental Family Psychology and Psychopathology (pp. 330-349). Oxford, England: John Wiley \& Sons.

Outlaw, M. (2009). No one type of intimate partner abuse: Exploring physical and nonphysical abuse among intimate partners. Journal of Family Violence, 24, 263-272.

Ozer, E.M. \& Bandura, A. (1990). Mechanisms governing empowerment effects: A selfefficacy analysis. Journal of Personality and Social Psychology, 58, 472-486.

Panchanadeswaran, S., El-Bassel, N., Gilbert, L., Wu, E., \& Chang, M. (2008). An examination of the perceived social support levels of women in methadone maintenance treatment programs who experience various forms of intimate partner violence. Women's Health Issues, 18, 35-43. 
Paranjape, A \& Liebschutz, J. (2003). STaT: A three-question screen for intimate partner violence. Journal of Women's Health, 12, 233-239.

Paranjape, A., Rask, K. \& Liebschutz, J. (2006). Utility of the STaT for the identification of recent intimate partner violence. Journal of the National Medical Association, $98,1663-1669$.

Park, H.I., Beehr, T.A., Han, K. \& Grebner, S.I. (2012). Demand-abilities fit and personality strain: Moderating effects of personality. Interpersonal Journal of Stress Management, 19, 1-33.

Patzel, B. (2001). Women's use of resources in leaving abusive relationships: A naturalistic inquiry. Issues in Mental Health Nursing, 22, 729-747.

Pipes, R.B. \& LeBov-Keeler, K. (1997). Psychological abuse among college women in exclusive heterosexual dating relationships. Sex Roles, 36, 585-603.

Raphael, J. (1996). Domestic violence and welfare receipt: Toward a new feminist theory of welfare dependency. Harvard Women's Law Journal, 201.

Riger, S., Ahrens, C., \& Blickenstaff, A., (2001). Measuring interference with employment and education reported by women with abusive partners: Preliminary data. In K.D. O'Leary \& E.M. Woodin (Eds.), Psychological and Physical Aggression in Couples (pp. 119-133).Washington, DC: American Psychological Association.

Riger, S., Raja, S., \& Camacho, J. (2005). The radiating impact of intimate partner violence. Joumal of Interpersonal Violence, 17, 184-205.

Russell, D.E. (1982). Rape in marriage. New York, NY: Collier Books. 
Sackett, L.A., \& Saunders, D.G. (1999). The impact of different forms of psychological abuse on battered women. Violence and Victims, 14, 105-117.

Salbach, N., Jaglal, S.B., Korner-Bitensky, N., Rappolt, S., \& Davis, D. (2007). Practitioner and organizational barriers to evidence-based practice of physical therapists for people with stroke. Physical Therapy, 87, 1284-1303.

Saltzman L.E., Fanslow, J.L., McMahon, P.M., Shelley, G.A. (2002) Intimate partner violence surveillance: Uniform definitions and recommended data elements, version 1.0. Atlanta, GA: Centers for Disease Control and Prevention, National Center for Injury Prevention and Control.

Sanders, C.K., Weaver, T.L., \& Schnabel, M. (2007). Economic education for battered women:An evaluation of outcomes. Journal of Women and Social Work, 2, 240254.

Scherbaum, C.A., Cohen-Charash, Y, \& Kern, M.J. (2006). Measuring general selfefficacy: A comparison of three measures using item response theory. Educational and Psychological Measurement, 66, 1047-1063.

Schunk, D.H. (1983). Ability versus effort attributional feedback: Differential effects on self-efficacy and achievement. Journal of Educational Psychology, 75, 848-856.

Shell, D.F. \& Husman, J. (2008). Control, motivation, affect, and strategic self-regulation in the college classroom: A multidimensional phenomenon. Journal of Educational Psychology, 100, 443-459.

Sedikides, C. \& Strube, M. (1995). The multiply motivated self. Personality and Social Psychology Bulletin, 21, 1330-1335. 
Sherer, M. \& Adams, C.H. (1983). Construct validation of the Self-Efficacy Scale. Psychological Reports, 53, 899-902.

Soffer, N., Gilboa-Schectman, E., \& Shahar, G. (2008). The relationship of childhood emotional abuse and neglect to depressive vulnerability and low self-efficacy. International Journal of Cognitive Therapy, 1, 151-162.

Sonkin, D.J., Martin, D., \& Walker, L.E.A. (1985). The male batterer: A treatment approach. New York, NY: Springer Publishing Co.

Stets, J.E. (1991). Psychological aggression in dating relationships: The role of interpersonal control. Journal of Family Violence, 6, 97-114.

Straight, E.S., Harper, F.W.K., \& Arias, I. (2003). The impact of partner psychological abuse on health behaviors and health status in college women. Journal of Interpersonal Violence, 18, $1035-1054$.

Straus, M.A. (2004). Cross-cultural reliability and validity of the Revised Conflict Tactics Scales: A study of university student dating couples in 17 nations. CrossCultural Research, 38, 407-432.

Straus, M.A., Hamby, S.L., McCoy, S., \& Sugarman, D.B. (1996). The revised Conflict Tactics Scale (CTS2): Development and preliminary psychometric data. Journal of Family Issues, 17, 283-316.

Straus, M.A., Hamby, S.L., \& Warren, W.L. (2003). The Conflict Tactics Scales Handbook: Revised Conflict Tactics Scale (CTS2) and CTS: Parent-Child Version (CTSPC). Los Angeles, CA: Western Psychological Services.

Swanberg, J.E., Macke, C., \& Logan, T.K. (2006). Intimate partner violence, women, and work: Coping on the job. Violence and Victims, 21, 561-578. 
Tabachnick, B.G. \& Fidell, L.S. (2001). Chapter 4: Cleaning Up Your Act. In B.G. Tabachnick \& L.S. Fidell, Using Multivariate Statistics: Fourth Edition (pp. 56110). Needham Heights, MA: Allyn \& Bacon.

Tabernero, C. \& Wood, R.E. (2009). Interaction between self-efficacy and initial performance in predicting the complexity of task chosen. Psychological Reports, $105,1167-1180$.

Taylor, D.M. \& Doria, J.R. (1981). Self-serving and group-serving bias in attribution. The Journal of Social Psychology, 113, 201-211.

Taylor, A.B., MacKinnon, D.P., \& Tein, J. (2008). Tests of the three-path mediated effect. Organizational Research Methods, 11, 241-269.

Thombs, B.D., Bernstein, D.P., Ziegelstein, R.C., Bennett, W., \& Walker, E.A. (2007). A brief two-item screener for detecting a history of physical or sexual abuse in childhood. General Hospital Psychiatry, 29, 8-13.

Thompson, M.P., Kaslow, N.J., Short, L.M., \& Wyckoff, S. (2002). The mediating role of perceived social support an resources in the self-efficacy - suicide attempts relation among African American abuse women. Journal of Consulting and Clinical Psychology, 70, 942-949.

Tipton, R.M. \& Worthington, E.L. (1984). The measurement of generalized selfefficacy: A study of construct validity. Journal of Personality Assessment, 48, 545-548.

Toburen, T. \& Meier, B.P. (2010). Priming God-related concepts increases anxiety and task persistence. Journal of Social and Clinical Psychology, 29, 127-143. 
Tolman, R.M. (1989). The development of a measure of psychological maltreatment of women by their male partners. Violence and Victims, 4, 159-177.

Tolman, R.M. (1998). The validation of the Psychological Maltreatment of Women Inventory. Violence and Victims, 14, 25-37.

Trice, A.D., Elliott, K.A., Pope, N.J., \& Tryall, T. (1991). Self-efficacy as a moderator of the effects of failure at a mathematics task. Journal of Social Behavior and Personality, 6, 597-604.

Tuccitto, D.E., Giacobbi, P.R., \& Leite, W.L. (2009). The internal structure of positive and negative affect: A confirmatory factor analysis of the PANAS. Educational and Psychological Measurement, 70, 125-141.

Tzeng, J. (2009). The impact of general and specific performance and self-efficacy on learning with computer-based concept mapping. Computers in Human Behavior, $25,989-996$.

U.S. Department of Justice, (2003). Intimate Partner Violence, 1993-2001. (NCJ 197838). Washington, DC: Bureau of Justice Statistics, Crime Data Brief.

Unsworth, K.L. \& Mason, C.M. (2012) Help yourself: The mechanisms through with a self-leadership intervention influences strain. Journal of Occupational Health Psychology, 17, 235-245.

Varvaro, F.F. \& Palmer, M. (1993). Promotion of adaptation in battered women: A selfefficacy approach. Journal of American Academy of Nurse Practitioners, 5, 264270. 
Watson, D., \& Clark, L. A. (1997). Measurement and mismeasurement of mood: Recurrent and emergent issues. Journal of Personality and Social Psychology, $68(2), 267-296$.

Watson, D., Clark, L. A., \& Tellegan, A. (1988). Development and validation of brief measures of positive and negative affect: The PANAS scales. Journal of Personality and Social Psychology, 54(6), 1063-1070.

Williams, S.L. (1982). Perceived self-efficacy and phobic disability. In R. Schwarzer (Ed.) Self-Efficacy: Thought Control of Action (pp.149-172). Washington, DC: Hemisphere Publishing Corp.

Wise, J.B. \& Trunnell, E.P. (2001). The influence of sources of self-efficacy upon efficacy strength. Exercise Psychology, 23, 268-280.

Woodruff, S.L. \& Cashman, J.F. (1993). Task, domain, and general efficacy: A reexamination of the Self-Efficacy Scale. Psychological Reports, 72, 423-432.

Yeo, G.B. \& Neal, A. (2006). An examination of the dynamic relationship between selfefficacy and performance across levels of analysis and levels of specificity. Journal of Applied Psychology, 91, 1088-1101.

Zimmerman, B.J. \& Ringle, J. (1981). Effects of model persistence and statements of confidence on children's self-efficacy and problem solving. Journal of Educational Psychology, 73, 485-493. 


\title{
APPENDICES
}

\author{
Appendix A
}

Demographic and Relationship History Information

\section{Demographic Information}

Please provide the following information about yourself.

What is your age?

What is your ethnicity? (Choose an option below)

1) Non-Hispanic White American

4) Hispanic American/Latina

2) African American

5) Native American

3) Asian American

6) Biracial / Multiracial

7) Other

What is your current academic class? (Choose an option below)

1) Freshman

2) Sophomore

3) Junior

4) Senior

5) Graduate Level Student (e.g., Med Student, Law Student, etc.)

6) Specialty School (e.g., hair design school, beautician's school, etc.)

7) Not currently enrolled in school

How many children do you have? 


\section{Relationship History}

Please answer the following questions based on your romantic relationship that recently ended.

Was your recently ended romantic relationship with a

$$
\text { MALE FEMALE }
$$

How long ago did your recent romantic relationship end? (in months)

Please indicate who initiated the break-up of your recently ended relationship

I initiated the break-up

My former partner initiated the break-up

The break-up was mutual

Please indicate the level of commitment in your recently ended romantic relationship.

(Choose one)
1) Married
3) Engaged
5) Dating but not monogamous

2) Cohabitating

4) Dating and monogamous 


\section{Appendix B}

\section{Emotional Attachment to Former Partner}

Please indicate the level of emotional attachment you experienced in your recently ended romantic relationship

1. Casual dating, little emotional attachment.

2. Someone I dated often, but to whom I was not emotionally attached.

3. Someone to whom I was emotionally attached, but I was not in love.

4. Someone with whom I was in love.

5. Someone with whom I was in love and would have liked to marry, but I never discussed marriage with him/her.

6. Someone with whom I was in love and had discussed marriage, but we made no plans.

7. Someone with whom I was engaged to marry. 
Appendix C

Conflict Tactic Scale - Revised (CTS2)

Psychological Aggression Subscale

How often has this happened in your CURRENT romantic relationship?

My partner insulted or swore at me

$\begin{array}{ccccccc}0 & 1 & 2 & 3 & 4 & 5 & 6 \\ \text { Never } & \text { Once } & \text { Twice } & 3-5 \text { times } & 6-10 \text { times } & 11-20 \text { times } & \text { More than } 20 \text { times }\end{array}$

My partner called me fat or ugly

$\begin{array}{ccccccc}0 & 1 & 2 & 3 & 4 & 5 & 6 \\ \text { Never } & \text { Once } & \text { Twice } & 3-5 \text { times } & 6-10 \text { times } & 11-20 \text { times } & \text { More than } 20 \text { times }\end{array}$

My partner destroyed something that belonged to me

$\begin{array}{ccccccc}0 & 1 & 2 & 3 & 4 & 5 & 6 \\ \text { Never } & \text { Once } & \text { Twice } & 3-5 \text { times } & 6-10 \text { times } & 11-20 \text { times } & \text { More than } 20 \text { times }\end{array}$

My partner shouted or yelled at me

$\begin{array}{lllllll}0 & 1 & 2 & 3 & 4 & 5 & 6\end{array}$

Never Once Twice 3-5 times 6-10 times 11-20 times More than 20 times

My partner stomped out of the room or house or yard during a disagreement

$\begin{array}{lllllll}0 & 1 & 2 & 3 & 4 & 5 & 6\end{array}$

Never Once Twice 3-5 times 6-10 times 11-20 times More than 20 times

My partner accused me of being a lousy lover

$\begin{array}{lllllll}0 & 1 & 2 & 3 & 4 & 5 & 6\end{array}$

Never Once Twice 3-5 times 6-10 times 11-20 times More than 20 times

My partner did something to spite me

$\begin{array}{ccccccc}0 & 1 & 2 & 3 & 4 & 5 & 6 \\ \text { Never } & \text { Once } & \text { Twice } & 3-5 \text { times } & 6-10 \text { times } & 11-20 \text { times } & \text { More than } 20 \text { times }\end{array}$

My partner threatened to hit or throw something at me

$\begin{array}{ccccccc}0 & 1 & 2 & 3 & 4 & 5 & 6 \\ \text { Never } & \text { Once } & \text { Twice } & 3-5 \text { times } & 6-10 \text { times } & 11-20 \text { times } & \text { More than } 20 \text { times }\end{array}$




\section{Negotiation Subscale}

How often did this happen in your RECENTLY ENDED romantic relationship?

My partner showed care for me even though we disagreed.

$\begin{array}{ccccccc}0 & 1 & 2 & 3 & 4 & 5 & 6 \\ \text { Never } & \text { Once } & \text { Twice } & 3-5 \text { times } & 6-10 \text { times } & 11-20 \text { times } & \text { More than } 20 \text { times }\end{array}$

My partner explained his or her side of a disagreement to me.

$\begin{array}{ccccccc}0 & 1 & 2 & 3 & 4 & 5 & 6 \\ \text { Never } & \text { Once } & \text { Twice } & 3-5 \text { times } & 6-10 \text { times } & 11-20 \text { times } & \text { More than } 20 \text { times }\end{array}$

My partner showed respect for my feelings about an issue.
0
$\begin{array}{lll}1 & 2 & 3\end{array}$
34
45
6

Never Once Twice 3-5 times 6-10 times 11-20 times More than 20 times

My partner was sure we could work it out.

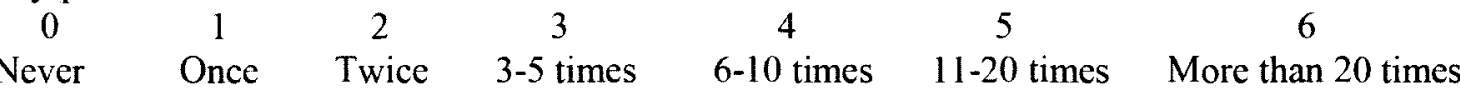

My partner suggested a compromise to a disagreement

$\begin{array}{ccccccc}0 & 1 & 2 & 3 & 4 & 5 & 6 \\ \text { Never } & \text { Once } & \text { Twice } & 3-5 \text { times } & 6-10 \text { times } & \text { 11-20 times } & \text { More than } 20 \text { times }\end{array}$

My partner agreed to try a solution I suggested.

$\begin{array}{ccccccc}0 & 1 & 2 & 3 & 4 & 5 & 6 \\ \text { Never } & \text { Once } & \text { Twice } & 3-5 \text { times } & 6-10 \text { times } & 11-20 \text { times } & \text { More than } 20 \text { times }\end{array}$


Appendix D

Slapped, Threatened, and Throw (STaT)

Did your former partner ever push or slap you?

YES NO

Did your former partner ever threaten you with violence?

YES NO

Did your former partner ever throw, break, or punch things in your presence?

YES NO 


\section{Appendix E}

\section{Two-Item Screener for History of Abuse in Childhood}

Please answer the following questions about childhood experiences by checking the best answer.

When I was growing up, people in my family hit me so hard that it left me with bruises or marks

YES NO

When I was growing up, someone tried to touch me in a sexual way or tried to make me touch them.

YES

NO 


\section{Appendix F}

\section{Psychological Maltreatment Inventory (PMI)}

This questionnaire asks about actions you may have experienced in your recently ended relationship with your former parther. Answer each item as carefully as you can by choosing a number next to each statement according to the following scale:

$$
\begin{gathered}
1=\text { never } \\
2=1-2 \text { times } \\
3=3-5 \text { times } \\
4=6-10 \text { times } \\
5=10-20 \text { times } \\
6=\text { more than } 20 \text { times }
\end{gathered}
$$

My partner put down my appearance

$\begin{array}{llllll}1 & 2 & 3 & 4 & 5 & 6\end{array}$

$\begin{array}{llllllll}\text { My partner insulted or shamed me in front of others } & 1 & 2 & 3 & 4 & 5 & 6\end{array}$ $\begin{array}{lllllllll}\text { My partner trusted me with members of the } & & 1 & 2 & 3 & 4 & 5 & 6\end{array}$ opposite sex

My partner treated me like I was stupid

$\begin{array}{llllll}1 & 2 & 3 & 4 & 5 & 6\end{array}$

My partner was insensitive to my feelings

$\begin{array}{llllll}1 & 2 & 3 & 4 & 5 & 6\end{array}$

$\begin{array}{lllllllll}\text { My partner told me I couldn't manage by myself } & 1 & 2 & 3 & 4 & 5 & 6\end{array}$

My partner said things to spite me

$\begin{array}{llllll}1 & 2 & 3 & 4 & 5 & 6\end{array}$

$\begin{array}{llllllll}\text { My partner brought up things from my past to hurt } & 1 & 2 & 3 & 4 & 5 & 6\end{array}$ me

My partner called me names

My partner swore at me

My partner yelled and screamed at me $\begin{array}{llllll}1 & 2 & 3 & 4 & 5 & 6\end{array}$

$\begin{array}{llllll}1 & 2 & 3 & 4 & 5 & 6\end{array}$

$\begin{array}{llllll}1 & 2 & 3 & 4 & 5 & 6\end{array}$


My partner treated me like I was inferior

My partner sulked and refused to talk about problems

My partner stomped out of the house or yard during a disagreement

My partner gave me the silent treatment

My partner withheld affection from me

My partner did not let me talk about my feelings

My partner was insensitive to my sexual needs and desires

My partner monitored my time and made me account for my whereabouts

My partner treated me like his/her personal servant

My partner ordered me around

My partner was jealous and suspicious of my friends

My partner was jealous of other men/women

My partner did not want me to go to school or to other self-improvement activities

My partner did not want me to socialize with my same sex friends

My partner accused me of seeing another $\operatorname{man} /$ woman

My partner tried to keep me from seeing or talking to my family

My partner interfered in my relationship with family members

My partner tried to keep me from doing things to help myself

$\begin{array}{llllll}1 & 2 & 3 & 4 & 5 & 6\end{array}$

$\begin{array}{llllll}1 & 2 & 3 & 4 & 5 & 6\end{array}$ $\begin{array}{lllll}2 & 3 & 4 & 5 & 6\end{array}$ $\begin{array}{llllll}1 & 2 & 3 & 4 & 5 & 6\end{array}$ $\begin{array}{llllll}1 & 2 & 3 & 4 & 5 & 6\end{array}$ $\begin{array}{llllll}1 & 2 & 3 & 4 & 5 & 6\end{array}$ $\begin{array}{llllll}1 & 2 & 3 & 4 & 5 & 6\end{array}$ $\begin{array}{llllll}1 & 2 & 3 & 4 & 5 & 6\end{array}$ $\begin{array}{lllll}2 & 3 & 4 & 5 & 6\end{array}$ $\begin{array}{llllll}1 & 2 & 3 & 4 & 5 & 6\end{array}$ $\begin{array}{llllll}1 & 2 & 3 & 4 & 5 & 6\end{array}$ $\begin{array}{llllll}1 & 2 & 3 & 4 & 5 & 6\end{array}$ $\begin{array}{llllll}1 & 2 & 3 & 4 & 5 & 6\end{array}$ $\begin{array}{llllll}1 & 2 & 3 & 4 & 5 & 6\end{array}$ $\begin{array}{llllll}1 & 2 & 3 & 4 & 5 & 6\end{array}$ $\begin{array}{llllll}1 & 2 & 3 & 4 & 5 & 6\end{array}$ $\begin{array}{llllll}1 & 2 & 3 & 4 & 5 & 6\end{array}$ $\begin{array}{llllll}1 & 2 & 3 & 4 & 5 & 6\end{array}$ 
My partner told me my feelings are irrational or crazy

My partner blamed me for his/her problems

My partner tried to turn my family and friends against me

My partner blamed me for causing his/her violent behavior

My partner tried to make me feel like I was crazy

My partner's moods changed radically, from very calm to very angry or vice versa

My partner blamed me when upset even if I had nothing to do with it

My partner tried to convince my family and friends that I was crazy

My partner threatened to hurt him/herself if I left $\operatorname{him} /$ her

My partner threatened to have an affair with someone else

My partner threatened to leave the relationship $\begin{array}{llllll}1 & 2 & 3 & 4 & 5 & 6\end{array}$

$\begin{array}{llllll}1 & 2 & 3 & 4 & 5 & 6\end{array}$

$\begin{array}{llllll}1 & 2 & 3 & 4 & 5 & 6\end{array}$

$\begin{array}{llllll}1 & 2 & 3 & 4 & 5 & 6\end{array}$

$\begin{array}{llllll}1 & 2 & 3 & 4 & 5 & 6\end{array}$

$\begin{array}{llllll}1 & 2 & 3 & 4 & 5 & 6\end{array}$

$\begin{array}{llllll}1 & 2 & 3 & 4 & 5 & 6\end{array}$

$\begin{array}{llllll}1 & 2 & 3 & 4 & 5 & 6\end{array}$

$\begin{array}{llllll}1 & 2 & 3 & 4 & 5 & 6\end{array}$

$\begin{array}{llllll}1 & 2 & 3 & 4 & 5 & 6\end{array}$

$\begin{array}{llllll}1 & 2 & 3 & 4 & 5 & 6\end{array}$ 


\section{Appendix G}

\section{New General Self-Efficacy Scale}

Please rate the degree to which you agree with each of the following statements.

I will be able to achieve most of the goals that I have set for myself.

$$
\begin{array}{llllll}
1 & 2 & 3 & 4 & 5
\end{array}
$$

Strongly Disagree Strongly Agree

When facing difficult tasks, I am certain that I will accomplish them.

$\begin{array}{ccccc}1 & 2 & 3 & 4 & 5 \\ \text { Strongly Disagree } & & & & \text { Strongly Agree }\end{array}$

In general, I think that I can obtain outcomes that are important to me.

$\begin{array}{ccccc}1 & 2 & 3 & 4 & 5 \\ \text { Strongly Disagree } & & & & \text { Strongly Agree }\end{array}$

I believe I can succeed at most any endeavor to which I set my mind.

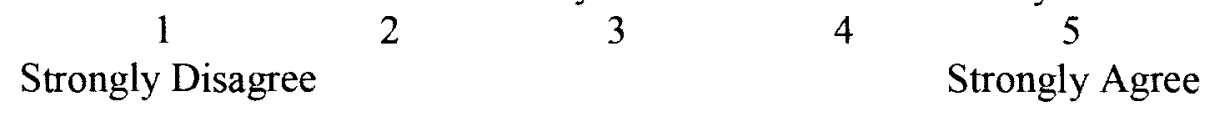

I will be able to successfully overcome many challenges.

$\begin{array}{ccccc}1 & 2 & 3 & 4 & 5 \\ \text { Strongly Disagree } & & & & \text { Strongly Agree }\end{array}$

I am confident that I can perform effectively on many different tasks.

$\begin{array}{ccccc}1 & 2 & 3 & 4 & 5 \\ \text { Strongly Disagree } & & & & \text { Strongly Agree }\end{array}$

Compared to other people, I can do most tasks very well.

$\begin{array}{ccccc}1 & 2 & 3 & 4 & 5 \\ \text { Strongly Disagree } & & & & \text { Strongly Agree }\end{array}$

Even when things are tough, I can perform quite well.

$\begin{array}{ccccc}1 & 2 & 3 & 4 & 5 \\ \text { Strongly Disagree } & & & & \text { Strongly Agree }\end{array}$




\section{Appendix $\mathrm{H}$ \\ Specific Self-Efficacy Scale}

Below are a number of questions about how well you believe you can perform anagrams and word problems. In each of the blanks on the right please rate how certain you are that you can perform an anagram or word problem.

Using the scale below rate your degree of certainty by recording a number from $0-100$ :

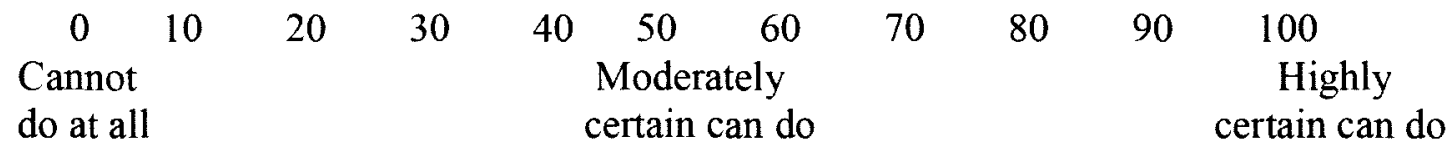

Certainty

$(0-100)$

I can regularly solve anagrams or word problems when slightly distracted.

On a regular basis, I can solve more anagrams or word problems than the average person.

I can regularly solve anagrams or word problems when tired.

I can regularly solve anagrams or word problems that include over 10

letters.

I can regularly solve anagrams or word problems when relaxed.

On a regular basis, I can find the solution to a typical anagram or word problem.

Using the same scale, please rate your certainty for solving the upcoming anagrams, at each of the levels listed below.

Certainty

$(0-100)$

I will be able to solve a few of the anagrams presented to me.

I will be able to solve several of the anagrams presented to me.

I will be able to solve at least half of the anagrams presented to me.

I will be able to solve almost all of the anagrams presented to me.

I will be able to solve all of the anagrams presented to me. 


\section{Appendix I}

Positive Affect / Negative Affect Scale

This scale consists of a number of words that describe different feelings and emotions.

Read each item and then circle the appropriate answer next to that word. Indicate to what extent you feel this way AT THIS MOMENT.

\begin{tabular}{|l|c|c|c|c|c|}
\hline & $\begin{array}{c}\text { Very slightly or } \\
\text { not at all }\end{array}$ & A little & Moderately & Quite a bit & Extremely \\
\hline Interested & 1 & 2 & 3 & 4 & 5 \\
\hline Distressed & 1 & 2 & 3 & 4 & 5 \\
\hline Excited & 1 & 2 & 3 & 4 & 5 \\
\hline Upset & 1 & 2 & 3 & 4 & 5 \\
\hline Strong & 1 & 2 & 3 & 4 & 5 \\
\hline Guilty & 1 & 2 & 3 & 4 & 5 \\
\hline Scared & 1 & 2 & 3 & 4 & 5 \\
\hline Hostile & 1 & 2 & 3 & 4 & 5 \\
\hline Enthusiastic & 1 & 2 & 3 & 4 & 5 \\
\hline Proud & 1 & 2 & 3 & 4 & 5 \\
\hline Irritable & 1 & 2 & 3 & 4 & 5 \\
\hline Alert & 1 & 2 & 3 & 4 & 5 \\
\hline Ashamed & 1 & 2 & 3 & 4 & 5 \\
\hline Inspired & 1 & 2 & 3 & 4 & 5 \\
\hline Nervous & 1 & 2 & 3 & 4 & 5 \\
\hline Determined & 1 & 2 & 3 & 4 & 5 \\
\hline Attentive & 1 & 2 & 3 & 4 & 5 \\
\hline Jittery & 1 & 2 & 3 & 4 & 5 \\
\hline Active & 1 & 2 & 3 & 4 & 5 \\
\hline Afraid & 1 & 2 & 3 & 4 & 5 \\
\hline
\end{tabular}




\section{Appendix $\mathbf{J}$ \\ Difficulty Level Rating Scale}

Below is a scale representing anagram tasks ranging from easy to difficult. The difficulty level of the anagrams you just performed can be described as "moderate." On a 10-point scale ( 1 = easy, $10=$ very difficult $)$ the anagrams you just performed could be rated as a "5."

You will now work on a second set of anagrams. Please indicate the level of anagrams you would like to perform next by circling a number on the scale below.

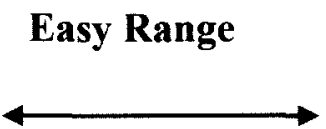

Easy Anagrams:

No more than 5 letters

Less difficult than those just performed. $\begin{array}{llll}4 & 5 & 6 & 7\end{array}$

Moderate Range

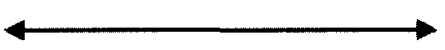

Moderate Anagrams:

Between 6 and 10 letters

Similar in difficulty to those just performed. $\begin{array}{lll}8 & 9 & 10\end{array}$

Difficult Range

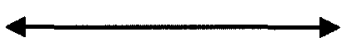

Difficult Anagrams: More than 10 letters More difficult than those just performed. 


\section{Appendix K}

\section{Unsolvable Anagram Task}

Below is a list of anagrams. Please attempt to form ONE WORD by rearranging each set of letters listed below. Take as much time as you would like to perform the anagram task. You may stop at any point and continue on to the remainder of the study by alerting the researcher of your desire to do so.

\section{1) AULCANDR}

2) AKLANSWFE

3) IOARFPLEC

4) ILOIELG

\section{5) OTRSERCAY}

\section{6) OCRANFGAR}




\section{CURRICULUM VITAE}

\section{KRISTEN E. (ALLISON) HOSEY, M.A.}

\section{Contact Information:}

$\begin{array}{ll}\text { Home Address: } & \begin{array}{l}\text { 3121 Ewart Dr. } \\ \text { Pittsburgh, PA 15219 } \\ \text { (502) 939-8925 }\end{array} \\ \text { Home Phone: } & \begin{array}{l}\text { VA Pittsburgh Healthcare Systems } \\ \text { University Drive Campus } \\ \text { University Drive }\end{array} \\ \text { Work Address: } & \begin{array}{l}\text { Pittsburgh, PA 15219 } \\ (412) 360-1825\end{array} \\ \text { Email: } & \text { Kristen.Hosey@va.gov }\end{array}$

Education:

$2007-2012 \quad$ University of Louisville, Louisville, Kentucky

Department of Psychological and Brain Sciences Doctoral Candidate, Clinical Psychology (APA-accredited)

All Ph.D. degree requirements completed: August 2012

Degree formally conferred by institution: December 2012

$\begin{array}{ll}2005-2007 & \begin{array}{l}\text { University of Dayton, Dayton, Ohio } \\ \text { Master of Arts, Clinical Psychology }\end{array} \\ 2000-2004 & \begin{array}{l}\text { Centre College, Danville, Kentucky } \\ \text { Bachelor of Science, Psychology, Cum laude }\end{array}\end{array}$

Honors and Awards:

2006

$2005-2007$

2004

2002

2002

2002
University of Dayton Graduate Student Summer Fellowship University of Dayton Graduate Assistantship

Phi Beta Kappa National Academic Honor Society

Psi Chi Psychology Honor Society Gamma Sigma Alpha Academic Honor Society Rho Lambda Academic/Leadership Honor Society 


\section{Clinical Experience:}

Apr. - July 2012 Psychology Intern, Substance Abuse Treatment Program, Major

Rotation, Salem VA Medical Center, Salem, Virginia.

Duties: Co-lead Cognitive Behavioral Relapse Prevention psychotherapy groups with veterans enrolled in residential treatment. Co-lead psychotherapy groups for veterans dually diagnosed with substance abuse and severe mental and for veterans maintaining sobriety. Conduct Motivational Interviewing sessions. Supevisors: Steve Lash, Ph.D., Josie DeMarce, Ph.D.

Apr. - July 2012 Psychology Intern, Psychosocial Rehabilitation and Recovery Center, Minor Rotation, Salem VA Medical Center, Salem, Virginia.

Duties: Co-lead Recovery Skills and ACT group psychotherapies. Conduct evidence based individual psychotherapy with veterans diagnosed with a severe mental illness.

Supervisor: Katie LeSauvage, Psy.D.

Jan. - Apr. 2012 Psychology Intern, Neuropsychology, Minor Rotation, Center for Neurocognitive Services, Salem VA Medical Center, Salem, Virginia.

Duties: Complete flexible battery, neuropsychological assessments with veterans with a variety of presenting problems (e.g. memory loss, traumatic brain injury, stroke, etc.). Score and interpret assessment materials, draft neuropsychological reports, provide assessment and diagnostic feedback.

Supervisor: Brian Shenal, Ph.D.

Dec. $2011-$

Apr. 2012
Psychology Intern, Center for Traumatic Stress, Major Rotation, Salem VA Medical Center, Salem, Virginia.

Duties: Conduct evidence based, time-limited psychotherapy (e.g. Prolonged Exposure) with veterans diagnosed with Posttraumatic Stress Disorder. Conduct intake and psychodiagnostic assessments with veterans referred to the Center for Traumatic Stress and provide treatment recommendations. Co-lead InVivo Exposure group and DBT Skills group, Emotion Regulation Module. Supervisor: Theodore Wright, Ph.D. 
Aug. 2011 -

Jan. 2012

Aug. - Dec. 2011

$2010-2011$

$2008-2011$

$2008-2010$
Psychology Intern, Military Sexual Trauma, Minor Rotation, Center for Traumatic Stress, Salem VA Medical Center, Salem, Virginia.

Duties: Conducted evidence based, time-limited and/or long-term psychotherapy (e.g. Cognitive Processing Therapy, Dialectical Behavior Therapy) with survivors of military sexual trauma. Conducted intake and psychodiagnostic assessments with veterans referred for treatment related to military sexual trauma and provided treatment recommendations. Co-led Dialectical Behavior Therapy Skills group, Interpersonal Effectiveness Module. Supervisor: Dana Holohan, Ph.D.

Psychology Intern, Outpatient Psychological Services, Major Rotation, Salem VA Medical Center, Salem, Virginia.

Duties: Conducted evidence based, time-limited psychotherapy with veterans referred for a variety of psychopathology symptoms. Conducted psychodiagnostic assessments, scored and interpreted assessment materials, and provided treatment recommendations. Co-led cognitive-behavioral anger management group. Supervisor: Susan Duma, Psy.D.

Student Therapist, Mindfulness Based Therapy Team, Noble H. Kelley Psychological Services Center, University of Louisville, Louisville, Kentucky.

Duties: Created treatment plans and provided mindfulness and acceptance based interventions to psychotherapy clients reporting a variety of psychopathology symptoms. Provided peer supervision.

Supervisor: Paul Salmon, Ph.D.

Graduate Clinic Assistant, Noble. H. Kelley Psychological Services Center, University of Louisville, Louisville, Kentucky.

Duties: Conducted intake interviews, scored intake measures, drafted intake reports, aided in the assignment of new clients. Conducted phone intakes for therapy and assessment clients. Provided crisis management as needed. Supervisor: Bernadette Walter, Ph.D.

Student Therapist, Cognitive Behavioral and Anxiety Team, Noble H. Kelley Psychological Services Center, University of Louisville, Louisville, Kentucky.

Duties: Created treatment plans and provided cognitive behavioral interventions to psychotherapy clients with a 
primary anxiety disorder diagnosis. Received and provided peer supervision.

Supervisor: Janet Woodruff-Borden, Ph.D.

$2007-2008$

Student Therapist, Home-Based Primary Care Team, Geriatric Extended Care, Veterans Affairs Hospital, Louisville, Kentucky.

Duties: Aided fellow student therapists in treatment planning and the implementation of cognitive behavioral, behavioral activation, and medical compliance interventions for home-bound veterans.

Supervisor: Barbara Stetson, Ph.D.

$2006-2007$

2006

Psychology Student, Children's Medical Center, Dayton, Ohio. Duties: Provided co-therapy to individual and family therapy clients. Performed academic assessments, drafted reports, and interpreted assessment results for clients. Supervisors: Sarah Fillingame, Psy.D. (clinical) James Huebner, M.Ed. (academic assessment)

2006

Student Evaluator, Richard Allen Academy, Dayton, Ohio.

Duties: Performed intellectual assessments on pre-school age children for permanent records of the Academy. Supervisor: Carolyn Roecker-Phelps, Ph.D.

\section{Clinical Training in Evidence Based Treatments:}

Sept. 2011

Cognitive Processing Therapy (CPT), Salem VA Medical Center, Salem, Virginia.

Completed three-day, VA Provider Training in CPT. Trained in both individual and group provision of CPT. Completing accreditation process to become a CPT provider within the VA.

Sept. 2011

Acceptance and Commitment Therapy (ACT), Salem VA Medical Center, Salem, Virginia.

Completed two-day introductory training in ACT. Trained in theoretical framework of ACT and experiential exercises to be used in either individual or group psychotherapy.

\section{Related Emplovment Experience:}

$2004-2005$

Residential Youth Worker, Maryhurst, Inc., Louisville, Kentucky Duties: Created structured environment based on individual treatment plans. Drafted individual treatment goals for 
specific clients, led therapeutic groups, utilized verbal deescalation and crisis management skills.

Supervisor: Suzie Frey

2003

Residential Youth Counselor, Childplace, Jeffersonville, Indiana Duties: Created structured environment; followed treatment guidelines; aided residents in accomplishing focus goals. Supervisor: Rick Hurst

\section{Research Experience:}

$2010-2012$

$2007-2011$

$2005-2007$

$2005-2007$
Dissertation Research, Health and Stress Research Lab, University of Louisville, Louisville, Kentucky.

Project Title: Self-efficacy in the Context of Psychological Abuse: A Model of Efficacy Erosion Chair: Tamara Newton, Ph.D.

Graduate Research Assistant, Health and Stress Research Lab, University of Louisville, Louisville, Kentucky.

Project Title: Women's Stress and Aging Study

Duties: Administered Patient Health Questionnaire, SCID

Psychotic Module, Short Portable Mental Status

Questionnaire, and Clinician Administered PTSD Scale. Aided in protocol development, study recruitment, data management, and manuscript preparation.

Supervisor: Tamara Newton, Ph.D.

Graduate Research Assistant, Department of Psychology, University of Dayton, Dayton, Ohio.

Duties: Aided in literature reviews, organization and facilitation of research participants, data analysis, and manuscript preparation.

Supervisor: Keri Brown Kirschman, Ph.D.

Thesis Research, University of Dayton, Dayton, Ohio.

Project Title: Effect of Adult Attachment Style on

Perceptions of Relationship Conflict

Chair: Carolyn Roecker-Phelps, Ph.D.

2004
Undergraduate Independent Research, Centre College, Danville, Kentucky.

Project Title: Female Body Satisfaction and State Anxiety Duties: Performed literature review, drafted study methodology, performed data collection and analysis, drafted results and discussion.

Supervisor: Jan Wertz, Ph.D. 


\section{Publications:}

Newton, T.L., Fernandez-Botran, R., Miller, J., Cambon, A.C., Burns, V.E., \& Allison, K.E. (2011). Interleukin-6 and remitted Posttraumatic Stress Disorder in midlife women. Manuscript submitted for publication.

\section{Presentations:}

Allison, K. \& Newton, T.L. (2010, November). Age and past-year potentially traumatic events are associated with women's physical functioning and mental health in midlife and beyond. Poster accepted to the annual Association for Cognitive and Behavioral Therapies Conference, San Francisco, CA.

Newton, T.L., Fernandez-Botran, R., Miller, J., Cambon, A.C., Burns, V.E., \& Allison, K.E. (2010, August). Plasma interleukin-6 levels and PTSD history in midlife women. Paper presented at the $11^{\text {th }}$ International Congress of Behavioral Medicine, Washington, D.C.

Allison, K., Fleming, K., Newton, T.L., Fernandez-Botran, R., Miller, J.J., Burns, V.E. (2009, November). Current PTSD symptoms moderate associations between past intimate partner violence and physical health status in postmenopausal women. Poster session presented at the annual International Society for Traumatic Stress Studies, Atlanta, GA.

Allison, K. \& Roecker-Phelps, C. (2007, April). Effect of adult attachment style on perception of relationship conflict. Poster session presented at the annual Stander Symposium, Dayton, $\mathrm{OH}$.

Brown Kirschman, K.J., Johnston, M., \& Allison, K., (2006, October). Focus study on helmet use among adolescent skateboarders. Poster session presented at the Kansas Conference in Clinical Child and Adolescent Psychology: Translating Research into Practice, Lawrence, KS.

Allison, K. \& Wertz, J. (2004, March). Television commercials' effects on female body satisfaction and state anxiety. Poster session presented at the annual meeting of the Southeastern Psychological Association, Atlanta, GA.

\section{Teaching Assistantships:}

$2009-2011 \quad$ Intellectual and Cognitive Assessment (graduate), University of Louisville, Louisville, Kentucky.

Duties: Taught proper administration of the WISC-IV and WAIS-IV to first year graduate students, observed training administrations, provided feedback on training reports. Supervisor: Bernadette Walter, Ph.D.

\footnotetext{
${ }^{1}$ Publications and presentations made under maiden name, Kristen E. Allison
} 
Interviewing Skills Practicum (graduate), University of Louisville, Louisville, Kentucky.

Duties: Observed and provided feedback on interviewing skills modules to first year graduate students.

Supervisor: Bernadette Walter, Ph.D.

Introduction to Psychology (undergraduate), University of Louisville, Louisville, Kentucky.

Duties: Administered weekly quizzes, maintained grade book, and provided assistance to students, as needed, for at least two lab sections of Introduction to Psychology. Supervisors: Edna Ross, Ph.D., Paul DeMarco, Ph.D.

Assessment of Intelligence (graduate), University of Dayton, Dayton, Ohio.

Duties: Instructed first year graduate students on proper administration of various intellectual assessment measures (WAIS, WISC, WPPSI, Stanford-Binet). Observed and provided feedback on training administrations, scoring of training protocols, and training reports.

Supervisor: Roger Reeb, Ph.D.

Introduction to Clinical Interviewing (graduate), University of Dayton, Dayton, Ohio.

Duties: Observed and provided feedback on clinical training interviews to first year graduate students. Aided in class preparation and instruction.

Supervisor: Keri Brown Kirschman, Ph.D.

Psychology of Women (undergraduate), University of Dayton, Dayton, Ohio.

Duties: Performed all teaching responsibilities for the final two weeks of the Fall 2006 semester. Aided in lecture preparation and grading throughout the semester.

Supervisor: Catherine Lutz Zois, Ph.D.

Child Psychopathology (undergraduate), University of Dayton, Dayton, Ohio.

Duties: Performed supplemental research to aid in lecture preparation, organized and led exam review sessions, and aided in grading of assignments.

Supervisor: Keri Brown Kirschman, Ph.D. 

preparation, organized and lead exam review sessions, and aided in grading of assignments.

Supervisor: Keri Brown Kirschman, Ph.D.

\section{References:}

Dana Holohan, Ph.D., Director of Training for Psychology, Center for Traumatic Stress, Salem VA Medical Center, Salem, Virginia, 24153.

Voice (540) 982-2461 ext. 2964; email: Dana.Holohan@va.gov

Susan Duma, Psy.D., MPH, Staff Psychologist, Center for Traumatic Stress, Salem VA Medical Center, Salem, Virginia, 24153.

Voice (540) 982-2461 ext. 2562; email: Susan.Duma@va.gov

Janet Woodruff-Borden, Ph.D., Professor and Director of Clinical Training, Department of Psychological and Brain Sciences, University of Louisville, Louisville, Kentucky, 40292.

Voice (502) 852-6070; email: j.woodruff-borden@louisville.edu 